\title{
ZUR METHODIK DER GEOGRAPHISCHEN GRENZZIEHUNG AM BEISPIEL DES GRENZBEREICHES DER KANTONE SCHWYZ, ZUG UND ZÜRICH
}

\author{
Mit 9 Karten und 2 Abbildungen
}

HANS WINDLER

\section{VORWORT}

Die vorliegende Abhandlung entstand auf Anregung von Herrn Prof. Dr. H. Gutersohn, Direktor des Geographischen Instituts der E.T.H. Meinem verehrten Lehrer bin ich für das rege Interesse an meiner Arbeit und für wertvolle Hinweise zu herzlichem Dank verpflichtet.

Mein Dank gilt auch Herrn Pd. Dr. E. WINkLER, der mir bei meinen Studien zahlreiche Ratschläge und Anregungen gab. In vielen Diskussionen half er mir, manches Problem zu klären.

Auch der Redaktionskommission der "Geographica Helvetica“ danke ich bestens für ihren großzügigen Beitrag an die Druckkosten.

Die Gemeindebeamten der untersuchten Gegend erteilten mir immer bereitwillig und freundlich Auskunft. Ihnen gebührt besonderer Dank.

Herzlich danken möchte ich schließlich meiner lieben Frau für die Erstellung der Zeichnungen und die sonstige Mithilfe.

Reinach (Bld.), 28. Oktober 1953.

Erster Teil

\section{BEGRIFFE UND METHODEN DER GRENZZIEHUNG}

\section{A. EINLEITUNG UND PROBLEMSTELLUNG}

Nach E. WinkLER (67, S. 344) * zielt die erdkundliche Wissenschaft wie jedes andere Erkenntnisgebiet auf die begriffliche, vorstellungsmäßige Erfassung (eines Teils) der Wirklichkeit; sie erstrebt mit andern Worten nichts anderes als Ordnung (System) der menschlichen Gedanken über die Welt. E. WinkLer führt weiter dazu aus: «Weshalb sie dies tut, sagt überaus zutreffend das sarkastische Merkwort eines jüdischen Weisen: Ordnen wollen wir die Natur, um in ihr nicht unterzugehn. In diesem Satz ist schlaglichtartig nicht nur Wesen und Notwendigkeit von Erkennen und Wissenschaft schlechthin, sondern immerwährende Notwendigkeit jeder Systematik (die sich im Grunde mit Wissenschaft als identisch erweist, vergl. auch Kant hierüber) ausgedrückt. Wir Menschen betreiben und schufen die Wissenschaft und mithin auch die Geographie, um uns in unserer Umwelt zurecht zu finden. Da Wissenschaft nichts anderes darstellt als einen stets sich erneuernden Ordnungs- oder Orientierungsversuch, ist auch Systematik, Einteilen und Zusammenfügen zugleich mit dem Ziel der wesensgemäßen Erfassung der objektiven Ordnung, des Systems der Natur ebenso Alpha und Omega jeder geographischen Arbeit ».

Die Unterteilung der Erde in Landschaftsganzheiten niederer Ordnung, ihre Beschreibung, Erklärung und Klassierung ist somit eine Aufgabe der Geographie. Damit dieses Ziel erreicht und eine geographische Systematik erarbeitet werden kann, muß zuerst das Problem der Grenzziehung zwischen zwei Landschaftseinheiten befriedigend gelöst werden. Das Grenzproblem ist heute allerdings nur noch ein Teilproblem der Geographie, seitdem erkannt wurde, daß Grenze und innerer Bau einer Landschaft voneinander untrennbare Begriffe sind. Trotzdem kommt einer Lösung große Bedeutung zu, denn erst nach der Begrenzung wird eine Landschaft vollends anschaulich, erst dann können wir eigentlich von einer konkreten Landschaftseinheit oder Ganzheit, einer bestimmten Individualität sprechen, denn diese Begriffe schließen die Vorstellung einer bestimmten Gestalt ein.

* Die kursiv gedruckten Zahlen in Klammern beziehen sich auf das Literaturverzeichnis. 
Namhafte Geographen haben immer wieder versucht, das Grenzproblem durch geeignete Arbeitsmethoden zu lösen. Die reichhaltige Literatur legt ein beredtes Zeugnis ab von den Kontroversen über dieses Thema.

Die bisherigen Bemühungen um vermehrte Objektivität in der geographischen Wissenschaft, sowie um einheitliche Arbeitsmethoden für Grenzziehungen, zeitigten verschiedene Arbeitsweisen. Die bei Grenzproblemen lebhaft geführten Diskussionen beweisen aber, da $\beta$ die bis heute ausgearbeiteten Methoden immer noch nicht befriedigen.

In der folgenden Arbeit wird von mir eine eigene Arbeitsweise für die geographische Grenzziehung entwickelt. Sie will aber nicht mehr als einen Versuch darstellen und eine kartographische Methode unter andern Gesichtspunkten am Beispiel des Grenzbereiches der Kantone Schwyz; Zug und Zürich überprüfen. Grundsätzlich könnte auch eine andere Gegend gewählt werden. Dieses Grenzgebiet scheint jedoch besonders geeignet. Obwohl die ganze Landschaft dem gleichen Sprach- und Kulturkreis angehört, bedingten die politischen und religiösen Gegensätze der letzten Jahrhunderte zwischen der Innerschweiz und $Z$ ürich, als auch die Grenzlage zwischen Mittelland und Voralpen mit tektonischen und pflanzensoziologischen Übergängen, auf beiden Seiten individuelle Entwicklung und Gestaltung.

Die Grenzen des untersuchten Gebietes sind absichtlich nicht auf die Gemeindegrenzen ausgerichtet worden, sondern es wurde eine beliebige Region gewählt. Sie umfaßt die Gemeinden Wädenswil, Schönenberg, Richterswil, Hütten, Wollerau und Feusisberg, sowie zur Abrundung Teile der Gemeinden Menzingen, Neuheim, Hirzel und Freienbach. Die Fläche mißt ca. $95 \mathrm{~km}^{2}$.

\section{B. PROBLEME DER GRENZZIEHUNG}

\section{Die Landschaft als Ganzheit}

Jede geographische Monographie zerlegt die Landschaft vorerst in ihre Elemente oder Bildner, wie Relief, Klima, Gewässer, Vegetation, Bevölkerung, Siedlungen usw. Diese Analyse ist notwendig, um die landschaftliche Bedeutung jedes dieser Elemente ins rechte Licht zu rücken. Die ganze Arbeit wäre aber ungeographisch, würde am Schluß nicht die Synthese folgen, die den innern Verband der Landschaft wieder herstellt. „Die Landschaft ist eben mehr, ist etwas anderes als die bloße Summe ihrer Bestandteile. Wäre einer imstande, uns sämtliche Elemente einer Landschaft zu nennen, er würde uns damit noch nicht die Landschaft selber vermitteln “ ( $($, S. 41/42). Sie ist keine „Undverbindung“. Die einzelnen Bestandteile stehen unter inniger gegenseitiger Beeinflussung und sind gegenseitigen Wechselwirkungen unterworfen. „Die Landschaft läßt sich nicht allmählich zusammensetzen, noch zerlegen. Nehmen wir ihr einen Teil oder fügen etwas hinzu, so zerstören wir ibr Wesen und damit sie selbst" ( $($, S. 44). Die Landschaft ist daher ein Ganzes, eine geographische Gestalt, eine Ganzheit, wobei nach E. WinkLer (67, S. 341) und L. BerTalanfFy (4, S. 97-99) allerdings noch abzuklären wäre, welches die entscheidenden Kriterien dieser Ganzheiten sind. Die Gestaltsauffassung der Biologen ist dieselbe. L. BerTalanfFY $(4$, S. 98) faßt wie folgt zusammen : „Während die ,Summe' allmählich zusammengesetzt werden kann, so muß die Gestalt als die Gesamtheit ihrer Teile samt den zwischen diesen bestehenden Wirkungsweisen mit einem Schlage gesetzt werden; ist sie freilich gesetzt, dann ist ihr Verhalten aus den Wechselbeziehungen der Teile erklärbar". Die ganzheitliche Auffassung der Landschaft darf heute als gesichert gelten. Ihre Begrenzung dagegen bereitet immer noch große Schwierigkeiten, was zum größten Teil in ihrer komplexen Natur begründet liegt.

\section{Problematik der Grenzen}

Jeder Vorstellung einer Sache oder eines Dings ist zugleich auch der Begriff der Grenze eingeschlossen, man stellt sich zum Beispiel unter einer Erbsenblüte, einem Pferd, unwillkürlich ein Wesen mit einer bestimmten Gestalt vor. Bei allen solchen häufig verwendeten Begriffen scheint das Grenzproblem ohne weiteres gelöst. Jedermann wird ohne Bedenken die Kutikula als Begrenzungsfläche annehmen. Das Kriterium des räumlichen Zusammenhangs wird als ausreichend für die Begrenzung betrachtet. L. BerTaLANFFY (4, S. 274/75) zeigt, wie unklar die Umrisse biologischer, als auch anderer Objekte bei eingehender Betrachtung sind, und wie unzureichend das Kriterium des räumlichen Zusammenhangs bei einer ganzheitlichen Auffassung der Objekte ist. Er schreibt: „Das letztere Kriterium (räumlicher Zusammenhang) ist $\mathrm{ja}$ in der Tat sehr vage, relativ und durchaus von unserer menschlichen Perspektive abhängig. Wir nennen die Biene einen ,Einzelorganismus', weil sie jener Größenordnung von Dingen angehört, die uns , mit freiem Auge ${ }^{6}$ als distinkte Ein- 
zelwesen erscheinen. Ebenso mag uns der Bienenschwarm auf einem entfernten Baume als, Einzelding $^{6}$ erscheinen, und wir bemerken erst bei näherem Zutreten, daß er aus einer großen Zahl von ,Einzeldingen' zusammengesetzt ist. Aber auch die miteinander, verwachsenen' Zellen des höhern Organismus sind durch - wenn auch minimale - Entfernungen voneinander getrennt; und die Entodermzellen einer Hydra krabbeln, indem sie Nahrungstoffe phagozytieren, fast ebenso ,selbständig' herum, wie die Bienen im Schwarm. Die Biene erscheint zwar für den groben Sinnenschein, nicht aber für eine tiefere Betrachtung scharf distinkt von dem, was nicht Biene ${ }^{6}$ ist; fortwährend treten Materien und Energien aus ihrer ,Umwelt ${ }^{6}$ in sie ein und aus ihr aus. In physikalischer Betrachtung ist nichts - oder alles zusammenhängend. Stellen wir uns auf den Boden der korpuskulären Auffassung, so ist die Biene ein Schwarm durcheinanderwirbelnder Atome genau so wie der Bienenschwarm ein Schwarm durcheinanderwirbelnder Einzeltiere ist. Daß die räumliche Entfernung der Einzeldinge sich in dem einen Fall in der Größenordnung von $\mu \mu$, im letzteren von mm bewegt, bedeutet keinen essentiellen Unterschied. Stellen wir uns aber auf den ,Wellenstandpunkt', so hängt letzten Endes alles in der Welt zusammen, die Materiewellen in dem Ding ,Atom ' ebensogut wie jene in dem Ding ,Bienenschwarm6. Räumlicher Zusammenhang ein Begriff, der durchaus von der Perspektive unserer menschlichen Sinnesorgane abhängig ist kann also nicht in die Definition des Begriffs, organisiertes System ${ }^{6}$ hineingenommen werden; sondern dieses ist dahin zu definieren, daß in ihm ,Komponenten ${ }^{6}$ durch , Relationen ${ }^{6}$ zu einer ,Ganzheit' vereinigt sind, wobei hierarchische Ordnung und Erhaltung im stationären Zustand (respektive deren Herstellung, Wiederherstellung, Neuerzeugung) als wesentliche Bestimmungen der letzteren erscheinen“.

Nach dieser Definition kann also der Bienenschwarm als Einzelindividuum betrachtet werden, während die Arbeitsbiene, Königin, Drohne lediglich als Organe desselben aufzufassen sind, da eine Drohne oder Königin allein keine Gewähr bieten für die Erhaltung der Art im stationären Zustand.

Auch in der Geologie treten Abgrenzungsschwierigkeiten bei stratigraphischen und lithologischen Übergängen auf, besonders im Penninikum ( $I$, S. 153). E. WINKLER (55, S. 244) zitiert zur Grenzproblematik den Chemiker W. Ostw Ald (Grundriß der Naturphilosophie, Leipzig 1908, S. 10), der den Mangel vollständiger und eindeutiger Grenzen als eine ganz allgemeine Erscheinung bei allen natürlichen Dingen wie auch bei der Wissenschaft betrachtet.

Wir sehen daraus, daß die Geographie mit der ungeklärten Abgrenzung ihres Forschungsobjektes keineswegs allein steht, sondern daß alle Wissenszweige mit Grenzproblemen zu kämpfen haben. Im weiteren ist deutlich ersichtlich, daß keine scharfen Grenzen (Linien), sondern in der Regel kontinuierliche Übergänge von einem Medium in das benachbarte auftreten.

Die Anschaulichkeit, die richtige Vorstellung einer Gestalt erfordert für die menschlichen Sinne aber die Begrenzung einer Ganzheit. Grenzen sind daher immer etwas vom Menschen Gedachtes, also subjektiv. Sie sind in jedem Falle relativ und nie absolut. Für den Forscher besteht demnach das Problem darin, sein Untersuchungsobjekt möglichst zweckmäßig zu umreißen.

In den folgenden Abschnitten werden die bei der Abgrenzung einer Landschaft auftretenden Begriffe erläutert.

\section{Begriffe der Landschaftsbegrenzung}

\section{a) Grenzsaum, Grenzgïrtel, Grenzraum, Grenzlinien, Ober- und Untergrenze}

Wie die biologischen Objekte sind die Landschaften Ganzheiten, geographische Gestalten. Jede Gestalt ist eine Einheit. Jede einzelne Landschaft unterscheidet sich daher von den benachbarten durch andersartiges Aussehen, durch ihre Physiognomie. Im Gegensatz zu früher wird eine Landschaft heute nicht mehr von außen her, sondern auf Grund ihres innern Aufbaus, ihres Charakters abgegrenzt.

E. Hozel (27, S. 444) definiert die Grenze als „die Linie, in welcher der lokale Charakter der in einem individualisierten Raume vereinigten Realitäten erlischt, bzw. von einem andern abgelöst wird“. In dieser Definition tritt der Begriff der Grenzlinie zu sehr in den Vordergrund, ohne den Hinweis, daß eine Linie in den seltensten Fällen den tatsächlichen Verhältnissen entspricht. Wichtig in der Definition von Hcezel ist aber die Feststellung, daß der Charakter der geographischen Gestalt zuerst erkannt werden muß; erst dann kann ihre Abgrenzung erfolgen. Bei jeder Grenzziehung sind also die abzugrenzenden Landschaften zuerst auf ihr Gefüge zu untersuchen, sofern dies nicht schon aus der Literatur bekannt ist.

F. RATZEL (54, S. 448) erkannte den allmählichen, flächenhaften Übergang einer Landschaft in die benachbarte, mit andern Worten, daß selten Grenzlinien, sondern meistens Grenzstreifen auftreten.

O. Maull (45, S. 602) hat den Begriff des Grenzsaums und des Grenzgürtels genau definiert. Unter Grenzsaum versteht er das Übergangsgebiet eines einzigen Landschaftsbildners, während der Grenzgürtel den Durchdringungsraum mehrerer Grenzsäume darstellt.

D. Gurlit T (2o, S. 431) legt meines Erachtens den Begriff der Landschaftsgrenze eindeutig fest: „Da die Länder und Landschaften keine abstrakten, sondern dinglich erfüllte Räume sind, werden sie nicht durch Flächen, sondern durch Räume begrenzt, die sich auf der Grundfläche als Säume abbilden, deren Weite beträchtlich schwankt...". 
Diese Definiton entspricht tatsächlich der Natur der abzugrenzenden Objekte, denn Landschaften sind dreidimensionale Gebilde (sofern von ihren zeitlichen Wandlungen abgesehen wird).

Die Projektionen der Grenzräume GuRLitr's auf eine Ebene entsprechen den Begriffen von Maull. Geographische Abgrenzungen werden immer in Karten festgehalten, bei deren Besprechung leisten daher die Ausdrücke Grenzsaum und Grenzgürtel gute Dienste. Ich behalte sie darum bei im Bewußtsein, daß einer Fläche auf der Karte in der Wirklichkeit ein Raum, einer Linie dagegen eine Fläche entspricht.

J. SœLCH (62, S. 25) nennt ein Gebiet, in welchem ein Landschaftsbildner einheitlich ist, einen geographischen Raum. O. Maull $(45$, S. $601 \mathrm{ff}$.) bezeichnet den Bildner als Strukturelement, seine Grenzen als Strukturgrenzen. Solche umreißen demnach den Grenzsaum.

Bei der Begrenzung von einheitlichen Landschafts- oder Strukturelementen (geographischen Räumen) wurden bisher, mit Ausnahme der Arbeiten von O. MAull, ganz selten diese Strukturgrenzen berücksichtigt. Die Grenze zweier Merkmale wurde stillschweigend, ohne sie neu zu definieren, in den Grenzsaum gelegt. Diese Grenze besitzt aber einen andern Trennungscharakter als die Strukturgrenze und muß daher eindeutig von ihr unterschieden werden. Weil sie nur die Häufigkeit oder die Dominanz zweier Merkmale gegeneinander abwägt und scheidet, nenne ich sie relative Grenze.

Landschaftselemente können auf der Erdoberfläche über weite Gebiete durchlaufend sein, dabei aber sehr stark in ihrer Verbreitungsintensität oder Dichte wechseln wie z. B. Temperatur, Niederschlag, Flüsse, Straßen, Ackerflächen usw. Daher dürfen sie zur Grenzziehung herangezogen werden. „Man untersucht nun statistisch die Verbreitung einer solchen Erscheinung und verzeichnet auf der Karte Isolinien, die gleiche Dichten dieser Erscheinung veranschaulichen. Die entsprechenden Isolinien heißen Isothermen, Isohyeten usw. Die relative Größe des Abstandes zwischen den Isolinien bezeichnet man als Gradient oder Gefälle“ (44, S. 43).

W. SCHAFFNer $(57$, S. 47-50) hat den Begriff der generellen Grenze geprägt. Sie tritt als Linie an Stelle des Grenzgürtels.

Die Dreidimensionalität der Landschaft bedingt neben der seitlichen oder lateralen Begrenzung auch eine Ober- und Untergrenze. E. Markus hat dies schon erkannt, wenn er in seiner Schrift „Chorogenese und Grenzverschiebung“ $(43$, S. 7$)$ das Vordringen der untern Grenzfläche von London beim Bau der Untergrundbahn erwähnt.

O. Lehmann $(42$, S. 234/35) und H. Lautensach $(38, \mathrm{~S} .26)$ sprechen sich ganz unbestimmt über eine Ober- und Untergrenze aus, während D. GuRLITT (2o, S.431-436) die Obergrenze direkt über den Hausdächern verlaufend annimmt, ohne sie näher zu beyründen.

A. HetTNer (26, S. 232) unterscheidet folgende drei verschiedene Begriffe der wirklichen Erdoberfläche, die in gewissem Sinne mit der Ober- und Untergrenze vergleichbar sind. Als die eigentliche Erdoberfläche bezeichnet er die obere Grenze der Atmosphäre. Die zweite, augenfälligste Erdoberfläche, ist die Grenze hier der festen Erdrinde, dort der Wasserhülle gegen die Lufthülle. Die dritte Erdoberfläche ist die Grenze der festen Erdrinde teils gegen die Wasser-, teils gegen die Lufthülle.

E. WINKLER leitet (mündliche Mitteilung) die Begrenzung aus der Definition der Landschaft als Korrelationseffekt von Litho-, Hydro-, Atmo- und Biosphäre her. Nach ihm liegen die Grenzflächen (der Globallandschaft) dort, wo im Gefüge dieser Sphären eine derselben aussetzt.

Diese Begrenzung der Landschaft nach WINKLER ist sicher geographisch logisch begründet und entspricht von allen angeführten Grenzführungen am ehesten der Wirklichkeit. Sie müßte aber noch genauer präzisiert werden. Hernach würden sich sicher gewisse Übereinstimmungen mit den Auffassungen von HeTtNer und GurlitT ergeben.

Diese Präzisierung der natürlichen Grenzen der irdischen Landschaft ist nicht die Aufgabe dieser Arbeit. Sie befaßt sich lediglich mit der lateralen Begrenzung irdischer Kernlandschaften niederer Ordnung.

\section{b) Grenzbildner}

Landschaften müssen auf Grund ihrer verschiedenen Charaktere abgegrenzt werden. Es stellt sich dabei die Frage, welche Landschaftselemente als Grenzbildner in Betracht zu ziehen sind.

S. PASSARGE hat bei der Aufstellung seiner "Natürlichen Landschaften“ nur Oberflächengestaltung, Bewässerung, Boden, Klima und Vegetation berücksichtigt. Die Komponenten der Kulturlandschaft scheidet er aus. Auch A. HETTNER (25) scheinen die anthropogeographischen Elemente untauglich wegen ihrer Labilität im Vergleich zu den übrigen Landschaftsgliedern. J. G. Graxö ( $I 8)$ benützt zur Abgrenzung die Formen der Erdrinde, des Wassers, der Vegetation und den durch Mensch und Tier „umgeformten Stoff“.

Um diese Vorgehen richtig beurteilen zu können, müssen wir den Blick auf das vorgenommene Ziel unserer Arbeit, nämlich auf die Erkennung und Abgrenzung von Landschaftseinheiten richten. K. Bürger ( $(9$, S. 52) will die geographischen Gestalten der Wirklichkeit entsprechend erforscht und dargestellt wissen. Daher darf nichts übersehen oder bewußt weggelassen werden was für die betreffende Gestalt wesentlich ist.

In vielen Kulturlandschaften dominieren sogar die durch den Menschen geschaffenen Züge oder sind mindestens so wirksam wie naturlandschaftliche Elemente. K. BÜRGER ( $($, S. 53) schreibt 
mit Recht: „Wir verzichten auf eine wichtige Erkenntnishilfe und entfernen uns von den Raumgegebenheiten, wenn wir bei der Landschaftsbegrenzung bestimmte Elemente grundsätzlich unberücksichtigt lassen “. Es ist somit klar ersichtlich, daß jedes Landschaftselement für die Grenzziehung benützt werden soll, wenn die Nachbarlandschaft im gleichen Landschaftsbildner merkliche Verschiedenheit in der Intensität oder neue Glieder aufweist.

Viele Landschaftsbildner verändern sich mit den Jahreszeiten und vermitteln dadurch dem Beschauer ganz andere Eindrücke. Durch das Wachstum der Pflanzen oder bei Schneefall und Schneeschmelze usw. treten neben Farb- auch Gestaltwechsel auf. Sogar verschiedene Wetterlagen erzeugen ganz anders geartete Bilder einer Landschaft. Es stellt sich daher die Frage, ob alle diese Faktoren zu berücksichtigen sind. Die meisten dieser Wechsel wiederholen sich in kaum veränderter Weise rhythmisch jedes Jahr $(44, \mathrm{~S} .78)$. Aus diesem Grund wurden sie bei geographischen Grenzziehungen nie direkt in Betracht gezogen. In der vorliegenden Arbeit bleiben sie ebenfalls unberücksichtigt, da diese Probleme den Rahmen dieser Arbeit sprengen würden. Für eventuelle spätere Vergleiche oder Überarbeitungen leistet die Angabe der Inspektionszeit sicher nützliche Dienste.

\section{c) Kern- und Übergangslandschaften}

Die Ausscheidung von Landschaftseinheiten ist so zu treffen, daß zunächst die ausgewählten grenzbildenden Elemente gegeneinander abgegrenzt werden. Es sind also die relativen, wenn möglich die sogenannten Strukturgrenzen sowie die markanten Isolinien zu bestimmen. Mit diesem Vorgehen werden wir nach J. SœLCH $\left(6_{2}, S .25\right)$ geographische Räume erhalten, in denen die entsprechenden Landschaftsbildner wie Klima, Vegetation, Formen usw. relativ einheitlich sind.

Es ist gezeigt worden, $\mathrm{da} ß$ auch durchlaufende Landschaftselemente grenzbildend wirken, wenn ihre Erscheinung starke Intensitätswechsel aufweist. Diese Verschiedenheiten in der Verbreitung werden statistisch erfaßt und mit Hilfe von Isolinien ausgewertet. Die Anwendung dieser Merkmale erheischt aber größte Vorsicht. Nur solche Isolinien, die ganz klar und eindeutig als grenzbildend erkannt wurden, dürfen für die Grenzziehung herangezogen werden. Das trifft dann zu, wenn sich die Isolinien eng scharen, der Gradient also groß ist und so eine schroffe Veränderung im Charakter des Landschaftselementes anzeigen ( 44 , S. 43).

Die so erhaltenen geographischen Räume werden, wie J. G. Granö ( $I 8$, S. 140) und S. Passarge $(5 I$, S. 323) vorschlagen, mit bestimmten Signaturen einzeln auf durchsichtige Karten gezeichnet, die wir übereinanderlegen. Im günstigsten Fall kann es vorkommen, daß sich gewisse geographische Räume nahezu decken. Meistens aber wird ein mehr oder weniger breiter Grenzgürtel entstehen. Bei solch breiten Grenzzonen sind daher sog. Randlandschaften ( worden. Sie zeichnen sich durch ihr variables Gefüge aus, entsprechend dem im Grenzgürtel zusammengefaßten und zum Teil ausklingenden Grenzbildner. Randlandschaften sind eben Übergangslandschaften. Im Gegensatz dazu stehen die Kernlandschaften. In ihnen decken sich die geographischen Räume. Deshalb weisen sie einen relativ gleichmäßigen Charakter auf. Nach R. SIEGER $(6 r$, S. 506) sind es gewissermaßen die Zentren, von denen die einzelnen Erscheinungsreihen sich als Wellen ausbreiten.

Eine weitere Möglichkeit besteht darin, daß sich die Grenzen der geographischen Räume beim Aufeinanderlegen kreuz und quer schneiden. In diesem Fall ergeben sich außerordentlich große Schwierigkeiten für die Ausscheidung von Kernlandschaften; ja bei extremen Verhältnissen kann sie sogar unmöglich werden. Auf diese Abgrenzungsschwierigkeiten kommen wir im nächsten Abschnitt nochmals zurück.

O. Maull (45, S. 601) hat spezielle Begriffe für die Verschiedenartigkeit der Grenzgürtel geprägt. Dabei bezweckt er, den mehr oder weniger raschen Wechsel der Landschaftselemente im Grenzgürtel und somit auch seine Breite zu charakterisieren.

Er nennt den Grenzgürtel einen Scheidegürtel, wenn sehr viele Strukturgrenzen auf engem Raum vereinigt sind, die Landschaftselemente sich also rasch wandeln, einen Schwellengürtel, wenn nicht mehr so viele Strukturgrenzen vorhanden sind, einen Übergangsgürtel, wenn die Strukturelemente sich nur allmählich wandeln und dadurch ganz verschwommene Grenzen zu erkennen geben. Endlich hält er unter den letztern noch Rand- und Endgürtel auseinander, in welchen bestimmte Strukturelemente allmählich verschwinden.

Im nächsten Abschnitt werden die Grundzüge der bisherigen Arbeitsmethoden kurz beschrieben, kritisch beleuchtet und nachher Vorschläge zur Lösung einiger strittiger Fragen gemacht.

\section{Arbeitsprinzipien bisheriger Methoden}

\section{a) Dic Methode von Granö}

J. G. Granö ( $I 8)$ berücksichtigt bei der Aufstellung seiner komplexen Erdräume nur die "Gesichtserscheinungen" und zwar die Erdrinde, das Wasser, die Vegetation und den durch Mensch und Tier umgeformten Stoff. Von diesen Elementen werden kartographisch die Verbreitungsgebiete bestimmt und gegeneinander abgegrenzt. Dabei tritt an Stelle des Grenzsaums eine Linie als Grenze. Die Synthese erfolgt, wie bereits im letzten Abschnitt beschrieben wurde, durch Übereinanderlegen der analytischen Karten, wobei alle Elemente als gleichwertig betrachtet werden. Es kristallisieren 
sich dabei mehr oder weniger deutlich Kernlandschaften heraus. Dazwischen liegen Übergangslandschaften. Diese Landschaften werden nach einer speziellen Terminologie benannt.

\section{b) Die Methode von Maull}

O. Maull (45) analysiert einen Erdraum nach seinen einzelnen Strukturelementen und deren Arealen. Er bestimmt somit die Verbreitungsgebiete dieser ausgewählten Grenzbildner physischund kulturgeographischer Art. Welche Grenzlinien ihm nachher im einzelnen zur Erkennung der Grenzgürtel und Kerngebiete dienen sollen, hängt vom Untersuchungs- und Darstellungsmaßstab ab $(45$, S. 607). Wie K. Hassert, H. Hassinger, A. Hettrer und H. Lautensach benützt O. Maull diese gewonnenen Verbreitungsgebiete der Strukturelemente lediglich zur Gewinnung vorläufiger Anhaltspunkte. Die endgültige Abgrenzung der Zentralgebiete und Grenzgürtel ist nicht nur auf die Verbreitung der Landschaftsbildner ausgerichtet; viel eher werden ihre Beziehungen untereinander, ihr gestaltmäßiges Zusammenwirken im Landschaftsganzen zu berücksichtigen versucht. Sie erstreben eine Landschaftsgliederung, die nach H. HASSINGER (24, S. 75) auf den hervorstechendsten Zügen ihrer ganzen Wesenheit beruht und nehmen deshalb eine Wertung der Landschaftselemente vor.

Die Grenzgürtel unterteilt MaUll, je nach ihrer Breite und trennenden Wirkung, in verschiedene Typen, die Kerngebiete je nach Untersuchungsmaßstab in Länder, Landschaften und Landschaftsteile (Landschaften niederer Ordnungen), die sie trennenden Grenzräume in Grenzgürtel höherer und niederer Ordnungen.

\section{c) Die Methoden von Passarge}

S. PASSARGE benützte anfänglich für die Grenzziehung prinzipiell nur die Elemente der Naturlandschaft (mit Ausnahme der Zoosphäre). Die so erhaltenen Landschaften ordnete er nach Art des Linnéschen Systems in Klassen, Ordnungen, Familien, Gattungen sowie Arten. Ihre Benennung erfolgte nach ihrem physiogeographischen Charakter.

Da er auf diese Art in Kulturlandschaften nicht die gewünschten Erfolge erzielte, entwickelte er später am Beispiel der Gegend von Meran (52) eine neue Methode mit folgendem Arbeitsgang: Zuerst wird die Gegend inspiziert und eine gefühlsmäßige Gliederung in Ganzheiten vorgenommen. Über die Grenzführung spricht sich PASSARGE dabei nicht aus. Aus den gefühlsmäßig ausgeschiedenen Ganzheiten werden durch Generalisierung physiognomische Typen gebildet. Diese werden beschrieben und erklärt. Die Landschaftsgrenze erhält man, indem die Verbreitung des Typs bestimmt wird.

\section{d) Andere Methoden}

Neben diesen erwähnten Arbeitsweisen existieren noch zahlreiche andere, von denen sich im Prinzip die meisten einer der oben erwähnten zuordnen lassen. Einige Geographen stellen bei der Landschaftsgliederung ein Strukturelement als wegleitenden Faktor in den Vordergrund oder stützen sich auf eine kleine Auswahl bestimmter Landschaftsbildner. In aller Kürze sollen noch einige solche Versuche skizziert werden. J. BüHLER ( 8 ) unterteilt die Schweiz zunächst in ihre Kulturkreise und diese in kleinere Landschaften vorwiegend nach wirtschaftlichen Gesichtspunkten. F. JÆGGR (34) nimmt die übliche Unterteilung in Jura, Mittelland und Alpen vor und gliedert diese weiter nach Wirtschaft und Siedlungsform. Wieder andere Gliederungen stützen sich auf ethnologisch-soziologische, klimatische, morphologische, genetische Grundlagen. Die Grenzen werden in diesen Arbeiten in der Regel intuitiv erfaßt.

H. GuTERSOHN (22, S. 201) will sog. physiologische Landschaftstypen ausscheiden. Er untersucht dazu die administrativen Einheiten auf ihr Gefüge und erkennt seine Ganzheiten je nach der Region in einer Hofeinheit (Landschaft 1. Ordnung), einer Gemeinde (Landschaft 2. Ordnung) oder in einem ganzen Bezirk (Landschaft 3. Ordnung). Die Klassierung der Landschaften erfolgt nach Orographie, agrarischer Nutzung, Siedlungscharakter und Berufsstruktur, wobei jede kulturlandschaftliche Ganzheit, anhand einer vorher aufgestellten Merkmalliste entsprechende Kennziffern als Formel zugeordnet erhält, ähnlich wie es GRANÖ $(18)$ und PASSARGE (52) vorgeschlagen haben.

H. LAUTENSACH $(40)$ typisiert die Erdräume nach Lageprinzipien, die er in folgende Lagetypen zerlegt: 1. die planetarische Lage, d. h. Lage im System der Breitenkreise, 2. die Lage innerhalb der Festländer oder Meeresräume, 3. Ost-Westlage und 4. Höhenlage oder hypsometrische Lage. Die Interferenzwirkungen dieser vier Faktoren erlauben ihm eine Typisierung der Landschaftsinhalte als auch ihrer Grenzen. Jedem Raum kommen gemäß seiner Stellung innerhalb der vier Kategorien vier Buchstaben mit diesbezüglichen Zahlen (Phasen) zu, die zu einer Landschaftsformel vereinigt werden. Diese bestimmt die Stellung des Raumes innerhalb der vier Kategorien und legt seinen Charakter fest.

In seiner Dissertation kombiniert W. Schaffner (57) die Methode von Granö mit der sog. Inspektionsmethode von Passarge. Der erste Teil der Arbeit, die Auswahl der Landschaftsbildner zur Gewinnung des Grenzsaums und die Bildung des Typs, erfolgt im Sinne von Passarge. Die Synthese wird rein kartographisch nach GraNö durchgeführt. Bei einer zweiten Geländebegehung wird die Wertung der Faktoren vorgenommen und damit die Physiologie der Landschaft zu berück- 
sichtigen versucht. Zur. Arealbestimmung der Ganzheit setzt W. Schaffner (57, S. 49/50) an Stelle des Grenzgürtels die sog. generelle Grenze.

Die sog. „Unit-Area-Method“ von G. D. Hudson (37) dient ausschließlich der Kartierung von Agrarlandschaften.

\section{e) Vor- und Nachteile dieser Arbeitsweisen}

Die größte Schwierigkeit der sog. Inspektionsmethode von S. PASSARge liegt in der Typenbildung. Sie erfordert große Erfahrung und eine sehr gute Beobachtungsgabe. Einen großen Vorteil aber bedeutet die. Zeitersparnis, die sich durch das Wegfallen von Analyse und Synthese ergibt. Die Grenzführung gestaltet sich dagegen sehr fragwürdig. Auch der Inhalt der Landschaft tritt dabei zu wenig in den Vordergrund. Ein großer Nachteil der Methode liegt in der übertriebenen Subjektivität. Die Bildung der Typen sowie die Grenzführung erfolgen rein gefühlsmäßig und werden daher bei Anwendungen stets Angriffspunkte bilden.

Bei allen wertenden Methoden (O. Maull, W. Schaffner u. a.) tritt das subjektive Moment zu stark in Erscheinung. Die intuitive Erfassung der einzelnen Grenzlinien und ihre Wertung führt sicher zu großen Unstimmigkeiten und uneinheitlichen Grenzführungen. Trotz der zum Teil starken Generalisierung dieser Arbeitsweisen stellen sich immer noch große Schwierigkeiten bei der Abgrenzung von Landschaften ein.

Die Methode von H. GuTERsohn scheint die üblich auftretenden Grenzprobleme umgehen zu können, indem administrative oder Besitzgrenzen zugleich zu Landschaftsgrenzen erhoben werden. Doch stellen sich auch Schwierigkeiten bei dieser Arbeitsweise ein, wenn Landwirte (22, S. 52) auch Land jenseits der Grenze ihrer Wohngemeinde bewirtschaften oder in Hofgebieten, wo die Landwirtschaftsbetriebe nicht vollständig arrondiert sind. Es ist auch fraglich, ob diese anthropogen bedingten Linien immer Landschaftsgrenzen darstellen. Gewisse Mängel der Methode würden sich bei der Gliederung von Gegenden zeigen, die der Mensch nur wenig umgestaltet hat. Große Vorteile bietet bei der Methode die direkte Verwendbarkeit der Statistiken für die Erfassung und Klassierung einer Gemeinde oder eines Bezirks. Der Versuch ist sicher bemerkenswert und läßt sich von den dargelegten Gesichtspunkten aus gut rechtfertigen.

Die zuerst ausgearbeitete Methode von S. PASSARge und diejenige von J. G. Granö werden allgemein als sog. kartographische Methoden bezeichnet.

$\mathrm{Da}$ sie von verschiedenen Geographen als wenig zweckmäßig betrachtet werden, sollen sie nun objektiv auf ihre Vor- und Nachteile geprüft und nachher den andern Methoden gegenübergestellt werden.

Als ein Vorteil der kartographischen Methode kann deren Objektivität gelten, indem die Verbreitungskarten der Strukturelemente ein genaues Bild der Wirklichkeit vermitteln, ohne Korrekturen aufzuweisen, die durch die Berücksichtigung der physiologischen Beziehungen verursacht werden. Durch die meist intuitive Erfassung der Grenzlinie oder die Ersetzung des Grenzsaums durch eine Linie wird ihre Objektivität allerdings wieder fraglich.

Ein klarer Vorteil dagegen ist der eindeutig vorgeschriebene Arbeitsgang. Nur auf diese Weise, mit Hilfe einer einheitlichen Methode, erreichen wir für alle Anwendungen richtige Vergleichsbasen.

Als entschiedener Nachteil der kartographischen Methode ist die bisher erfolgte grundsätzliche Ausscheidung bestimmter Landschaftselemente, bzw. deren vorausbestimmte Wahl, zu betrachten. Dabei wird ein Landschaftsindividuum nicht nach seinen charakteristischen Zügen beurteilt, sondern nach durchlaufenden Faktoren, die auch in andern Ganzheiten enthalten sind. Das ist auch der Hauptfehler der an sich bedeutenden Methode von H. LaUtensaCh (4o). Ein weiterer, kaum auszumerzender Fehler der kartographischen Methode liegt darin, da $ß$ meistens nur physiognomisch wirksame Faktoren berücksichtigt werden können. Es ist unmöglich, die gegenseitigen Beziehungen der Landschaftsbildner direkt zu erfassen, das heißt, die Landschaftsphysiologie tritt in den Hintergrund. Dieser Nachteil wird jedoch durch die Tatsache abgeschwächt, daß sich die Effekte der Wechselbeziehungen zu einem großen Teil im Antlitz der Landschaft äußern und diese in die Untersuchung einbezogen werden können.

Die obigen Angriffspunkte sind eindeutige Mängel, während die folgenden leicht widerlegbar sind.

Die gleichwertige Behandlung aller Grenzbildner wird der kartographischen Methode als Nachteil ausgelegt. Das geschieht meines Erachtens zu Unrecht. Die Landschaft ist ein außerordentlich komplexes Gebilde. Alle Landschaftsbildner sind durch enge Wechselbeziehungen miteinander verknüpft, und somit trägt jedes Element Wesentliches bei zur Bildung der Ganzheit. Sicher gilt das Gesetz: Kleine Ursache, große Wirkung; mit andern Worten, ein unwichtig erscheinender Faktor vermag durch das komplizierte Wechselspiel der Beziehungen in seiner praktischen Konsequenz große Bedeutung zu besitzen. Diese Komplexheit der Landschaft verbietet daher die Bevorzugung, ja verunmöglicht überhaupt eine genaue quantitative Bestimmung der Anteile einzelner Landschaftsbildner am Charakter der Landschaft. K. Bürger ( 9, S. 42) und L. BertalanfFy (4, S. 99) betonen, wie schwierig die Erforschung ursächlicher Zusammenhänge in Ganzheiten, also auch in Landschaften, ist, und daß jede diesbezügliche Schlußfolgerung mit großer Vorsicht aufgenommen werden müsse. 
Sollte trotz allen soeben angeführten Einwänden eine Wertung vorteilhaft erscheinen, so besteht auch bei der kartographischen Methode die Möglichkeit, eine Grenze als doppelt, dreifach usiv. wirksam anzunehmen.

Die kartographische Methode wurde auch schon des starren Schematismus bezichtigt. Das ist sicher richtig. Deswegen ist noch keineswegs bewiesen, daß dies wirklich ein Nachteil sei. Das Wesen der wissenschaftlichen Arbeit besteht überhaupt darin, unserer beschränkten Vorstellungskraft mit Schemata nachzuhelfen, die allerdings möglichst der Wirklichkeit entsprechen müssen. Jede Arbeitsweise, die eine Methode sein will, ist daher schematisch, denn wir vermögen in den seltensten Fällen Erscheinungen in ihrer Gesamtheit quantitativ zu erfassen und darzustellen. Wir sind gezwungen zu analysieren, zu ordnen und zu gliedern. Auch ein wissenschaftliches System stellt immer ein Schema dar.

Wichtig bei jeder wissenschaftlichen Arbeit ist, daß Klarheit herrscht in welchen Belangen schematisiert wird, wie über den Grad, die Stärke der Schematisierung, d. h., wie weit das angewandte Arbeitsschema die Wirklichkeit wiederzugeben vermag. Dabei darf nicht übersehen werden, daß neben der bewußten Vereinfachung auch immer unbewußt vereinfacht wird, weil viele Erscheinungen, besonders in einem solch komplexen Gebilde, wie es die Landschaft darstellt, selten restlos erfaßt werden können. Umso wichtiger ist dieses Darstellungsproblem. Bei jedem Arbeitsgang sollte somit der Schematisierungsgrad abgeklärt werden, wie bei der Zeichnung von topographischen Karten Generalisierungsgrade unterschieden werden. Analog dem Generalisierungsgrad soll der Schematisierungsgrad die Abweichung einer Darstellung (zeichnerische wie schriftliche) von den tatsächlichen Verhältnissen ausdrücken. Er ist umso größer, je mehr die Darstellung eines Objektes von der Wirklichkeit abweicht. Es sollte diesbezüglich durch eine zahlenmäßige Erfassung, z. B. mit Hilfe einer Wahrscheinlichkeitsrelation oder einem Maßstab eine eindeutige Abstufung geschaffen werden.

Wie bereits gezeigt wurde, besteht bei der Schaffung der synthetischen Karte die Möglichkeit, $\mathrm{da}$ sich die gewonnenen Strukturgrenzen kreuz und quer schneiden und sich somit keine Kernlandschaften abzeichnen. Besonders bei der Verwendung vieler Grenzbildner erhöht sich die Möglichkeit. Diese Tatsache wurde der kartographischen Methode als Versager ausgelegt. In einem solchen Fall liegen meines Erachtens keine Kernlandschaften vor, denn die vorher ermittelten Strukturgrenzen demonstrieren die uneinheitliche Struktur des Gebietes.

Durch die Schaffung einer entsprechenden Systematik wird es möglich, trotzdem noch ziemlich einheitliche Landschaftsräume auszuscheiden, z. B.:

Landschaft 1. Ordnung: Einheitliche Landschaftsbildner (im Sinne von Homogenität).

Landschaft 2. Ordnung: 1 Landschaftselement variiert innerhalb bestimmter Werte in seiner Verbreitungsintensität.

Landschaft 3. Ordnung: 2 Landschaftselemente variieren innerhalb bestimmter Werte in ihrer Verbreitungsintensität.

Landschaft 4. Ordnung: 3 Landschaftselemente variieren innerhalb bestimmter Werte in ihrer Verbreitungsintensität.

Landschaft 5. Ordnung: 4 Landschaftselemente variieren innerhalb bestimmter Werte in ihrer Verbreitungsintensität.

Grenzgürtel mit verschiedenen Wirksamkeitsquotienten.

Die Landschaften niederer Ordnungen können wir als Unterarten einer größern, physiognomisch klarer in Erscheinung tretenden Landschaft auffassen. Diese Systematik ist bei der praktischen Anwendung noch besser zu erläutern.

Die Kritik der bisherigen Methoden läßt sich folgendermaßen zusammenfassen:

Die sog. Inspektionsmethoden sind immer stark subjektiv. Je nach den Fähigkeiten des Geographen kann ihnen das zum Vor- oder Nachteil gereichen. Dafür wird die Physiologie der Landschaft direkt $\mathrm{zu}$ berücksichtigen versucht. Im allgemeinen sind die Inspektionsmethoden nicht so zeitraubend wie die kartographischen Arbeitsweisen.

Alle kartographischen Methoden schließen den Fehler ein, daß sie die physiologischen Beziehungen teilweise vernachlässigen müssen. Die subjektiven Momente dagegen treten stärker in den Hintergrund. Die kartographischen Methoden weisen in dieser Beziehung noch vermeidbare Lücken auf, weshalb ihnen Gegner vorwerfen, sie seien nur scheinbar objektiv. Auch die grundsätzliche Eliminierung bestimmter Landschaftselemente für die Grenzziehung sollte unterbleiben.

Als großer Vorteil ist der eindeutige Arbeitsgang zu werten. Die Resultate entstehen daher unter sehr ähnlichen oder sogar gleichen Bedingunen und stellen folglich einheitliche Vergleichsgrundlagen dar. Zur Untersuchung eines größern Gebietes bietet die kartographische Methode den nicht zu unterschätzenden Vorteil, $\mathrm{da} ß$ Studienequipen eingesetzt werden können, die eindeutige vergleichbare Resultate liefern.

Als Fehler der meisten bisherigen Methoden ist die intuitive Erfassung der Grenzen zu betrachten. Sie führt sicher zu großen Unstimmigkeiten in der Grenzführung.

Bei der Ausarbeitung einer neuen Methode gilt es, die obigen Nachteile möglichst auszumerzen oder wenigstens zurückzudämmen. 


\section{Die Quadratmethode}

Es soll nun zunächst theoretisch der Arbeitsgang der Quadratmethode entwikkelt werden. Sie muß vermeidbare Mängel der bisherigen sog. kartographischen Arbeitsweisen zu beheben versuchen unter Beibehaltung ihrer Vorteile.

Der eindeutige Arbeitsgang von J. G. Granö (18) bleibt für alle Methoden wegleitend. Es dürfen aber nicht nur eine prinzipiell beschränkte Anzahl, sondern es müssen alle bei der Feldbegehung ausgewählten Grenzbildner Verwendung finden.

Dann erfolgt die Festlegung der Kartierungsvorschriften. Auf diese Weise wird eine einheitliche Feldaufnahme garantiert, denn durch die Einwirkung der Umgebung sowie der vielleicht mehrere Wochen dauernden Kartierungsarbeit, könnten sich leicht Fehler einstellen. Für den Einsatz einer Arbeitsequipe wird diese Maßnahme zur Erreichung guter Resultate ohnehin unumgänglich sein.

Jetzt kann die Feldaufnahme mit genauer Lokalisierung der grenzbildenden Objekte in Angriff genommen werden. Darauf erstellt man für jeden Grenzbildner besondere Verbreitungskarten. Auf die Verbreitungskarte legt man nun ein Quadratnetz. Seine Maschenweite erheischt für jedes grenzbildende Element spezielle Ermittlung.

Hierauf werden in jeder quadratischen Einheitsfläche die grenzbildenden Landschaftselemente gezählt oder ausgemessen. In der sog. Zahlenkarte erhält nun jedes Quadrat ein oder mehrere Zahlen, welche die Häufigkeit oder Dichte des Grenzbildners ausdrücken.

Der nächste Arbeitsgang besteht in der Bestimmung des kritischen Grenzwertes oder der Leitzahl für die Grenzziehung. Für jeden Grenzbildner ist die Leitzahl verschieden und erfordert wiederum besondere Beurteilungen. Mit Hilfe der gefundenen Leitzahl erfolgt die Ziehung der Isolinie.

Die relative Grenze wägt die Dominanz zweier vergleichbarer Merkmale (zweier Haustypen, zweier Konfessionen) gegeneinander ab. Für diese Grenzziehung wird das zahlenmäßige Auftreten der zwei Merkmale in jeder Einheitsfläche gegeneinander abgewogen und die Grenze zwischen zwei Quadraten mit verschiedenen dominanten Merkmalen hindurchgezogen.

In der anschließenden Beschreibung wird auch der mittlere Fehler des Grenzverlaufs angegeben. Die Synthese und nachfolgende Gebietseinteilung wird durch Übereinanderlegen der durchsichtigen analytischen Karten erreicht und danach die Ausscheidung der Landschaften vorgenommen. Schließlich werden die Wesenszüge der so erhaltenen Landschaften beschrieben und erklärt. Die einzelnen Arbeitsgänge der Quadratmethode sind zusammengefaßt folgende:

1. Begehung und Studium des Untersuchungsgebietes.

2. Beschreibung der Wesenszüge der Landschaft.

3. Auswahl der grenzbildenden Landschaftselemente.

4. Festlegung der Kartierungsrichtlinien.

5. Feldaufnahme mit genauer Lokalisierung der grenzbildenden Objekte.

6. Erstellung der Verbreitungskarten für jeden Grenzbildner.

7. Bestimmung der günstigsten Quadratgröße und Aufteilung des Gebiets durch das entsprechende Quadratnetz.

8. Auszählung (Dichtebestimmung) oder Messung der grenzbildenden Landschaftselemente in jedem Quadrat (Zahlenkarte).

9. Ermittlung des kritischen Grenzwertes, der Leitzahl.

10. Ziehung der analytischen Grenzen mit Angabe der mittleren Fehler.

11. Synthese der Landschaften (Ausscheidung der Landschaften).

12. Beschreibung und Erklärung der Wesenszüge der Landschaften.

Der II. und III. Teil zeigen die praktische Anwendung der Quadratmethode am Beispiel des Grenzbereichs der Kantone Schwyz, Zug und Zürich. 


\section{DIE ANALYSE DES UNTERSUCHUNGSGEBIETES}

\section{A. DIE KARTIERUNG}

\section{Die Feldbegehung}

Jede geographische Grenzziehung setzt die umfassende Kenntnis des Untersuchungsgebietes voraus. Diese Kenntnis eignet man sich durch Feldbegehungen an. Weitere ergänzende Hilfsmittel bietet das Literaturstudium. Die Zeit der Feldbegehung kann aus den weiter vorn angeführten Gründen beliebig gewählt werden. Die Inspektionsrouten sind mit Hilfe der Karte festzulegen und aus praktischen Gründen dem Gelände anzupassen. Streng genommen müßte jede Lokalität aus der gleichen Distanz inspiziert werden, damit der gleiche Generalisierungsgrad gewährleistet wäre. Praktisch ist das nicht gut durchführbar.

Man inspiziert daher das Gelände längs den in der Karte eingezeichneten und numerierten Routen, die das Gebiet mehr oder weniger parallel durchziehen. Die Routen sollen dabei so gelegt werden, daß sie jede Landschaftszelle berühren und ein Geländeabschnitt aus 2 Richtungen gut eingesehen werden kann. Ihr Abstand darf somit nicht über $800 \mathrm{~m}$ betragen.

Im Feldbuch werden für jeden Querschnitt die die Landschaftsobjekte betreffenden Beobachtungen notiert. Flugbilder und eigene photographische Aufnahmen helfen, den gewonnenen Einblick in die Struktur und in die hervorstechendsten Züge des Untersuchungsgebietes zu vertiefen. Auch die nachfolgende Kartierung kann der Bearbeiter durch den so erhaltenen Überblick rationeller gestalten.

Über die Gegend um die Dreiländerecke der Kantone Schwyz, Zug und Zürich liegt bereits wertvolle geographische Literatur wie auch solche aus den Nachbarwissenschaften vor (siehe Literaturverzeichnis). Sie erleichterte die Arbeit wesentlich.

Die günstigsten Inspektionsrouten in Richtung West-Ost für das vorliegende Gebiet sind (Namen nach Top. Atlas der Schweiz) :

1. Hauptstraße von Naglikon ( $\mathrm{Au}$ ) bis Pfäffikon (Sz.).

2. Unter Ort ( $\mathrm{Au})$ - Mittel Ort - Steinacker - Langwies - Schützenhaus - Gwaad - Stoffel — Bühlen (Wädenswil) - Reidbach - Burghalden - Breiten - Hafen (Richterswil) - Frohburg - Wilen (Wollerau) Leutschen.

3. Dächenwies (Burstel) - Rüti - Büelenebnet - Holzmoosrüti - Untermoosen - Rötiboden - Sandhof - Waisenhaus (Wädenswil) - Eichhof - Feld - Krummbächli (Richterswil) - Sennhütte - Schwalbenboden Wollerau - Obere Mühle - Fälmis - Ober Eulen - Miesegg — Schwä begg - Halten - Roggenacker (Pfäffikon).

4. Hegimoos (Burstel) - Neubühl — Herrlisberg - Feld - Gehrenau Sennweid - Obermatt - Schwanden - Sternenschanz - Schellhammer Junker - Riedgutsch - Felsen (Wollerau) - Roos - Unter Fritsch Unterstoß - First - Stalden - Fuchsberg - Wilhelmenhof.

5. Aamühle (Burstel) - Stocken - Waggithal - Langrüti - Hofacker Feldweid - Kleinweid - Frohe Aussicht - Hügsam - Sattelbogen Sentenhof - Erlen - Sihlegg - Roosweid - Brand - Feld - Feusisberg - Ried - Schneckenburg.

6. Burstel - Bachgaden - Buchhof - Mittelberg - Tanne - Egg Haslen - Zopf (Samstagern) - Feldmoos - Neumühle - Neufeld Weidli - Aesch - Ramensbühl - Peterschwendi - Baumen -- Althaus -. Wies - Milten - Rohnen - Sagen — Strickli. 
7. Burstel - Sennhaus - Mugern - Moos - Kaltenboden - Bubenwies Mühlestalden - Külpen - Rothenblatt - Oberholz - Unter Laubegg Seeli - Neumühle.

8. Gehrensteg (nördlich Hirzel) - Schlieregg - Rechberg - Stollen - Zweierhof - Hohenberg - Unter Wolfbühl - Baalet - Unter Hengerten Rebgarten - Moos - Schafrain - Blegi - Neufeld.

9. Hirzel - Spitzen - Müsli - Aesch - Au - Stollenweid - Palmisacker - Neubad - Schönenberg - Gschwendmatt - Segel - Hütten.

10. Boden (südl. Hirzel) - Erni - Spreuermühle - Brunnen - Brunnenhüsli - Weisserlen - Suhner - Sihlmättli - Bubheini - Schwarzenbach - Rain - Waldrain - Am Rain - Haslaub - Finsterseehalden - Hinter Langmoos - Hütten - Bergli — Schindellegi - Kastenegg - Weni Bleiken - Bühl — Loch - Hoher Etzel.

11. Hof (Neuheim) - Ölegg - Oberschwelli - Schwand - Dändlimoos Hinterkehr - Haltsäge - Euw - Bostadel - Unter Mühlestock - Boden - Hüttnerbrücke - Heiten.

12. Hof - Hinterbühl - Blachen - Brand - Winzwilen - Knechtlischwand - Zubenweid - Brettingen - Harget - Erlenmoos - Ziegelhütte Finstersee - Ober Mühlestock - Sparen - Schönau - Mistlibühl Gschwendboden - Örischwand - Roßberg - Schindellegi - Kaltenboden - Geißboden.

13. Menzingen - Grund - Schwandegg - Gschwend - Vorderblack - Dutz - Greit - Gottschalkenberg - Dreiländerstein — Schindellegi.

\section{Wesenszüge der Landschaft}

Die Feldbegehung und das Literaturstudium vermitteln Wesen und Charakter des Untersuchungsgebietes. Die folgende kurze Beschreibung erhebt nicht Anspruch auf Vollständigkeit. Es sollen sich nur die wesentlichen Züge der Landschaft abzeichnen. Dabei wird der regionalen Verbreitung der Landschaftselemente wie dem Wechsel in deren Häufigkeit und Aufbau besondere Beachtung geschenkt.

Das Gelände steigt vom Zürichsee, im nordwestlichen Teil sanft, im südöstlichen Teil steiler, gegen die Hohe Rone und den Hohen Etzel an. Der regelmäßige Anstieg wird nördlich der Hohen Rone vom tief eingeschnittenen Sihltobel, langgestreckten, flachen Mulden nördlich des Hohen Etzel und durch die Felsrippen von Freienbach und Wollerau unterbrochen.

Die Großformen sind weitgehend durch die Tektonik bestimmt. Die wagrechten Molasseschichten des nördlichen Teils steigen südlich der Linie Wädenswil-Hirzel allmählich an und bilden den Nordschenkel der nördlichsten Antiklinale, die in der Richtung Hütten-Feusisberg verläuft. Dieser Nordschenkel äußert sich klar durch die harten Sandsteinschichten des Burdigalien in den Rippen von Freienbach und Wollerau. Dieser schwyzerische Teil der Vordern Höfe wurde von A. Sсносн (58) als Rippenlandschaft bezeichnet.

Die markante Großform des Hohen Etzel ist durch eine zweite Antiklinale bedingt, die sich ungefähr parallel zur ersten hinzieht. Diese beiden Antiklinalen sind bis zur Linie Alpmündung-Hütten vom Südschenkel der Hohen Rone-Antiklinale überschoben. Die Hohe Rone ist die andere auffallende Großform. Die Gletscherablagerungen der Eiszeit modellierten zur Hauptsache die Kleinformen des Reliefs. Das Gebiet $\mathbf{z w i s c h e n}$ der Hohen Rone und dem Zürichsee mit seinen vielen parallel verlaufenden Moränenwällen, den zahlreichen großen und kleinen Moränenhügeln, Drumlins, Sümpfen und Terrassen stellt nach W. HöнN (28, S. 7) eine der großartigsten Moränenlandschaften der Schweiz dar.

Die Grundmoränen kleistern die Muldenböden aus und machen sie wasserundurchlässig. Daher sammelte sich das Wasser in diesen Vertiefungen an und bildete 
kleine Seelein und Weiher. Ihre Zahl reduzierte sich im Laufe der Zeit durch Verlandung auf vier (natürliche). Diese verlandeten Gewässer bilden heute zahlreiche, zum Teil ausgedehnte Sümpfe. Viele von ihnen wurden während des letzten Krieges melioriert und unter Kultur genommen.

Die zürcherische Moränenlandschaft wird zur Hauptsache durch Aabach und Reidbach entwässert, die bei Käpfnach und Wädenswil in den Zürichsee münden. Die Bäche der Hohen Rone, der zugerischen- und auch des südlichen Teils der zürcherischen Moränenlandschaft, fließen der Sihl zu. In der Zone der gefalteten Molasse des Kantons Schwyz isț der Verlauf von Krebs-, Eulen- und Staldenbach durch die Rippen von Freienbach und Wollerau vorgezeichnet. Eulen- und Staldenbach fließen in ausgesprochenen Isoklinaltälchen. Die Wasserkraft wird vielfach an Terrassenkanten ausgenutzt.

Der Versuch, das Klima des Gebietes zu umschreiben, kann nur teilweise gelingen, weil das bestehende Netz der Beobachtungsstationen zu großmaschig ist. Sehr fein auf das Klimaregime reagiert aber die Pflanzenwelt. Pflanzensoziologische Daten bilden deshalb eine gute Grundlage zur Charakterisierung des Klimas. Dabei darf allerdings nicht vergessen werden, daß neben dem Klima auch der Boden ein wichtiger Faktor für die Ausbildung der Vegetation darstellt und alle drei ein unstabiles Kräftesystem bilden. Trotzdem dürften pflanzensoziologische Untersuchungen für die Erfassung des Klimas die besten Resultate liefern. H. ETter (13) führte in unserm Gebiet vegetationskundliche Studien durch und bestimmte die Grenze zwischen der sog. kollinen oder Hügelstufe und der montanen oder Bergstufe. Physiognomisch äußert sie sich im Übergang der Eichen-Hainbuchenwälder in Buchenwälder. Ich übernehme diese Grenze von Etter als Klima- und Vegetationsgrenze.

Die Ablagerungen des Diluviums und Alluviums bestimmen unter anderm die Lage der Siedlungen, indem die Menschen ihre Wohnsitze an oder auf den trokkeneren Hügeln errichteten. Es herrscht im ganzen Gebiet Streusiedlung vor. Sie ist in weitem Maßè durch das unübersichtliche, eher verkehrsfeindliche Gelände bedingt und begünstigt zusammen mit Bodenbeschaffenheit, Höhenlage und Klima die Graswirtschaft und den Weidebetrieb, der tiefgründige schwere Boden insbesondere auch den Obstbau.

Die Großzahl der Siedlungen besteht aus Einzelhöfen und Weilern. Dörfer entwickelten sich nur wenige. Sie liegen meistens an verkehrsgünstigeren Orten. Als Flecken können Richterswil und Wädenswil bezeichnet werden.

Sehr augenfällig im Untersuchungsgebiet sind die verschiedenen Haustypen. Jeder Typ zeigt ein eigenes Verbreitungsgebiet. Für die Wohnhaustypen übernehme ich die Bezeichnungen von $\mathrm{H}$. Brockman (6). Am reinsten erhalten und am besten erkennbar ist das sog. Innerschweizer Landenhaus oder Schwyzerhaus (6). Es ist vielstöckig und besitzt ein auffallend steiles Satteldach, das nicht weit über die Wände vorsteht. Die gekoppelten Fensterreihen oder die zahlreichen Einzelfenster sind durch Klebdächer gegen den Regen geschützt. Die Lauben auf beiden Seiten unter der Dachschräge sind meistens nach außen abgeschlossen. Unter dem ganzen Haus ist ein gemauerter Sockel, der-weit über den Boden hinausragt. Er umschließt den sog. Oberkeller, der von außen betretbar ist und als Keller oder heute auch als Waschküche benützt wird. Der Dachraum ist mit Zimmern ausgebaut (bis fünf). Der ganze Oberbau über dem Steinsockel besteht aus Holz. Die Wände werden aus liegenden, die tragenden Elemente aus stehenden Hölzern gebildet. Ein Schindelschirm schützt sie gegen Regen und Wind. Heute ist er leider manchenorts durch Eternitplatten ersetzt.

Die Hausorientierung bei den Schwyzerhäusern ist außerordentlich einheitlich. Die vordere Giebelfront mit den vielen Fenstern schaut gegen SSE-S.

Das Flarzhaus oder Zürcher Landenhaus herrscht im Zürcher Gebiet vor und tritt in einer großen Variationsbreite auf. Es umfaßt folgende Merkmale: Die An- 
einanderreihung zweier oder mehrerer Wohnhäuser in der Richtung des Firsts ist allgemein verbreitet. Vereinzelt stehen die Wohnhäuser auch quer zueinander. Diese meist einstöckigen, höchstens zwei Stockwerke aufweisenden Wohnstätten sind nur ganz selten mit Scheune und Stall zusammengebaut. Alle Flarzhäuser besitzen ein massives Mauerwerk mit einem aus dem Boden herausragenden Keller. Auf dem Estrich befinden sich in der Regel zwei Zimmer. Die Giebelfront besitzt keine oder dann nur wenige Fenster wegen der meist traufseitigen Stellung des Hauses gegen S.

Das Zürcher Weinbauernhaus ist sehr selten anzutreffen. Charakteristisch an ihm sind der große Kellereingang, der sich darüber befindliche zweiseitige Treppenaufgang zur Haustüre, sowie der kleine Quergiebel auf der Vorderseite des Daches. Scheune und Stall sind vom Wohnhaus getrennt.

Das sog. Dreisäßenhaus ist ein Riegelbau. Wohnhaus, Scheune und Stall sind zusammengebaut und besitzen meistens keine Einfahrt. Der Tenneingang zum Wohnhaus ist in der Regel vorhanden, ebenso die «Brüggi» und der Estrich. Als Folge der Hausindustrie treten manchmal gekoppelte Fenster auf.

Neben den in jeder Gemeinde vorhandenen Kirchen treten im vorwiegend katholischen schwyzerischen und zugerischen Gebiet vermehrte Kultbauten auf. Es sind dies Steinhäuschen, die Kruzifixe bergen. Sie befinden sich ausschließlich an den alten Pilgerwegen oder am Dorfeingang. An Wegen und Straßen sind auch hölzerne Wegkreuze anzutreffen.

Moderne Bauten ohne einheitlichen Baucharakter sind im ganzen Gebiet, besonders aber in den größern Siedlungen $z u$ finden. Sie wirken jedoch auf dem Lande im Siedlungsbild störend.

Die Wirtschaftsgebäude stehen meist vom Wohnhaus getrennt. Fast alle besitzen eine Einfahrt. Vorbauten sind auffallend häufig an der Nordwestseite, seltener an der Südostwand angebaut. Sie wurden erst später angegliedert (unterbrochene Rafen) und sind vielleicht als eine Entwicklungsstufe der Vordächer des Mittellandes anzusehen. Diese Form der Ökonomiegebäude ist im ganzen Untersuchungsareal ziemlich gleich häufig vertreten. Ganz neue Scheunen und Ställe sind nach dem Einheitsmuster des Schweiz. Bauernsekretariats errichtet.

Die Gras- und Milchwirtschaft spielt in der Moränen- und Rippenlandschaft seit jeher eine überragende Rolle. Das äußert sich auch in der Physiognomie der Landschaft durch die vielen Lebhecken und Zäune. Besonders die Lebhecken verleihen der Gegend im schwyzerischen und zugerischen Teil ein eigenes Gepräge; im Kanton Zürich fehlen sie beinahe ganz. Es treten an ihre Stelle meistens Holzoder Drahtzäune. Neuestens findet auch der Elektrozaun in zahlreichen Betrieben Verwendung. Alle diese Drahtzäune sind physiognomisch weniger stark wirksam.

Die Landwirte züchten mit wenigen Ausnahmen das Schwyzer Braunvieh.

Schon zwischen den beiden Weltkriegen besaß der Ackerbau keine große Bedeutung, denn die Bauern deckten kaum den eigenen Bedarf an Kartoffeln. Durch die Anbaupflicht wandelte sich das «Gesicht»der Landschaft wesentlich. Dabei gewann der Ackerbau insbesondere in den tiefern Lagen der Moränenlandschaft wieder an Bedeutung. Im Kanton Schwyz dehnten sich die Ackerflächen hauptsächlich auf Kosten des Streuelandes aus. Nach dem Krieg zeigte dieser Produktionszweig sofort wieder rückläufige Tendenz.

Der Obstbau ist über das ganze Gebiet verbreitet. Gegen die Hohe Rone und den Hohen Etzel nimmt die Obstbaumdichte ab, in den obersten Partien fehlen die Obstbäume ganz. Dieser Produktionszweig stellt für den Bauern eine wichtige $\mathrm{Ne}$ beneinnahmequelle dar. Die Obstgärten befinden sich in der Regel in der Nähe der Häuser. Das Hauptgewicht liegt auf der Produktion von Mostbirnen. Unter dem Einfluß der Versuchsanstalt für Obst- und Weinbau in Wädenswil findet gegenwärtig die schon lange dringend nötige Umstellung auf die Produktion von Qualitätsobst statt. Neben Kernobst werden auch bedeutende Mengen Steinobst produziert. 
Der Weinbau wird nur noch an den günstigsten Lagen, wie der Rippe von Freienbach (Kloster Einsiedeln) und im Reidbach (Wädenswil) gepflegt. Er ist heute von untergeordneter Bedeutung.

Waldareale treten in der Physiognomie einer Landschaft immer stark in Erscheinung. In unserer Gegend bestimmen im allgemeinen Relief und Exposition die Waldstandorte. Mit wenigen Ausnahmen sind daher nur noch steile Geländepartien, vor allem Schattenhänge, mit Wald bewachsen.

Alle Fabriken waren bei ihrer Gründung im letzten Jahrhundert auf die Wasserkraft und eine günstige Verkehrslage angewiesen. Daher finden wir alle alten Betriebe an Bächen, am Fuße der untersten oder zweituntersten Terrasse gegen den See. Weiter abseits von der Uferstraße stehen lediglich die Fabriken von Wollerau und Schindellegi. Ihre Standorte sind erklärbar mit der leichten Ausnützbarkeit der Wasserkräfte des Krebsbaches und der Sihl, sowie der alten wichtigen Durchgangsstraße über die Schindellegi. Betriebe, die nach der Elektrifikation entstanden, mußten nur auf eine gute Verkehrslage bedacht sein. Sie liegen daher ausnahmslos an der Uferstraße oder an den Bahnlinien.

Mühlen und Sägereien für den Betrieb schon weniger Wasser und eine kleinere Gefällsstufe. Wir finden solche Betriebe deshalb auch an den Oberläufen der Bäche.

Das Gewerbe konzentriert sich in den größern Ortschaften am See, sowie in Wollerau und Schindellegi. Nur Schmieden, Bäckereien, kleinere Reparaturwerkstätten, Lebensmittelläden und Gasthöfe kommen auch in den verkehrsabgelegenen Teilen vor. Die Gasthöfe und Wirtschaften treten im Kanton Schwyz als Relikte (44, S. 136) des früher blühenden Pilgerverkehrs noch in großer Zahl auf. Im Kanton Zürich waren sie früher ebenso häufig. Viele gingen im Laufe der Zeit ein, oder es wurde ihnen das Patent entzogen. Die Gemeinden Feusisberg und Menzingen profitieren von dem ziemlich regen Kurverkehr.

Die konfessionellen Verhältnisse gestalteten sich früher sehr einfach, weil die Kantone Schwyz und Zug nie zur Reformation übertraten und daher zum größten Teil katholisch sind, während der Kanton Zürich sich zur neuen Lehre bekannte. Die Kantonsgrenzen bildeten damals zugleich scharfe Konfessionsgrenzen. Religionsund Gewissensfreiheit, in der Verfassung von 1848 endgültig verankert, begünstigten in größerm Maße die Vermischung der konfessionell verschiedenen Bevölkerung. Von den verkehrsabgelegenen, aber einen großen Geburtenüberschuß aufweisenden katholischen Kantonen strömten die Menschen besonders von der letzten Jahrhundertwende an hinaus in die Industriegebiete. Dabei blieb die Hauptrichtung der Wanderung immer dieselbe. Wahrscheinlich bewirkte das eine Verlagerung der Konfessionsgrenze.

Das Netz der Straßen 2. Kl., 3. Kl., Fahrwege und Fußwege ist weitgehend bedingt durch die Streusiedlung. Große Wegdichte ist daher bezeichnend für diese Siedlungsform. Hingegen sind die Straßen 1. Kl. von der geographischen Lage der Landschaft abhängig. Für die Verkehrsverbindung Ost-West kommt dem linken Zürichseeufer große Bedeutung zu. Es ist der von der Natur vorgezeichnete Weg. Die Schindellegi ist für die Verbindung der Ostschweiz mit der Innerschweiz von großer Wichtigkeit. Auch in der Geschichte spielte sie als Durchgangspforte eine hervorragende Rolle.

Die Bahnlinien folgen mit Ausnahme der Strecke Wädenswil-Samstagern den gleichen Gesetzen wie die Straßen 1. Kl.

Für diese Grenzziehung sind summarische statistische Angaben, die sich auf die ganzen Gemeinden beziehen, von untergeordneter Bedeutung. Ich verweise deshalb auf die Eidgenössische Statistik.

\section{Die Wahl der Grenzbildner}

Durch die Feldbegehung und das Literaturstudium erfaßt der Bearbeiter Wesen und Charakter des Untersuchungsgebietes. 


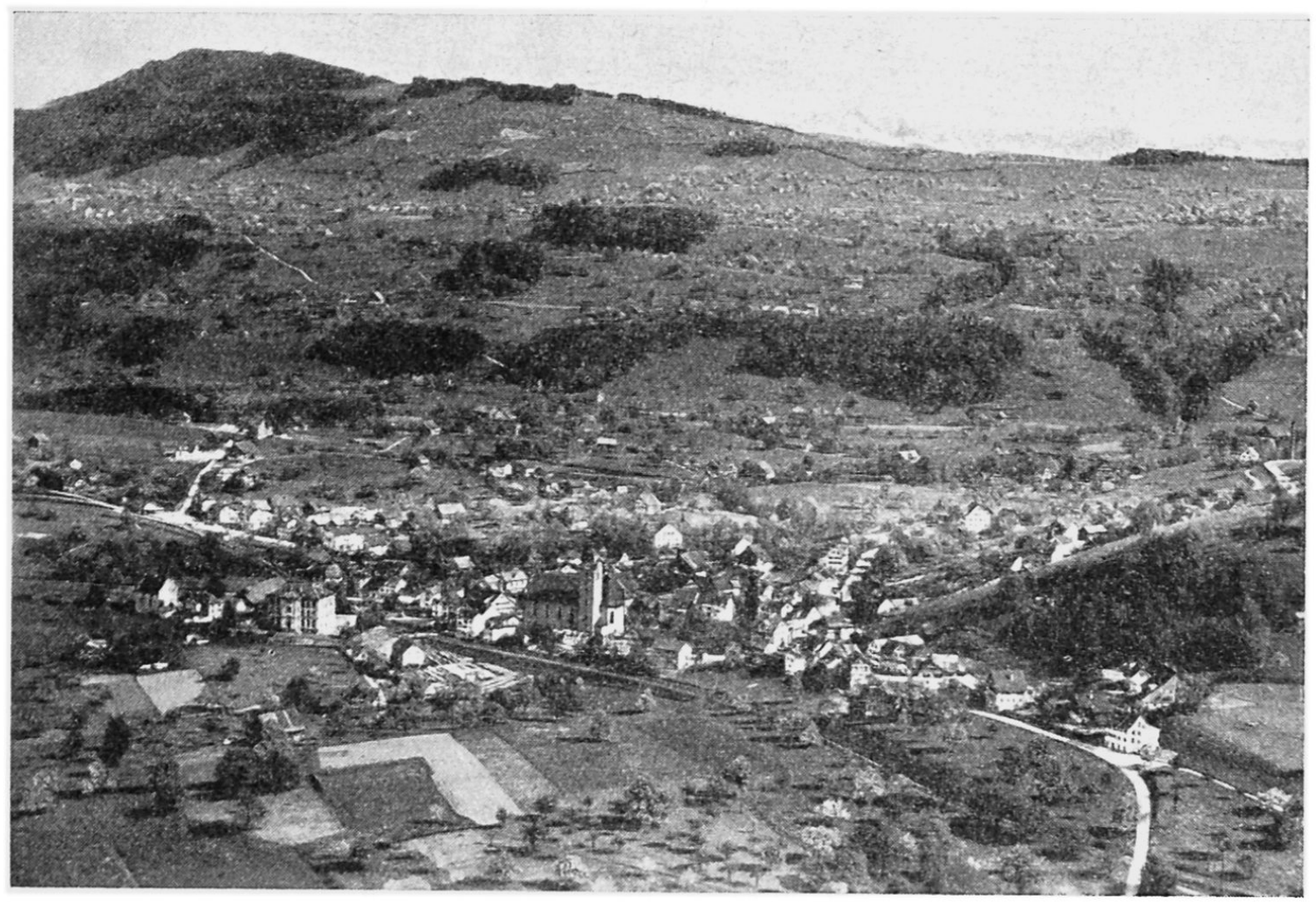

Abb. 1 Teil der Rippenlandschaft. Im Vordergrund Wollerau, dahinter die Terrasse von Feusisberg und Hoher Etzel (Photo Swissair)

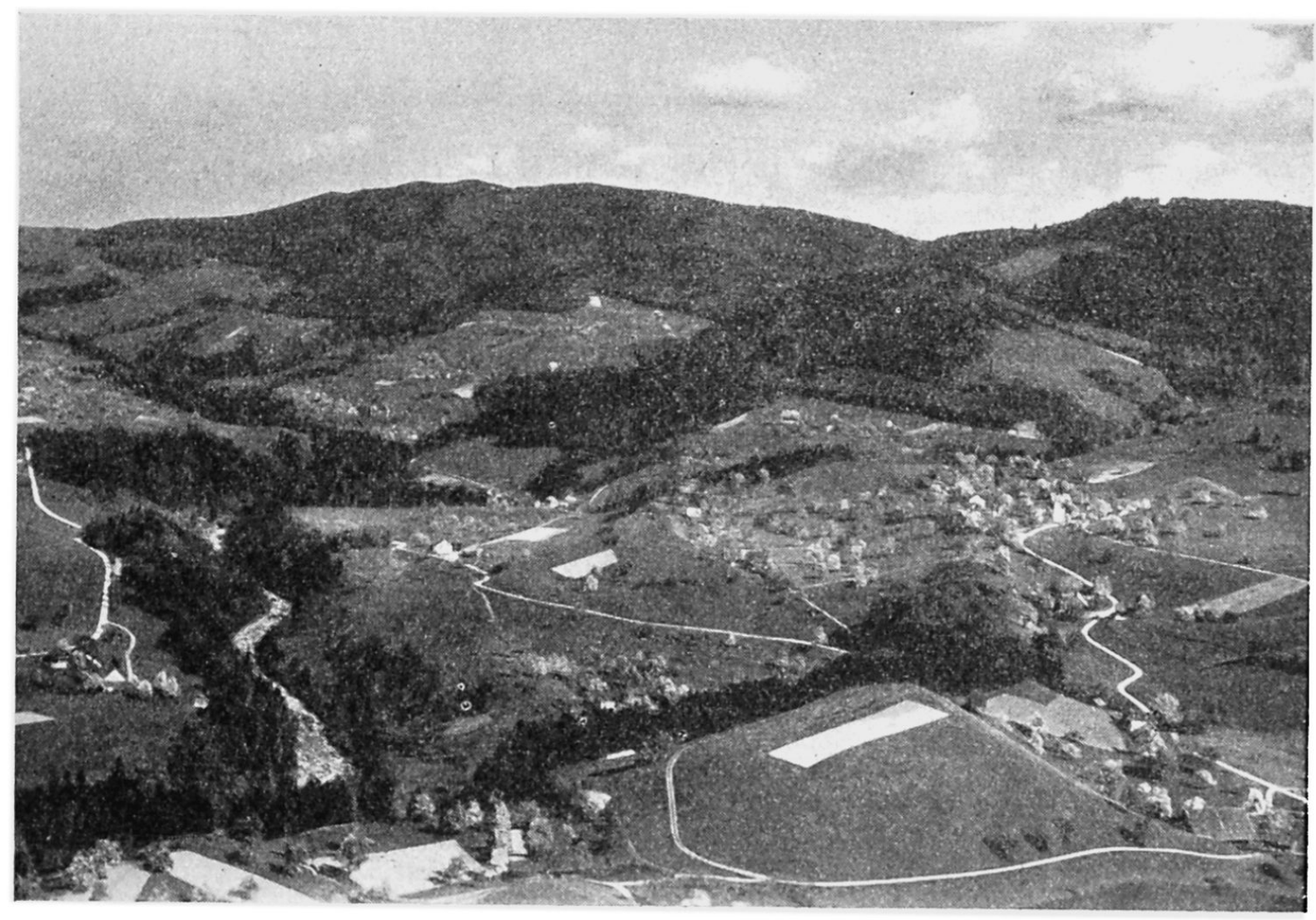

Abb. 2 Teil der Zuger- und Zürcher Moränenlandschaft. Im Mittelgrund rechts Finstersee, links der Sihlgraben. Hohe Rone (mitte), rechts Gottschalkenberg, links Roßberg (Photo Swissair) 
Es gilt nun, die Landschaftselemente in Bezug auf ihre regionale Verbreitung, wie auf eventuelle Intensitäts- oder Dichtewechsel zu prüfen. Nach E. Markus (44, S. 136) heißt das, nach den zurückweichenden, vordringenden und gleichgültigen Gliedern zu suchen. Dazu vergleicht man die Verbreitung entsprechender Landschaftsbildner verschiedener Ausschnitte der betrachteten Gegend. Anhand dieser Vergleichsresultate ist in den meisten Fällen eine Beurteilung darüber möglich, welche Landschaftsfaktoren grenzbildend auftreten. Sind die Intensitätswechsel gewisser Landschaftselemente aber klein, so kann vielleicht nicht sofort entschieden werden, ob sie grenzbildend wirken. In diesem Fall sind die Vorarbeiten für eine Grenzziehung trotzdem weiterzuführen, denn erst die Zahlenkarte gibt eindeutig Auskunft über die tatsächlichen Verhältnisse.

Im Prinzip sollte von allen Landschaftselementen eine Zahlenkarte erstellt und ihre Verbreitung auf diese Weise überprüft werden. Von einem Bearbeiter wäre diese Arbeit in nützlicher Frist kaum zu bewältigen. Die Wahl bleibt darum immer auf diejenigen Grenzbildner beschränkt, die leichter erkennbar sind. Sie ist deshalb immer sehr willkürlich und subjektiv.

Aus der Beschreibung des Untersuchungsgebietes geht eindeutig hervor, da $\beta$ sich die Geologie in den Groß- und Kleinformen des Reliefs äußert. Eine Grenzziehung nach geologischen Gesichtspunkten erübrigt sich daher. Sie wird in der Morphometrie und Morphologie berücksichtigt. Die Formen der Oberfläche weisen große Verschiedenheiten auf. Innerhalb gewisser Räume dominieren Terrassen, in andern Zonen Rippen, Moränenhügel, steile Hangpartien oder Aufschüttungsebenen. Es lassen sich somit sicher relativ einheitliche morphologisch - morphometrische Bezirke ausscheiden.

Bei den fließenden Gewässern ist anhand des Kartenbildes nicht eindeutig ersichtlich, ob sie grenzbildend wirken, weil die Gewässerdichten der verschiedenen Räume zu wenig genau beurteilt werden können. Die Vorarbeiten zur Erstellung der Zahlenkarte sind daher weiterzutreiben.

Die Vegetationsgrenze kann von H. Etrer (13) übernommen werden. Man darf sie zugleich auch als Klimascheide ansprechen.

Mit Sicherheit läßt sich eine konfessionnelle Grenze ziehen. Es wurde daher jeder Einwohner anhand der Einwohnerkontrollen der Gemeindekanzleien gezählt, sowie Konfession, Beruf und Wohnort herausgeschrieben. Die Berufsstruktur liefert keine Anhaltspunkte für eine Grenzziehung.

Bauten sind in der Regel zweckbedingt. Es ist darum folgerichtig, daß sich ihre Terminologie nach der zu erfüllenden Funktion zu richten hat, wie sie von der «Aktion Bauernhausforschung in der Schweiz» (2) auch angestrebt wird. Alle traditionellen Bauernhaustypen des betrachteten Gebietes können als Viehzüchterhäuser bezeichnet werden.

Die äußere und innere Ausgestaltung der bäuerlichen Wohnhäuser ist aber verschieden. Es treten also verschiedene Typen auf, was sehr wahrscheinlich auf die andersartigen natürlichen Gegebenheiten und auf Traditionsgebundenheit zurückzuführen ist.

Für die Wohnhaustypen übernehme ich die Bezeichnungen von $\mathrm{H}$. BrockmanN (6), da noch keine solchen für Unterarten der Viehzüchterhäuser bestehen. Auf die Praxis der Grenzziehung hat diese ältere Terminologie keinen Einfluß.

Das sog. Schwyzer- und das sog. Flarzhaus stellen die charakteristischen und auch zahlenmäßig hervortretenden traditionellen Wohnhaustypen. Die sog. Weinbauernund Dreisäßenhäuser kommen nur vereinzelt vor und dürfen daher vernachlässigt werden. Mit dem Flarzhaus zähle ich sie zum traditionellen Zürcher Haustyp.

Diese Wohnhaustypen vermischen sich nur in einem schmalen Grenzstreifen. Ihre Verbreitungszonen sind sonst relativ einheitlich und lassen sich sicher gut umreißen. 
Die modernen Bautypen und die getrennt stehenden bäuerlichen Wirtschaftsgebäude stellen Durchläufer oder, nach E. MARKus (44, S. 136), gleichgültige Glieder dar. Auch die Streusiedlung ist für das ganze Gebiet charakteristisch; Kleinweiler und Höfe herrschen vor. Profane Bauten und Kirchen sind in allen Gemeinden vorhanden. Andere Kultbauten wie Wegkreuze und Kapellen sind nur in den katholischen Teilen anzutreffen.

Großen Intensitätswechseln unterworfen sind die Anteile des Ackerlandes der Betriebe. Diese Variationsbreite wird verursacht durch Höhenlage, Klima, Boden und Wirtschaftssystem. Gleiches gilt für das Auftreten der Hecken und Zäune. Während der Anteil des Ackerlandes mit der Höhe zurückgeht, nehmen Heckenund Zaundichte im allgemeinen zu. Es lassen sich also sicher Grenzen bestimmen. Hecken und Zäune zusammengefaßt ergeben dabei eine Grenze, die wirtschaftsphysiologische Beziehungen der Landschaft berücksichtigt. Die starke physiognomische Wirksamkeit der Lebhecken rechtfertigt und verlangt sogar eine besondere Grenzziehung nach diesem Strukturelement.

Am Hohen Etzel trennt eine scharfe Linie das extensiv bewirtschaftete Land von den intensiver genutzten Mähwiesen. Die Weideflächen treten besonders im Frühjahr physiognomisch sehr stark in Erscheinung durch die verdorrten braunen Farnkräuter, die sich bei diesem Nutzungssystem immer einstellen. Diese Alpweidegrenze bildet in der Landschaft sicher eine eindrückliche Scheidelinie.

Der schwere, tiefgründige Boden eignet sich vorzüglich für den Obstbau. Alle Landwirtschaftsbetriebe hegen deshalb Obstgärten. An der Hohen Rone und am Hohen Etzel vermindert sich die Zahl der Obstbäume mit der Höhe und bildet schließlich die im Antlitz der Landschaft stark in Erscheinung tretende obere Obstbaumgrenze.

Eine gute Verkehrslage ist meist Grundbedingung für den gedeihlichen Ausbau einer Fabrik, damit die Zufuhr der Rohstoffe und der Abtransport der veredelten Produkte möglichst billig und rationell bleibt. Ausnahmen dieser Regel bilden nur Betriebe, die sehr hochwertige (z. B. Uhren) oder leichte Produkte fabrizieren, bei denen die Transportkosten nur einen sehr kleinen Teil im Verhältnis zum Wert ausmachen. Die Fabrikstandorte stehen also in Abhängigkeit von der Entfernung einer Bahnstation.

In der untersuchten Gegend lassen sich ausgesprochen verkehrsgünstige und verkehrsfeindliche Zonen ausscheiden.

In den Regionen mit großer Reliefenergie ist die Straßendichte kleiner. Diese Parallelität kommt bereits durch die Morphometrie des Geländes zum Ausdruck und muß deshalb nicht für sich behandelt werden.

Die Straßen 2. Kl., 3. Kl., Fahrivege und Fußwege sind zur Hauptsache durch die Streusiedlung bedingt. Sie bilden in der Landschaft Durchläufer oder gleichgültige Glieder.

Es können nach folgenden Gesichtspunkten mit Aussicht auf Erfolg Struktur-, relative Grenzen und Isolinien gezogen werden:

Naturfaktoren:

1. Morphometrie, Morphologie.

3. Klima und Vegetation

2. Eventuell Gewässer

Kulturfaktoren :

1. Konfession

6. Lebhecken

2. Haustypen

7. Obstbäume (Obergrenze)

3. Kultbauten

8. Alpweidegrenze

4. Ackerareale

9. Fabrikstandorte

5. Hecken und Zäune 


\section{Kartierungsrichtlinien}

Nach der Wahl der Grenzbildner sind die Kartierungsvorschriften festzulegen. Dazu dienen uns Feldbuchnotizen, Literatur und Karte. Unklarheiten beseitigt man durch erneute Geländebegehungen. Fixierte Kartierungsrichtlinien erleichtern die Feldarbeit wesentlich. Beim Einsatz von Arbeitsequipen sind sie von sehr großer Wichtigkeit zur Erreichung einheitlicher Resultate. Auch bei der Bearbeitung durch Einzelpersonen bieten sie allein Gewähr für exakte Ergebnisse, denn es wirken Einflüsse auf den Kartierenden wie Zeit, körperliche Anstrengung und andere, die seine Konzentrationsfähigkeit herabsetzen. Die schriftliche Fixierung trägt außerdem oft zur Klärung strittiger Punkte bei.

Einige Landschaftselemente sind bereits in den Landkarten aufgenommen und erfordern keine Kartierung durch den Geographen. Im vorliegenden Fall betrifft dies das Relief, die Gewässer sowie die Obstbäume (im Katasterplan enthalten). Am Studiertisch werden anhand von Statistiken und der kopierten Einwohnerkontrolle die Verkehrsgunst, Fabrikstandorte (Betriebsstatistik) sowie Konfessionsverhältnisse beurteilt. Für Klima und Vegetation liegt bereits eine Bearbeitung vor.

Für die Haustypen, Äcker, Hecken und Zäune wie auch für die Alpgrenze sind die Kartierungsrichtlinien zu diskutieren und festzulegen.

Die Unterscheidung der bäuerlichen Haustypen gestaltet sich insofern schwierig, da nicht alle stilrein gebaut, sondern vielfach Übergangsformen vorhanden sind, vorab in den größern Siedlungen. Darum muß zuerst untersucht werden, welchen Eigenheiten im Baustil das Hauptgewicht beizumessen ist. Dazu notieren wir zuerst alle Merkmale der Typen und wählen nachher die wichtigsten als Leitmerkmale aus.

Merkmale für das sog. Schwyzerhaus sind: Der auf einem aus dem Erdboden herausragenden Steinsockel errichtete reine Holzbau mit den liegenden Wandhölzern, die Klebdächer, der Schindelüberzug der Außenwände, der seitliche Treppenaufgang mit Laube und die Lauben unter den Dächern. Von diesen ist das größte Gewicht dem Auftreten des reinen Holzbaus mit den liegenden Wandbohlen beizumessen. Als Schwyzerhäuser werden daher alle Wohnhäuser bezeichnet, die aus Holz gebaut sind, liegende Wandbohlen besitzen und mindestens eines der obigen typischen Merkmale aufweisen.

Das sog. Flarzhaus tritt in großer Variationsbreite auf. Seine wichtigsten Merkmale sind: Die aus massivem Mauerwerk bestehenden Außenwände mit dem meist aus dem Boden herausragenden Keller, Ein- oder Zweistöckigkeit und die in der Regel vorhandene Trennung vom Ökonomiegebäude. Die Giebelfront weist keine oder nur wenige kleine Fenster auf im Gegensatz zur Traufseite.

Bei den sog. Weinbauernhäusern sind der große Kellereingang mit dem sich darüber befindlichen zweiseitigen Treppenaufgang und der kleine Quergiebel auf der Vorderseite des Daches eindeutige Merkmale.

Auch die sog. Dreisäßenhäuser erkennt man sofort an ihrer Dreiteilung in Tenn-, Stall- und Wohntrakt, den Riegeln sowie dem Durchgang vom Tenn zur Küche.

Als Kultbauten im betrachteten Gebiet fallen nur Kirchen, Kapellen und Wegkreuze in Betracht.

Als Ackerparzellen scheide ich alle Grundstücke aus, die frisch gepflügt sind, ebenso diejenigen, die Getreide oder Hackfrüchte tragen.

Die Lebhecken werden für sich aufgenommen. Als Zäune bezeichne ich alle toten Absperrvorrichtungen (aus Holz, Draht, Stangen usw). Von der Aufnahme der Elektrozäune wird abgesehen, da sie meist nur kurze Zeit am selben Ort stehen und auch physiognomisch schwach wirksam sind.

Die Alpweidgrenze ist eine in der Landschaft vorgezeichnete linienhafte Schranke zwischen zwei Gebieten mit verschiedener Nutzung. Sie kann direkt in die Karte eingetragen werden. 


\section{Die Feldaufnahme}

Nach der Auswahl der. Grenzbildner ist abzuklären, welche Kartengrundlage für die Feldaufnahme am zweckdienlichsten Verwendung findet. Die üblichen Landeskarten im Maßstab 1:25000 genügen meistens nicht. Auch die Katasterpläne 1:10000 reichen für eine detaillierte Aufnahme der Nutzungszonen kaum aus. Der vergrößerte Katasterplan 1:5000 genügt dagegen in der Regel den Anforderungen.

Die Route ist im Gelände so zu wählen, daß möglichst wenig Planmaterial mitgetragen werden muß. Das Blatt mit Kartierungslegende und Richtlinien klebt man am besten auf die Zeichnungsunterlage.

Bei der Aufnahme sind alle Objekte genau zu lokalisieren, und meistens ist es vorteilhaft, wenn alle gleichzeitig kartiert werden. Nur bei sehr vielen Kartierungsgegenständen sollen diejenigen Objekte, die man bereits in eine Karte mit kleinerem Maßstab eintragen kann, in einem zweiten Arbeitsgang eingezeichnet werden.

Die Zeit der Feldaufnahme kann man aus den bereits weiter oben angeführten Gründen beliebig auswählen. Bei der vorliegenden Arbeit erfolgte die Aufnahme im August, September und Oktober 1949.

\section{Die Verbreitungskarten}

Für jeden Grenzbildner separat wird nun eine Verbreitungskarte in möglichst kleinem Maßstabe auf Transparentpapier erstellt. Als Unterlage wählt man dabei eine der gebräuchlichen Landeskarten, am besten die Siegfriedkarte 1:25000. Die Angabe der Koordinaten am Rand ermöglicht auf diese Weise, den Standort eines Objektes im Gelände aus der stummen Verbreitungskarte jederzeit wieder zu bestimmen. Die Verbreitungskarten wurden der großen Kosten wegen nicht gedruckt. Interessenten können sie beim Autor einsehen.

\section{B. BESTIMMUNG DER ISOLINIEN, STRUKTUR- UND RELATIVEN GRENZEN}

Anhand der Verbreitungskarte wurde bisher direkt die Grenzziehung durchgeführt. Das war bei punktförmig auftretenden und besonders bei ausklingenden Landschaftselementen möglich, wie z. B. Siedlungs- und Baumobergrenzen, oder allgemein bei der Bestimmung von Verbreitungsgebieten nur eines Landschaftsbildners, folglich bei Strukturgrenzen. Sobald es sich jedoch um linien- oder flächenhafte, nicht ausklingende, sondern lediglich große Dichtewechsel aufweisende Grenzbildner handelte, mußte die Grenze gefühlsmäßig gelegt werden. Ebenso, wenn zwei gleichartige Objekte, wie z. B. die Verbreitungsgebiete von zwei Haustypen, gegeneinander abgegrenzt werden sollten. Die sogenannten relativen Grenzen und Isolinien konnte man nie exakt ziehen. Mit der Quadratmethode wird dieses subjektive Moment stark zurückgedrängt.

Subjektiv bleibt aber in jedem Fall die Kartierung. Es darf auch nie übersehen werden, da $\beta$ jede Grenzziehung willkürlich ist (25, S. 137/38) und lediglich mehr oder weniger zweckmäßig sein kann. Natürliche Landschaftsgrenzen bilden allein die Ober- und Untergrenzen der irdischen Landschaft, indem ihre Lage durch das Ausscheiden eines der vier Grundelemente (Litho-, Hydro-, Atmo-, Biosphäre) bestimmt wird und die äußern Räume mit nur drei Elementen somit nicht mehr als Landschaft bezeichnet werden dürfen.

Für den weitern Arbeitsgang der Quadratmethode teilt man das ganze Gebiet in gleich große Quadrate ein, deren Größe vorher für jeden Grenzbildner separat durch Berechnung oder Überprüfung anhand der Karte bestimmt werden muß. Die Maschengröße des Quadratnetzes hat sich also immer nach den abzugrenzenden Objekten zu richten. Sie darf nicht zu groß sein, weil sonst die Fehlergrenzen auch weit gespannt sind, aber auch nicht zu klein, weil sonst in viele Einheitsflächen keine Untersuchungsobjekte mehr fallen. Am vorteilhaftesten werden daher mittlere Weiten benutzt; sie liefern sicher die besten Resultate. 
Das durchsichtige Quadratnetz wird nun auf die entsprechende Verbreitungskarte gelegt. In jeder Einheitsfläche trägt man, je nach der Art des Auftretens, die Anzahl, die Länge oder die Fläche des grenzbildenden Landschaftselementes zahlenmäßig ein. In dieser sog. Zahlenkarte erhält jedes Quadrat eine oder mehrere Zahlen, welche die Häufigkeit oder Dichte der betreffenden Landschaftsobjekte ausdrücken.

Jetzt hat die Festlegung der Grenze zu erfolgen. Dabei ist zu beurteilen, welche Dichtezahl für die Grenzführung am zweckmäßigsten erscheint. Die Bestimmung dieses kritischen Grenzwertes kann mit Hilfe von Statistiken, erneuten Feldbegehungen oder aber rein empirisch gefunden werden. Für die Belange der Nachbardisziplinen (Geologie, Botanik, Wirtschaft usw.) ist die Befragung diesbezüglicher Spezialisten zu empfehlen. Die Ziehung der Isolinie geschieht anhand des ermittelten Grenzwertes, der sog. Leitzahl.

Die Bestimmung der Leitzahl stellt immer ein subjektives Monent dar, sie ist willkürlich und somit auch die damit gezogene Grenze (Isolinie). Sie hält sich aber überall genau an die voraus bestimmten Bedingungen. Das kann ihr zum Vor- oder Nachteil gereichen, je nach der bessern oder schlechtern Festlegung der Leitzahl.

Eine Isolinie scheidet Zonen verschiedener Dichten oder Intensität eines Landschaftselementes.

Für die Ziehung der relativen Grenze wägt man zunächst das Auftreten (Anzahl) zweier vergleichbarer Landschaftsobjekte (z. B. zweier Haustypen, zweier Konfessionen) in jedem Quadrat gegeneinander ab. Die relative Grenze zieht man alsdann zwischen Quadraten hindurch, in welchen einerseits das Merkmal A, andererseits das Merkmal B dominiert.

Der Arbeitsgang zur Bestimmung dieser Grenze weist nur bei der Auswahl und Kartierung der zwei grenzbildenden Merkmale subjektive Momente auf. Die Grenzlegung und Ziehung hingegen erfolgt nach rein mathematischen Gesichtspunkten.

Die relative Grenze ist mit Vegetationsgrenzen zu vergleichen, die zwei Vegetationszonen scheiden.

Für die Ziehung der Strukturgrenzen muß man nicht unbedingt eine Zahlenkarte erstellen, sie kann auch anhand der Verbreitungskarte erfolgen, indem die am weitesten vordringenden Merkmale einfach umfahren werden. Eine Strukturgrenze birgt im allgemeinen nur kleine subjektive Momente.

Nach der Grenzziehung wird der Grenzverlauf beschrieben, diskutiert und wenn möglich erklärt.

Physiognomisch betrachtet sind die Strukturgrenzen in der Regel am wirksamsten. Ihnen folgen die relativen Gronzen. Im allgemeinen am wenigsten auffallend treten die Isolinien in Erscheinung. Die physiognomische Wirksamkeit der Isolinien und relativen Grenzen hängt zudem weitgehend vom Gradienten oder Gefälle des betreffenden Grenzbildners ab.

Die relativen Grenzen und Isolinien sind nicht streng den Quadratseiten folgend zu ziehen; man hält sich zugleich auch an die Verhältnisse der darunterliegenden Verbreitungs- und topographischen Karte. Auf diese Weise wird die Grenzlinie nicht zackig, was sehr unnatürlich erscheinen würde.

Die Grenzlinien der einzelnen Grenzbildner wurden auch schon als analytische Grenzen bezeichnet. Dieser Sammelbegriff ist zweckmäßig, aber nicht gut gewählt, denn jede geżogene Grenze weist bereits synthetischen Charakter auf.

Die Lage des Quadratnetzes kann beliebig gewählt werden, ist also nicht durch einen bestimmten Geländepunkt fixiert. Diese unbestimmte Lage des Netzes, beziehungsweise seine Verschiebbarkeit, hat, mit einem andern, weiter unten angeführten 
Grund, einen Fehler im Grenzverlauf zur Folge. Die Fehlergrenzen sind aber bekannt und fallen deshalb nicht mehr so schwer ins Gewicht.

Die Festlegung des Netzes an irgend einen Geländepunkt oder an das Koordinatennetz der Karte würde die Unsicherheit nicht beseitigen, da der Fehler zugleich auch noch in der Methode selbst begründet liegt, denn sie nimmt eigentlich eine abstrakte, gleichmäßige, flächenhafte Verteilung der Objekte auf die ganze Quadratfläche an. Somit ergibt sich immer ein maximaler Fehler von plus oder minus einer ganzen Quadratseite. Der durchschnittliche oder mittlere Fehler beträgt plus oder minus eine halbe Quadratseite. Weil man sich bei der Grenzziehung aber auch an die Begebenheiten der Verbreitungskarte hält, ist der tatsächliche Fehler sicher immer kleiner.

Diese Fehlergrenzen müssen bei der Grenzziehung beachtet werden, indem auftretende Inseln, die nur eine Quadratseite breit sind, nicht als gesichert aufgefaßt werden dürfen, da sie bei einer andern Lage des Netzes verschwinden können. Solche Erscheinungen sind näher zu überprüfen. Liegen die Dichte- oder Häufigkeitszahlen der Inseln weit über (Kulmination) oder unter (Depression) der Leitzahl, so ist mit einer Insel $\mathrm{zu}$ rechnen, ist dieser Unterschied unwesentlich, so handelt es sich um eine Zufallserscheinung. Eine weitere Möglichkeit besteht darin, daß auch die benachbarten Einheitsflächen den kritischen Grenzwert beinahe erreichen. In diesem Falle darf die Insel ebenfalls als gesichert betrachtet werden.

Für die graphische Darstellung der gewonnenen Grenzen verwendet man mit Vorteil verschiedenartige Dreiecke, Halbkreise oder Trapeze. Man stellt diese Figuren so in die Grenzlinie, daß die verjüngenden Teile (Dreieckspitzen, kurze Parallele des Trapezes, Halbmond) die Richtung des Ausklingens des Grenzbildners angeben. Damit sind die zwei Teilgebiete bezüglich der Verbreitung des grenzbildenden Elementes auch graphisch eindeutig bezeichnet.

Die nun folgende praktische Anwendung demonstriert Arbeitsgang und Verwendbarkeit der Methode am besten.

\section{GRENZEN DER NATURLANDSCHAFT}

\section{Das Relief}

\section{a) Der Arbeitsgang}

Die Quadratmethode trachtet darnach, die Landschaftselemente irgendwie durch Zahlen auszudrücken. Für das Relief besteht diese Möglichkeit mit Hilfe der Arbeit von F. Gassmann und H. Gutersohn (17, S. 122-139) über die Kotenstreuung und den Relieffaktor. Den Begriff der Reliefenergie kann man in der Quadratmethode nicht verwenden, da die Bestimmung ihres Ausmaßes je nach dem Gelände verschieden große Quadrate verlangt.

In der nachfolgenden Beurteilung des Reliefs findet die sogenannte Kotenstreuung Anwendung. Sie gibt Auskunft über die vertikale Gliederung der Erdoberfläche und bezeichnet die Streuung sämtlicher Geländekoten um die mittlere Kote, welche die Geländeoberfläche erhielte, wenn der Geländekörper ohne Veränderung seines Volumens und seiner Grundfläche ausgeebnet würde. Aus dem quadratischen Mittelwert der Abweichungen aller Geländepunkte von ihrem arithmetischen Mittel ergibt sich die zahlenmäßige Größe der Kotenstreuung. Sie hat die Dimension einer Länge. Der andere morphometrische Begriff, der Relieffaktor, charakterisiert weitgehend die Reliefformen. Er ist für die vorliegende Arbeit nicht verwendbar, da das Quadratnetz die Hügel, Mulden, 'Täler und Hänge vielfach sehr willkürlich zerschneidet.

Die Maschenweite des Netzes richtet sich beim Relief nach der Größe der Hügel, im vorliegenden Falle der Moränenhügel, da diese in der Landschaft am weitesten verbreitet sind. Wie wir weiter oben abgeleitet haben, verwendet man mit Vor- 
teil keine Extrem-, sondern Mittelwerte. Ein mittelgroßer Moränenhügel soll also gerade in einer Einheitsfläche Platz finden. Das ergibt eine Quadratseitenlänge von $750 \mathrm{~m}$. Der mittlere Fehler der morphometrischen Grenzen beträgt somit $\pm 375 \mathrm{~m}$.

In die auf Transparentpapier erstellte, stumme Reliefkarte zeichnen wir also ein quadratisches Netz von $3 \mathrm{~cm}$ Seite (M. 1:25 000). Für jede Einheitsfläche wird nun die Kotenstreuung (17, S. 128/29) errechnet. Die erhaltenen Werte trägt man in die entsprechenden Felder eines zweiten gleichen Maschennetzes ein, das ebenfalls auf Transparentpapier gezeichnet wurde. Wir nennen dieses zweite Blatt morphometrische Karte (Karte 1). Sie bildet die Grundlage für die Grenzziehung. Die einzelnen Formengruppen werden dabei zuerst nach physiognomischen Gesichtspunkten bestimmt und nachher mit Hilfe der morphometrischen und topographischen Karte begrenzt.

Bei der Prüfung der Zahlen der morphometrischen Karte zeichnen sich Bezirke ab, deren Kotenstreuung sich in der gleichen Größenordnung hält. Eindeutig ersichtlich ist sofort das zürcherische Moränenplateau. Es ist charakterisiert durch eine Streuung von $0-20 \mathrm{~m}$. Diese kleine Variationsbreite widerspiegelt die relativ einheitlich wirkende, in sich geschlossene Formengruppe der Moränenhügel. Die Großform der Hohen Rone hebt sich durch die große Kotenstreuung von $50 \mathrm{~m}$ und mehr ab. Sie ist gekennzeichnet durch die steilen, von zahlreichen Bächen zerschnittenen Berghänge. In den untern Partien bis $900 \mathrm{~m}$ bilden einzelne an den Hang geschüttete Seitenmoränenzüge zum Teil breite Terrassen, die von den Wildbächen in mehrere Abschnitte gegliedert worden sind.

Zwischen dem zürcherischen Moränenplateau und der Hohen Rone tritt im westlichen Teil ebenfalls klar das Sihltobel in Erscheinung. Die steilen Hänge ergeben größere Kotenstreuungen als in den beidseitigen Moränenlandschaften. Die Streuungen halten sich in den Grenzen von $20-36 \mathrm{~m}$.

Der Hohe Etzel zeichnet sich durch große Kotenstreuungen (über $60 \mathrm{~m}$ ) aus. Die tatsächliche Form des Berges gelangt aber durch die Morphometrie nur mangelhaft zum Ausdruck, weil die Westseite zum Teil sanft ansteigt. Ganz klar durch die Zahlen hebt sich aber der Geländebruch des innern Terrassenrandes von Milten (Feusisberg) an ostwärts ab. Dieser Geländebruch gibt eine klare Begrenzung des Hohen Etzels und bildet daher die Leitlinie für die weitere Grenzziehung gegen Westen.

Durch die vier zuerst begrenzten Formengruppen ist beinahe das ganze Gebiet gegliedert. Nördlich des zürcherischen Moränenplateaus bilden die Hänge gegen den See mit einer Streuung von $0-40 \mathrm{~m}$ einen Bezirk für sich. Diese große Streuungsvariation ist einerseits bedingt durch die schmalen Uferebenen, andererseits durch die zum Teil ziemlich steilen und langen, gegen Norden exponierten Terrassenhänge.

Eine noch beträchtlichere Streuungsbreite als die Hänge gegen den See im Zürcher Gebiet, weist das schwyzerische Gebiet auf. Die Rippen wirken aber physiognomisch ganz anders, und es wird daher als eigene Formengruppe ausgeschieden. Die große Streuungsbreite ist gleichfalls durch die großen Gegensätze in der vertikalen Gliederung bedingt. Die steilen Rippen- und Terrassenhänge ergeben große, die leicht gegen Osten niedersteigenden Isoklinaltälchen kleine Kotenstreuungen.

Ein Formelement für sich bilden die Aufschüttungsebenen längs des Sees von Bäch an ostwärts. Bei Freienbach und Pfäffikon erreichen sie eine beachtliche Breite. In der morphometrischen Karte äußern sich diese Ebenen durch kleine Kotenstreuungen.

Nun verbleibt nur noch die zugerische Moränenlandschaft. Sie zeigt große Streuungen von $0-40 \mathrm{~m}$. Genetisch ist sie mit der zürcherischen Moränenlandschaft nahe verwandt. Der kulissenartige Anstieg gegen den Gottschalkenberg mit den dazwischenliegenden Terrassen und Hügeln vermittelt einen etwas andern physiognomischen Eindruck und ergibt mit den auf diese Weise erhöhten Nordhängen der Moränenhügel die große Kotenstreuung. 


\section{b) Der Verlauf der morphometrisch-morphologischen Grenzen}

Das zürcherische Moränenplatean weist Kotenstreuungen von 0-20 m auf. Seine Südgrenze verläuft in Abständen von 100-300 m nördlich der Sihl über die randlichen Moränenhügel von Boden (Hirzel) bis zum Bergli (Hütten). Von hier zieht sie sich über die Neumühle, östlich der Weberrüti und westlich des Sentenhofs vorbei zum Untern Schellhammer und Sternentobel. Hier wendet sie sich gegen Nordwesten. Diese Nordgrenze hält sich ausschließlich an den Außenrand der Terrasse, die über Gerlisberg, Frohberg, Obermatt, Sennweid, Hänsithal, Grundhof, Furthof - Mittlere Rüti nach der Dächenwies verläuft.

Die Grenzlinie wurde mit der Leitzahl $20 \mathrm{~m}$ unter starker Anlehnung an die topographische Karte gezogen. Längs der Sihl betrachte ich die steileren zum Fluß abfallenden Hänge der randlichen Moränenhügel zum Sihltobel gehörend.

In der Region Samstagern - Erlen (Wollerau) führt die Grenze zwischen zwei Quadraten hindurch, die unter $20 \mathrm{~m}$ Streuung $(16,12 \mathrm{~m}$ und $8,55 \mathrm{~m})$ besitzen. Der Grenzverlauf erscheint somit morphometrisch unmotiviert. Beim Itlimoos tritt jedoch nochmals die Fortsetzung der Rippe von Wollerau zutage. Darum wurde das Quadrat mit $8,55 \mathrm{~m}$ Kotenstreuung der Rippenlandschaft zugerechnet. Nordöstlich von Hirzel liegen im Moränenplateau zwei Quadrate, die über $20 \mathrm{~m}$ Kotenstreuung zeigen. Es beginnt sich hier der Hang zwischen der obersten und der zweitobersten Terrasse abzuzeichnen. Diese beiden Terrassen sind bereits in den Gemeinden Hütten und Schönenberg deutlich erkennbar. Die tiefer gelegene weist aber gegen Westen ein größeres Gefälle auf, so daß der dazwischen liegende Hang immer mehr hervortritt und schließlich bei der Schlieregg in der Morphometrie sich äußert.

Mit $50 \mathrm{~m}$ und mehr Kotenstreuung hebt sich klar die Hohe Rone ab. Ihre morphometrische Nordgrenze verläuft von Außerblack (Menzingen) südlich Finstersee vorbei nach Unter Mühlestock - Unter Sparen - Schönau - Schmitten - Heiten, nördlich an der Sennrüti vorbei nach Rüti (Schindellegi) - P. 813,9 - P. 821,2 P. 821 - P. 824 - St. Meinradsbrunnen - nach P. 823 Straßenknie, dann der Straße entlang nach Süden bis zur Koordinate 224/697,5.

Die Grenze hält sich an die Leitzahl $55 \mathrm{~m}$, dazu in der topographischen Karte an die untersten Terrassenränder gegen das Sihltobel.

Östlich des Roßbergs erscheint eine Einheitsfläche mit nur 39,22 m Streuung. Sie liegt innerhalb der Fehlergrenze und ist somit nicht als eine Insel zu werten.

Der Grenzverlauf zwischen der zugerischen Moränenlandschaft und der Hohen Rone ist eindeutig. Der Grenzverlauf auf schwyzerischem Gebiet wird besser bei der Begrenzung des Sihltobels diskutiert.

Die Grenzen des Sihltobels verlaufen in Abständen von 100-300 m beidseits der Sihl über die randlichen Moränenhügel oder Terrassenkanten. Von der Sihlmatt (südlich Hirzel) bis zur zürcherisch-schwyzerischen Kantonsgrenze ist der Grenzverlauf eindeutig, sowohl nach topographischen als auch nach morphometrischen Gesichtspunkten. Zwischen Sennrüti und Rüti auf Schwyzergebiet sind wegen dem weit nordwärts vorspringenden Scherenspitz die morphometrischen Anhaltspunkte unklar. Die Südgrenze hält sich in diesem Teilstück an das Niveau der Terrasse, die nördlich der Sennrüti die Kote 795 trägt, östlich davon erodiert ist, erst im Stollenwald westlich Schindellegi wieder zutage tritt und hier Kote 813,9 erreicht. Östlich von Schindellegi verbreitert sich das Tobel, und sein Südschenkel verflacht sich. Die sich weiter aufwärts befindliche Alpmündung dürfte die Genese stark beeinflußt haben.

Die Südgrenze hält sich auch hier an die vorhin erwähnte, leicht ansteigende Terrasse, die zum Teil nur undeutlich erkennbar ist. Sie verläuft daher von P. 813,9 zu P. 821,3 (südlich Schindellegi) auf demselben Niveau weiter über den Kaltenboden - St. Meinradsbrunnen zum P. 823 (Straßenknie).

Die Nordgrenze des Sihltobels hält sich bei morphometrischen Unklarheiten immer an die randlichen Moränenhügel oder Terrassen. 
Der ungegliederte Nordhang des Hohen Etzels fällt steil ab und bildet beim Übergang in die Terrasse von Feusisberg einen scharfen innern Terrassenrand, der sich in der morphometrischen Karte gut abzeichnet. Den innern Rand der Terrasse kann man daher gut als Nordgrenze des Hohen Etzels bezeichnen. Im westlichen Teil zeitigt die morphometrische Karte keine eindeutigen Resultate. Das äußert sich darin, daß die Grenze nach morphometrischen Gesichtspunkten gezogen, den ziemlich steilen Hang bei Milten quer durchschneidet. Ich begrenze daher den westlichen Teil nach morphologischen Erwägungen und lasse die Grenze dem Innenrand der Terrasse gegen Westen bis nördlich Schweigwiesweid folgen. H. CARoL und U. SENN (11, S. 129-134) legen ihre Voralpen-Mittelandgrenze ebenfalls an diese Stelle. Bei der Schweigwiesweid biegt sie nach Süden ab zum Sihltobel. Die Südgrenze des Hohen Etzels bilden die randlichen Moränenhügel des Sihlgrabens.

Der Hang gegen den See ist gekennzeichnet durch die parallel zum Seeufer verlaufenden Terrassen. Letztere werden von den Bächen, die das nördliche Moränenplateau entwässern, zum Teil zerschnitten und aufgegliedert. Die Nordgrenze ist naturgegeben durch den See. Auch die Südgrenze ergibt sich im ersten Teil morphometrisch eindeutig. Sie verläuft von der Dächenwies über Mittlere Rüti - Furthof Grundhof - Hänsithal - Sennweid - Obermatt - Gerlisberg zur Kantonsgrenze bei der Sternenschanze. Von hier folgt sie zunächst dem Sternentobel gegen Osten, verläuft dann über Ried - Frohburg zum See westlich von Bäch. Im letzten Teilstück von der Sternenschanze an konnte die Grenze nicht nach den morphometrischen Verhältnissen gezogen werden, da sie beidseitig ziemlich gleich sind. Die Grenzziehung erfolgte nach folgenden morphologischen Gegebenheiten: Zwischen Sternen- und Krebsbachtobel bei Bäch weist der Hang noch deutliche Terrassen auf wie im westlichen Abschnitt, während am Seehang, östlich vom Krebsbachtobel, keine solchen erkennbar sind, sondern ein charakteristischer, ungegliederter und unterrassierter Rippennordhang dominiert. Auch J. FRüH (16, Bd. I., S. 25) legt seine nach morphologischen Gesichtspunkten gezogene Voralpengrenze in diesem Teilstück dahin.

Die Rippenlandschaft weist eine sehr große Variationsbreite in der Kotenstreuung auf $(10-16 \mathrm{~m})$. Das ist bedingt durch die steilen Hänge der Rippen und Terrassen. Einen Wesenszug der Rippenlandschaft bilden die mehr oder weniger parallel verlaufenden Waldstreifen der Rippennordhänge.

Diese Landschaft ist im Süden und Westen durch weiter oben besprochene Formengebiete begrenzt. Eventuelle Unklarheiten im Grenzverlauf sind hier somit schon diskutiert. Die Westgrenze verläuft vom See westlich Bäch über Frohburg — Ried - Sternentobel — Unterer Schellhammer - Sentenhof - Neumühle - zum Bergli (Hütten). Von hier folgt sie den nördlichen randlichen Moränenhügeln des Sihltobels bis Schweigwiesweid, zieht sich südlich an Baumen - Althaus - Milten Rohnen vorbei zur Schneckenburg.

Die Nordgrenze der Rippenlandschaft gegen die Aufschüttungsebenen längs des Sees kommt in der Morphometrie besonders östlich von Bäch nur sehr undeutlich zum Ausdruck. Es werden daher auch morphologische Gesichtspunkte berücksichtigt. Der Nordfuß der Rippe von Freienbach zeichnet die Grenzführung von Bäch gegen Osten bis zum Oechsli (Freienbach) vor. Südlich und südöstlich von Freienbach leistet die Morphometrie für die Grenzführung wieder bessere Dienste.

Die Nordgrenze verläuft von der Krebsbachmündung an südlich Bäch vorbeiei, ostwärts längs dem Nordfuß der Rippe von Freienbach bis zum Oechsli, biegt hier nach Westen um, zieht sich südlich an Leutschen vorbei zum P. 450,8, wendet gegen Osten und folgt dem Nordrand des Eichholzes bis gegen Pfäffikon.

Die zum Teil breiten Seeuferebenen des Schwyzergebiets werden im Süden durch die soeben beschriebene Nordgrenze der Rippenlandschaft begrenzt. Die Nordgrenze bildet der Zürichsee. 
Trotz der genetischen Verwandtschaft mit dem zürcherischen Moränenplateau weist die Zuger Moränenlandschaft große Kotenstreuungen auf, weil das Gebiet gegen Westen und Süden stark ansteigt. Es ist im Norden durch die randlichen Moränenhügel und Terrassen des Sihltobels, im Osten durch die Linie Mühlestock - Außerblack gegen die Hohe Rone begrenzt.

Die Abgrenzung der Reliefformen konnte nicht nur nach der Morphometrie erfolgen; das hätte oft einen sehr unnatürlichen Grenzverlauf gegeben. Es mußten auch morphologische Gesichtspunkte für die Abgrenzung beigezogen werden, trotzdem bietet die Morphometrie eine sehr wertvolle Hilfe bei Grenzziehungen.

Die gezogenen Trennungslinien der verschiedenen morphologischen Formengebiete kann man daher als morphologisch-morphometrische Grenzen bezeichnen.

Morphometrische Grenzen sind Isolinien, währenddem morphologische Grenzen sog. relative Grenzen darstellen, da in diesem Fall die Dominanz zweier Merkmale gegeneinander abgewogen wird.

Die vorgenommene Ausscheidung der verschiedenen Reliefformen schließt große subjektive Momente in sich.

\section{Das Gewässernetz}

\section{a) Der Arbeitsgang}

Bei der ersten Wahl der Grenzbildner konnte nicht endgültig entschieden werden, ob die fließenden Gewässer im untersuchten Gebiet wirklich grenzbildend wirken. Die Vorarbeiten zu einer Grenzziehung mußten daher weiter verfolgt werden.

Man erstellt zunächst eine Gewässerkarte auf Transparentpapier (Kopie T.A.). Die Quadratșeitenlänge der Zahlenkarte der Flüsse (Karte 2) muß sicher größer angenommen werden als bei der morphometrischen Karte, da höchstens zwischen zwei Moränenhügeln in mittlerer Größe ein Bach fließen kann. Darum wird die doppelte Quadratseite $(1500 \mathrm{~m})$ der morphometrischen Karte gewählt. Der mittlere Fehler mißt also $\pm 750 \mathrm{~m}$.

In ein Netz von $6 \mathrm{~cm}$ Seite werden die Längen der fließenden Gewässer ausgemessen und eingetragen.

Klar und eindeutig scheidet sich in der Zahlenkarte eine Region mit einer Dichte von $6000 \mathrm{~m}$ (Flußdichte $2,66 \mathrm{~km} / \mathrm{km}^{2}$ ) und mehr aus. Unterhalb $6000 \mathrm{~m}$ besteht eine zahlenmäßige Lücke, indem die Mehrzahl der Einheitsflächen Dichten von nur $2000 \mathrm{~m}$ - $4500 \mathrm{~m}$ aufweisen. Die Zahl $6000 \mathrm{~m}$ wird daher zur Leitzahl für die Ziehung der Flußdichtenisolinie erhoben. Diese Wahl ist sehr willkürlich aber zweckmäßig, denn diese Isolinie trennt Zonen mit ziemlich unterschiedlicher Ausbildung des Flußnetzes.

\section{b) Der Grenzverlauf}

Die Grenze verläuft von der Dutzweid (Finstersee) nordwärts über Niederrüti - Bostadel bis Finsterseehalden (Hütten), von hier ostwärts über die randlichen Moränenhügel nördlich des Sihltobels bis zur Säge (Hütten), dann längs der Sihl bis Schindellegi, wendet sich nordwärts bis Gibel, biegt dann nach Osten ab und zieht sich über Feusisberg nach Fuchsberg und schließlich längs des Staldenbachs abwärts bis zum Kartenrand.

Die Gewässerdichtengrenze scheidet ziemlich genau eine Zone mit großer Reliefenergie von einer solchen mit kleinerer. Sie stellt somit eine gewisse Parallele zu einem Teil der morphometrischen Grenzziehung dar.

\section{Die Klima- und Vegetationsgrenze}

Die Vegetation reagiert äußerst fein auf das Klimaregime, was weiter unten genauer gezeigt werden soll. Deshalb darf eine Klimagrenze von der Vegetationsgrenze abgeleitet werden. Ich übernehme die Resultate von H. ETter (13). 
Er hat die Vegetationsgrenze zwischen der sog. Hügelstufe (Aronstabreicher Eichen - Hainbuchenwald) und der Bergstufe (Vorlandbuchenwald) bestimmt (Karte $3^{*}$ ). Diese Vegetationsgrenze stellt, dem Arbeitsgang entsprechend, eine relative Grenze dar. Als Klimascheide betrachtet, zeigt sie den Charakter einer Isolinie. Man darf diesen Fall als einen Spezialfall ansehen, der die zwei Arten von Grenzlinien zusammenfallen läßt und auf diese Weise auch ihre Verwandtschaft zeigt.

Die Grenze verläuft von Burstel (Wädenswil) längs der Straße nach Unter Gisenrüti, wendet sich hier nordwärts über Gisibach - Wyden nach Herrlisberg, hierauf ostwärts über Wendel nach der Sennweid. Darnach verläuft sie zunächst gegen Norden bis zur Eichmühle, dann durch das Reidholz nach der Vordern Schönau und weiter über Hirtenstall südlich an Richterswil vorbei zum Hafen. Hierauf zieht sie sich längs der Kantonsstraße nach Bäch und weiter der Bahnlinie entlang nach Freienbach, wendet sich westwärts über Oechsli - die Rippe von Freienbach (P. 455,2, 516,6) nach Eggli, Schnabel und Haslen. Hier biegt die Grenze gegen Süden ab, zieht sich westlich an Wilen vorbei nach Fälmis und wendet sich schließlich über die Miesegg, östlich an Fuchsberg vorbei zum Wilhelmenhof und nach dem Gräfli.

Sehr auffallend an diesem Grenzverlauf ist das starke Absteigen der Klima- und Vegetationsgrenze bis nahe zum See auf ca. $420 \mathrm{~m}$ zwischen Richterswil und Freienbach. Östlich und westlich von diesem Abschnitt verläuft sie bis in Höhen von $500 \mathrm{~m}$ bis $600 \mathrm{~m}$. Gründe hiefür bilden der schlechtere Boden (Sandsteinuntergrund an der Rippe von Freienbach) hauptsächlich aber der «Bächler 》 (14). Das ist ein kühler Fallwind aus dem Einsiedlerbecken, der sich über die Schwelle von Schindellegi in die Bucht von Richterswil ergießt. Sehr deutlich zeigen sich seine Einflüsse auch in den phänologischen Daten dieser Region.

\section{GRENZEN DER KULTURLANDSCHAFT}

\section{a) Der Arbeitsgang}

\section{Die Konfessionen}

Auf den Gemeindekanzleien wurde nach den Einwohnerkontrollen die Religionszugehörigkeit der Bevölkerung ermittelt und für jede Person einzeln lokalisiert. Die große Mehrheit der Bewohner gehört der katholischen und der reformierten Kirche an. Angehörige anderer Bekenntnisse (Christ-katholisch, Juden, Mohammedaner) stellen nur eine kleine Minderheit. Diese dürfen daher bei der Bestimmung einer Konfessionsgrenze vernachlässigt werden.

Anhand der Einwohnerverzeichnisse wurde nun eine Verbreitungskarte der Religionen gezeichnet, worin Katholiken und Protestanten in jeder Siedlung lokalisiert dargestellt sind. Zur Herabsetzung der Anzahl der Punkte sind verschiedene Figuren für die Bezeichnung von $1-5,10$ und 20 Personen verwendet. Die Katholiken wurden durch schwarz ausgefüllte Zeichen, die Protestanten durch unausgefüllte markiert.

Für eine größere Bevölkerungsdichte, wie sie in den beiden Flecken Wädenswil und Richterswil auftritt, reicht die obige Zahlenlegende nicht aus. Mit der Kartengrundlage 1:25000 ist es auch mit einer andern Legende wegen Platzmangel unmöglich, in einem Flecken oder einer Stadt, die Einwohner lokalisiert darzustellen. Im vorliegenden Fall ist die Verteilung der Konfessionsangehörigen in der Siedlung nicht von Interesse. Darum wurde auf eine spezielle Darstellung mit einer größern Kartenunterlage verzichtet.

Nach E. WinkLer und H. Windler (66) wurden die Siedlungsränder bestimmt und zur Übersicht die Gesamtzahl der beiden Religionsbekenntnisse in die Siedlung

* In die Karte 3 werden aus Spargründen mehrere Grenzen eingezeichnet, die von andern Autoren übernommen sind oder die man ohne eine Zahlenkarte ziehen kann. Diese Grenzlinien sind also ganz unabhängig voneinander zu betrachten. 
eingetragen. Quadrate, die noch randliche Teile dieser zwei Siedlungen decken, wurden rechts mit Punkten versehen. So ist klar ersichtlich, daß sich die eingetragenen Zahlen nur auf den restlichen Teil der Einheitsfläche (ohne Hauptsiedlung) beziehen.

Für die folgende Erstellung der Zahlenkarte der Konfessionen muß zuerst die Quadratgröße ermittelt werden. Der Bestimmung der Quadratseite liegt nachstehende Überlegung zugrunde: In jede Einheitsfläche muß mindestens eine bewohnte Siedlung fallen, um ein geschlossenes Bild zu erhalten. Die Quadratseite muß demnach dem mittleren Siedlungsabstand entsprechen. Diese Größe wird am besten rechnerisch bestimmt. Nach L. Boschkoff (5, S. 83-89) kommt eine theoretische Verteilung der Siedlungen in die Ecken gleichseitiger Dreiecke der Wirklichkeit am nächsten. Demnach wird die Seitenlänge a eines Quadrates gleich der Wurzel aus dem Quotienten der Gesamtfläche F und der Zahl der Siedlungen n.

$$
\mathrm{a}=\sqrt{\frac{\mathrm{F}}{\mathrm{n}}}
$$

Der mittlere Siedlungsabstand und somit die Länge der Quadratseite mißt im betrachteten Gebiet 390 m.

Es wurde ein Maschennetz von $1.6 \mathrm{~cm}$ entsprechend $400 \mathrm{~m}$ in der Natur gezeichnet, auf die Verbreitungskarte gelegt und die Angehörigen der zwei Konfessionen in jeder Einheitsfläche einzeln ausgezählt. Die Anzahl der Protestanten wurde im untern, die der Katholiken im obern Teil des Quadrates notiert (Karte 4).

Die Grenzziehung gestaltet sich nun sehr einfach, indem ein Quadrat beim Überwiegen der Katholiken zum katholischen Teil, beim Überwiegen von Protestanten zum protestantischen Teil geschlagen wird. Weist eine Einheitsfläche gleich viele Personen von beiden Bekenntnissen auf, so wird die Fläche bei der Grenzziehung unter Berücksichtigung der Verbreitungskarte geteilt. Bei der Grenzführung soll überhaupt immer auf Topographie und Verbreitungskarte Rücksicht genommen werden, um unsinnige Grenzlagen zu vermeiden. Es ist dabei aber immer darauf zu achten, daß die Verschiebung innerhalb des mittleren Fehlers bleibt, der $\pm 200 \mathrm{~m}$ beträgt.

Die Zahlenkarte zeigt, daß die Abnahme der Protestanten im katholischen Gebiet rasch erfolgt im Gegensatz zu den Katholiken im Zürcher Gebiet. Darnach richtet sich der sich verjüngende Teil des Grenzsymbols gegen die Innerschweiz.

Die Konfessionsgrenze besitzt im allgemeinen die Eigenschaften einer relativen Grenze. Da die Kartierung und Unterscheidung der zwei Merkmale eindeutig erfolgen kann und auch die Grenzführung nach rein statistischen Grundlagen erfolgt, weist diese Grenze nur sehr unbedeutende subjektive Momente auf.

\section{b) Der Verlauf der Konfessionsgrenze}

Die Grenze verläuft von Boden (Hirzel) ostwärts zur Sihl, dieser nach aufwärts bis zum Suhner (Schönenberg). Von hier zieht sie sich auf Zürcher Gebiet hin bis zum Sihlmättli, springt dann auf Zuger Gebiet über und umfährt das Dändlimoos im Süden, um wieder zur Sihl zurückzukehren. Vom Elektrizitätswerk (Schönenberg) bis zur Finsterseehalden (Hütten) durchquert die Konfessionsgrenze Zürcherboden und weist das Sihlknie von Haslaub (Schönenberg) zum katholischen Gebiet. Vom Ziegelhaus (Hütten) verläuft sie wieder längs der Sihl aufwärts bis gegen die Säge (Hütten). Hier umfährt sie die Vorder Schönau (Hütten) südlich der Sihl, verläßt dann endgültig das Südufer des Flusses, zieht sich östlich an Halten (Hütten) vorbei, umfährt Boden (Hütten), die Frohe Aussicht im Norden und erreicht südlich vom Bergli (Hütten) die Kantonsgrenze. Vom Bergli bis nördlich der Neumühle (Wollerau) decken sich Kantons- und Konfessionsgrenze. Hier dringt die letztere für ein kurzes Stück auf Schwyzergebiet vor und umschließt den Sentenhof (Wollerau) im Osten und kehrt dann südlich vom Sternen (Richterswil) wieder zur 
Kantonsgrenze zurück. Für ein kurzes Stück folgt die Konfessionsgrenze nun der Kantonsgrenze, umfährt den Kalchbühl (Richterswil) im Westen, erreicht im Sternentobel wieder die Kantonsgrenze und folgt dieser bis südlich vom Hafen (Richterswil). Hier schneidet die Konfessionsgrenze ein dreieckiges Stück vom Zürcher Gebiet weg und vereinigt sich schließlich am Seeufer wieder mit der Kantonsgrenze.

Aus der Zahlenkarte ist weiter ersichtlich, daß das katholische Gebiet viel weniger von Andersgläubigen durchsetzt ist, als das protestantische Zürcher Gebiet. Daraus ist die Hauptwanderungsrichtung klar zu erkennen, die vom Kanton Schwyz mit seinem großen Geburtenüberschuß in den industrialisierten Kanton Zürich hinausführt. Die Landflucht auf Zürcherboden fördert diese Durchsetzung der ländlichen Zonen mit Katholiken, da zum Verkauf gelangende Bauernhöfe meistens von Schwyzer- oder Zuger-Bauern erworben werden. Auf diese Weise bildeten sich im protestantischen Zürcher Gebiet bereits einzelne katholische Inseln, wie beim Sennhaus und Mugerrain (Wädenswil), Stollen, Bubenwies und Külpen (Schönenberg) sowie beim Seeli und in Mühlenen (Richterswil).

\section{a) Der Arbeitsgang}

\section{Die Haustypen}

Für jeden grenzbildenden Haustyp wählt man zunächst ein bestimmtes Symbol. Dann wird aus der Kartierungsgrundlagenkarte 1:5000 jeder Haustyp mit dem entsprechenden Symbol auf die Haustypen-Verbreitungskarte aus Transparentpapier mit der Kartengrundlage 1:25000 übertragen.

Die Maschenweite des Quadratnetzes der Zahlenkarte muß wieder dem mittleren Siedlungsabstand entsprechen, damit in jede Einheitsfläche eine Siedlung fällt. Es wird also wiederum ein Quadratnetz von $1,6 \mathrm{~cm}$ Seite konstruiert und auf die Verbreitungskarte gelegt. In jeder Quadratfläche werden die sog. Schwyzerhäuser und die neueren Bautypen je für sich ausgezählt. Die sog. Flarz-, Dreisäßen- und Zürcher Weinbauernhäuser bilden zusammen als Zürcher Typ die dritte Auszählgruppe (Karte 5).

Die neueren Bautypen stellen durchgehende oder gleichgültige Glieder dar und wurden nur der Vollständigkeit halber kartiert und mitgezählt. Zur Grenze tragen sie nichts bei. In den Flecken Wädenswil und Richterswil sind wegen Platzmangel nur die Häuser der zwei grenzbildenden Gruppen festgehalten. Durch die Ermittlung der Siedlungsränder konnten die Wohngebiete dieser zwei Flecken von den ländlichen Zonen geschieden werden. Damit wurde klargestellt, in welchen Bereichen die Wohnhäuser vollständig erfaßt sind.

Die Grenzziehung erfolgt erneut anhand der Zahlenkarte der Haustypen in dem Sinne, daß in jeder Einheitsfläche das zahlenmäßige Auftreten der zwei Typen gegeneinander abgewogen wird. Die Grenzführung richtet sich innerhalb der mittleren Fehlergrenze $( \pm 1 / 2$ Quadratseite $=200 \mathrm{~m}$ ) folgerichtig nach der Topographie des Geländes und den Verhältnissen der Verbreitungskarte.

Die Zürcher Haustypen nehmen gegen die Kantone Zug und Schwyz rascher ab, als die Schwyzerhäuser gegen den Kanton Zürich. Die Spitzen der Signaturzeichen richten sich daher gegen die Innerschweiz. Die Haustypengrenze ist eine relative Grenze. Subjektive Momente im Arbeitsgang schleichen sich bei der Bestimmung der Kartierungsrichtlinien sowie der Kartierung ein. Die Grenze wiedergibt aber genau die durch die Kartierung vorgezeichneten Verhältnisse.

\section{b) Der Verlauf der Haustypengrenze}

'Die Haustypengrenze zieht sich vom Feld (Hirzel) über Erni zur Mündung des Mühlebachs in die Sihl, dann sihlaufwärts bis zum Sihlmättli (Schönenberg), umschließt hier das Dändlimoos im Süden auf Zuger Gebiet, kehrt zur Sihl zurück und folgt dem Fluß bis zum Haslaub (Schönenberg), durchquert hier ein kurzes 
Stück Zürcherboden, erreicht westlich vom Ziegelhaus (Hütten) wieder die Sihl und folgt dem Fluß bis südlich von Vorder Langmoos (Hütten). Nun wendet sich die Grenze abrupt gegen Norden und verläuft über Vorder Langmoos - Hinter Langmoos - Frohe Aussicht - Segelrain zum Segel (Hütten), umfährt dann Baalet (Hütten) im Norden und Böschen (Hütten) im Süden, zieht sich dann westlich Unter Hengerten (Hütten), nördlich von Rebgarten und östlich von Halden (Hütten) vorbei gegen Süden zur Sihl. Hier folgt die Haustypengrenze dem Fluß aufwärts bis zur Kantonsgrenze und ist identisch mit dieser bis zum Sternen (Richterswil) und Sternentobel. Für eine kurze Strecke verläßt sie das Tobel und umfährt den Kalchbühl im Westen, kehrt aber sogleich wieder zum Mühlebach zurück. Dieser Bach bildet nun die Grenze bis zum See. Eine Insel mit Schwyzerhäusern bildet die Umgebung von Burghalden (Richterswil).

Auffällig am Grenzverlauf ist das relativ große Vordringen der Haustypengrenze auf $\mathrm{Zürcherboden} \mathrm{bei} \mathrm{Hütten.} \mathrm{Die} \mathrm{Ursache} \mathrm{dieses} \mathrm{Eindringens} \mathrm{kann} \mathrm{nicht} \mathrm{mit} \mathrm{Be-}$ stimmtheit angegeben werden. Die sog. Schwyzerhäuser um Hütten zeigen im allgemeinen sehr unreinen Baustil und stellen selbst eigentliche Übergangsformen dar, die aber noch die charakteristischen Merkmale der Schwyzer Typen besitzen. Dasselbe gilt für die Insel bei Burghalden.

Das Übertreten der Grenze auf den Kanton Zürich beim Haslaub (Schönenberg) kann erklärt werden. Das älteste Wohnhaus dieses Weilers wurde ca. 1911, das neuere 1940 von Schwyzer Landwirten in ihrem traditionellen Baustil errichtet. Ein weiteres solches Beispiel stellt das sog. Schwyzerhaus in Ober Külpen (Schönenberg) dar, nur treten die Zürcherhäuser dort zahlenmäßig noch stärker in Erscheinung.

\section{Die relative Grenze der Kultbauten}

Unter Kultbauten verstehe ich Bauwerke und Denkmäler, die im religiösen Leben des Volkes Bedeutung besitzen. Je nach Konfession zeigen diese ganz verschiedenes Gepräge und unterschiedliche zahlenmäßige Verbreitung.

Katholische Gegenden weisen im Gegensatz zu protestantischen mehr Kultbauten auf, wie Wegkreuze, Kapellen und andere Anbetungsstätten, währenddem Kirchen meistens durchlaufende Glieder darstellen. Auch im betrachteten Gebiet trifft dies zu. Die katholische Konfession kann man in diesem Zusammenhang als physiognomisch positiv, die reformierte als eher negativ wirksam bezeichnen.

Aus politischen und verwaltungstechnischen Gründen fällt die Grenze der Kultbauten nicht mit den Konfessionsgrenzen zusammen. Die Errichtung von Bauwerken ist der Bewilligungspflicht durch die Gemeindebehörden unterstellt. Darum treten Wegkreuze, Kapellen, die in der protestantischen Kirche keine Bedeutung besitzen, nur in Gemeinden mit katholischer Mehrheit auf.

Alle Schwyzer und Zuger Gemeinden sind mehrheitlich katholisch. Die Grenze der Kultbauten fällt daher mit der Kantonsgrenze von Zug und Schwyz einerseits und dem Kanton Zürich andererseits zusammen (Karte 3). Sie ist in unserer Gegend durch die politische Grenze eindeutig vorgezeichnet.

\section{a) Der Arbeitsgang}

\section{Die Ackerareale}

Dem Ackerbau kommt im betrachteten Gebiet keine große Bedeutung zu. Trotzdem gestaltete dieser Produktionszweig das Antlitz der Landschaft schon mehrere Male um.

Vor dem letzten Krieg versorgten sich meistens nur diejenigen Landwirte selbst mit Kartoffeln, die ursprünglich aus dem Mittelland stammen. Sie bildeten immer eine kleine Minderheit. Mit der Anbaupflicht wandelte sich das Aussehen der Gegend wesentlich, denn der Anbau von Ackerfrüchten mußte so erweitert werden, daß die Landwirte nicht nur den eigenen Bedarf deckten, sondern sogar einen kleinen Über- 
schuß produzierten. Nach dem Krieg zeigte der Ackerbau sofort wieder rückläufige Tendenz, vor allem im Schwyzer Gebiet. Als Folge davon nahm der Anteil des Akkerlandes an der Gesamtfläche des Kulturlandes bei der Kartierung im Herbst 1949 von Westen nach Osten, wie auch mit der Höhe beträchtlich ab. Mit Bestimmtheit ist daher mit einer Grenze zu rechnen.

Es stellt sich nun die Frage, wo die Lage einer Grenzisolinie des Ackerbaus im untersuchten Gebiet Berechtigung besitzt. Wenn irgend möglich sollte sie sich auf einen in der landwirtschaftlichen Betriebswissenschaft gebräuchlichen Begriff stützen können. Im vorliegenden Fall kann dies nur den Begriff des Selbstversorgerbetriebs an Ackerfrüchten betreffen.

Dazu muß die Selbstversorgungsfläche bezüglich Ackerfrüchte für eine Familie mittlerer Größe berechnet werden. Als Grundlage wurde eine 6-köpfige Familie (2 Eltern + 4 Kinder) genommen. Herr M. Pulver, dipl. ing. agr., Assistent an der Abteilung für Landwirtschaft der ETH., hat mir in verdankenswerter Weise anhand von landwirtschaftlichen Betriebsstatistiken diese Berechnung ausgeführt. Sie sei nachstehend kurz wiedergegeben:

Grundlagen: Betrieb 5-10 ha im Gebiet der Graswirtschaft, 6-köpfige Familie.

Bedarf:

Kartoffeln pro Männereinheit . . . . . . . . . . . . . ca. $200 \mathrm{~kg}$ Getreide (Brot) pro ME. (75\% von $200 \mathrm{~kg}$ ) . . . . . . . . ca. $150 \mathrm{~kg}$

Ertrag pro Aare:

Kartoffeln $160 \mathrm{~kg}$

Getreide $22 \mathrm{~kg}$ ( $150 \mathrm{~kg}$ Brot $=160 \mathrm{~kg}$ Korn $)$

Erforderliche Fläche pro Männereinheit:

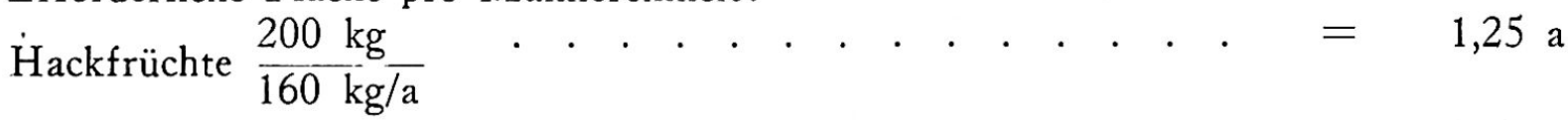

Getreide $\frac{160 \mathrm{~kg}}{22 \mathrm{~kg} / \mathrm{a}} \cdot \cdot \cdot \cdot \cdot \cdot \cdot \cdot \cdot \cdot \cdot \cdot \cdot \cdot \cdot \cdot \cdot=7,27 \mathrm{a}$

Ackerfläche für Selbstversorgung pro Männereinheit ca. . . . . . . . 8,5 a Benötigte Männereinheiten für 6-köpfige Familie:

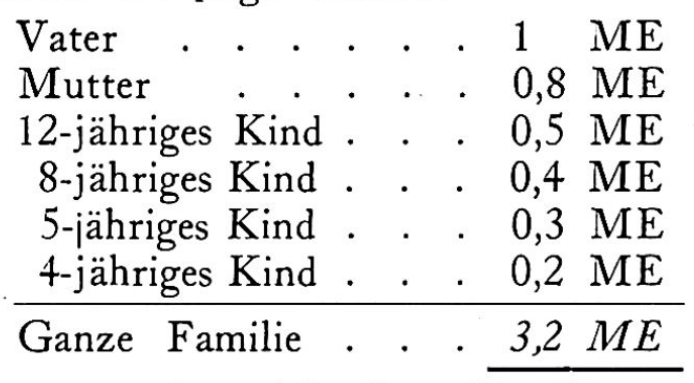

Ackerareal für Selbstversorgung einer 6-köpfigen Familie . . . . . = = 27,2 a.

Der Einfachheit halber werden 30 a als Selbstversorgungsfläche eines Betriebes angenommen.

Die Größe der Einheitsflächen des Maschennetzes richtet sich nach der mittleren Betriebsgröße, da wir von jedem Betrieb das mittlere Selbstversorgungsareal kennen. Die durchschnittliche Betriebsgröße beträgt für diese Gegend 6,25 ha. Der große Anteil von Kleinbetrieben drückt den Durchschnittswert sehr stark hinunter. Diese Tatsache, sowie die folgenden Gründe verlangen aber eine größere Einheitsfläche für das Quadratnetz: Erstens sind die Ackerparzellen in den Betrieben nicht regelmäßig auf die ganze Wirtschaftsfläche verteilt, und zweitens ist auch die Anordnung der Bauernhöfe in der Landschaft unregelmäßig (vor allem nicht quadratisch). Wir nehmen daher die vierfache Fläche der mittleren Betriebsgröße als Einheitsfläche an, also 25 ha. 
Das entspricht einer Quadratseite von $500 \mathrm{~m}$ und einem mittleren Fehler von $\pm 250 \mathrm{~m}$. Wir zeichnen auf Transparentpapier ein Maschennetz von $2 \mathrm{~cm}$ Seite (Maßstab 1:25 000).

In der Kartierungsgrundlagenkarte (1:5000) wird das maßstäblich gleiche Netz mit $10 \mathrm{~cm}$ Seite aufgezeichnet und in jedem Quadrat die Ackerflächen ausplanimetriert. Die erhaltenen Werte trägt man in die entsprechenden Quadrate der Zahlenkarte (1:25000, Karte 6) ein.

Der Größe einer Einheitsfläche entsprechen vier mittlere Betriebe, also ergeben vier errechnete Selbstversorgungseinheiten ( $4.30 \mathrm{a}=) 120$ a, die Leitzahl für die Grenzziehung.

Diese Grenze kann man als Selbstversorgergrenze (mit Ackerfrüchten) bezeichnen. Sie ist eine Isolinie und weist deren allgemeine, bereits beschriebenen Eigenschaften auf. Im vorliegenden Fall widerspiegelt sie auch gewisse wirtschaftsphysiologische Beziehungen der Landschaft.

\section{b) Der Grenzverlauf}

Die Grenze der Selbstversorgungsbetriebe umschließt in großen Zügen zwei Zonen, die pro Betrieb im Durchschnitt 30 a oder mehr Ackerfläche, aufweisen, nämlich das Zürcher Moränenplateau und einen Teil der Zuger Moränenlandschaft.

Die Grenzlinie, die die Selbstversorgungszone des Zürcher Moränenplateaus umschließt, verläuft von der Bodenweid (Hirzel) dem Waldrand des Sihltobels entlang bis südlich Weißerlen (Schönenberg), umfährt dann südlich der Sihl die Sihlmatt (Menzingen) und den Suhner (Schönenberg) im Süden, wendet nun gegen Norden und zieht sich über Gubel (Schönenberg) - Säge — Stollenweid — Palmisacker - Unter Külpen - Rothenblatt - Hohenberg - Buchegg - Vorder Schönenberg - Sonnenrain - Gisihegi zum Waldrand nördlich vom Tiefenbachweiher und folgt diesem bis zum Thor und Finsterseehalden (Hütten). Hier richtet sie sich gegen Osten und verläuft über Tannenmattli - Vorder Langmoos - Au - Baalet - Unter Laubegg - Seeli (Richterswil) - Bellen - Itlimoos (Wollerau) - Samstagern Zopf (Richterswil) - Vordere Egg - Moos - Frohe Aussicht - Obermatt Mittlere Schwanden - Geißer - Giger - Hügsam - Säge zum Sternen. Hierauf folgt sie dem Waldrand des Sternentobels, der Linie Kalchbühl - Neuhausrain Zweischürlen - Neugut (Richterswil) - Eichmühlen (Wädenswil) - dem westlichen Waldrand des Reidtobels - Grünthal - Sandhof — Gehrenau - Sennweid, weiter über Feld - Langrüti - Herrlisberg - Furthof - Neuhof - Untermoosen - Bühlen - Stoffel - Hangenmoos - dem südlichen Waldrand des Gelmenholzes - Vorder Rüti - Gwaad - Zopf - Appithal, und schließlich zieht sie sich längs dem südlichen Waldrand des Winterbergholzes zur Dächenwies.

Zwei Inseln, verursacht durch größere Gehölze und steile Nordhangpartien, liegen in dieser Zone. Die Umgebung des Kaltenbodenholzes (Bubenwies, Hintere Stollenweid) in der Gemeinde Schönenberg stellt die erste, das Schliereggholz mit den anschließenden Nordhängen beim Sennhaus, Mugerrain (Wädenswil) sowie das Spitzenmoos (Hirzel) ergibt die zweite Insel mit unter 120 a Ackerareal pro Quadratfläche.

Auch die zahlreichen Einbuchtungen der umgrenzten Selbstversorgerzone sind fast ausnahmslos durch Gehölze oder steilere Hangpartien bedingt.

Die Selbstversorgergrenze der Zuger Moränenlandschaft wird durch die wie folgt verlaufende Linie umschlossen: Spitzenbühl (Menzingen) - Moos - Brettingen Zubenweid - Winzwilen - Brand - Blachen - Schwand - südlicher Waldrand des Sihltobels bis Buchmatt - Harget - Würzgarten - Maienrain.

Eine kleine Selbstversorgerzone befindet sich südlich der Haltsäge (Finstersee) um das Mittlere Erlenmoos, sowie beim Hinterberg (Neuheim). 
Drei kleine Inseln mit über 120 a Ackerareal pro Quadrat liegen im Schwyzer Gebiet, und zwar bei Erlen (Wollerau), südlich von Freienbach und zwischen Weni und Ebnet (Feusisberg). Der größte Teil der drei Inseln fällt auf ehemaliges Sumpfland, welches zur Hauptsache während des letzten Krieges melioriert wurde. Dieser Boden eignet sich weniger für Wiesland, dagegen sehr gut für den Anbau von Akkerfrüchten. Die Nutzungsweise wird noch weiter begünstigt durch die relativ starke Parzellierung dieses ehemaligen Streuelandes. So verlegen mehrere Landwirte ihre Äcker in diese ehemaligen Moore. Es täuscht also Selbstversorgerzone vor. Nur bei Freienbach existieren einige Selbstversorgerbetriebe.

Große Häufungen von Ackerparzellen der Selbstversorgerzone, in der Zahlenkarte gut ersichtlich, stützen sich meist auf melioriertes Sumpfland. Das beruht wiederum auf der guten Eignung dieses Bodens insbesondere für Hackfrüchte.

Die Selbstversorgergrenze wirkt gegen den Kanton Schwyz physiognomisch ziemlich stark, da der Gradient groß ist und das betrachtete Element flächenhaft in Erscheinung tritt.

\section{a) Der Arbeitsgang}

\section{Die Lebhecken und Zäune}

Der Grasbau verbunden mit Milchwirtschaft spielt in der untersuchten Gegend die wichtigste Rolle in der landwirtschaftlichen Produktion. Mit der Graswirtschaft ist in der Regel ein intensiver Weidgang verknüpft. Damit kommt ein neues, sehr auffälliges Element in die Landschaft, nämlich Lebhecken und Zäune aller Art. Mit der Höhe verstärkt sich meistens dieses Element durch den vermehrten Weidebetrieb sowie die einseitigere Bewirtschaftung, indem solche Einfriedungen häufiger auftreten und auch ortsbeständiger bleiben. In der betrachteten Gegend sind die Lebhecken im Kanton Schwyz und im Kanton Zug sehr auffällig. Bei Häufungen erwecken sie den Eindruck einer eigentlichen Bocagelandschaft. Daneben treten auch Stangen- und Drahtzäune auf. Diese sind aber auch in der Gemeinde Hütten (Kt. Zürich) an den steilen Weidehängen diesseits und jenseits der Sihl in großer Dichte zu finden. Als weiteres Hilfsmittel für den Weidgang benützen die Landwirte Elektrozäune. In den tiefer gelegenen Teilen versehen an Stelle der Lebhecken und Stangenzäune hauptsächlich Draht- und vor allem Elektrozäune den Dienst. Gründe hiefür können die Waldarmut des Moränenplateaus und auch der vermehrt gepflegte Ackerbau darstellen, vielleicht auch die fortschrittlichere Bewirtschaftung.

Kartiert wurden alle Arten der Einfriedungen mit Ausnahme der Elektrozäune, weil diese den Standort rasch wechseln und auch physiognomisch am wenigsten wirken. Als Einheitsfläche wurde wiederum das Areal von vier mittleren Betrieben, 25 ha gewählt. Die Begründung ist im vorhergehenden Abschnitt über Ackerareale aufgeführt. Eine Quadratseite mißt in Wirklichkeit $500 \mathrm{~m}$. Die Zahlenkarte wird im Maßstab 1:25000 mit einem Maschennetz von $2 \mathrm{~cm}$ auf Transparentpapier gezeichnet (Karte 7). In der Kartierungsgrundlagenkarte werden nun die Lebhecken für sich allein ausgemessen und die Meterwerte in den untern Teil der entsprechenden Quadrate der Zahlenkarte eingetragen. In einem Arbeitsgang werden die Stangen- und Drahtzäune zusammen gemessen und in den obern Teil der entsprechenden Quadrate der Zahlenkarte (Karte 7) übertragen.

Charakteristisch für die Zonen mit großer Hagdichte ist die Einzäunung etwa der Hälfte der Wirtschaftsfläche eines Betriebes. Nun kommt es häufig vor, daß zwei Nachbarbetriebe aus wirtschaftlichen Gründen die Grenzhäge gemeinsam unterhalten. Unter diesen Voraussetzungen macht etwa der halbe Umfang eines Betriebes die durchschnittliche Haglänge (Zäune und Lebhecken) aus.

Die mittlere Betriebsgröße beträgt 6,25 ha. Setzen wir quadratische Form voraus, so mißt eine Seite $250 \mathrm{~m}$, der halbe Umfang $500 \mathrm{~m}$. Das Quadratnetz ist auf vier Betriebe bezogen, damit wird die Leitzahl für die Hagdichtengrenze $2000 \mathrm{~m}$. In den 
Einheitsflächen, die viel Wald aufweisen, wird zusätzlich die Hagdichte für das landwirtschaftlich genutzte Areal bestimmt. Beträgt diese auch über $2000 \mathrm{~m}$, so ist das Quadrat zur Weidzone zu schlagen, trotzdem die auf die ganze Fläche (mit Wald) bezogene Dichte unter $2000 \mathrm{~m}$ liegen kann. Es betrifft dies vor allem die Zonen an der Hohen Rone und am Hohen Etzel.

Die Bestimmung der Leitzahl weist gewisse subjektive Momente auf, währenddem die Grenze, wie jede Isolinie, überall die vorgezeichneten Bedingungen genau erfüllt. In dieser Hagdichtengrenze äußern sich wie mit der Selbstversorgungsgrenze gewisse wirtschaftsphysiologische Eigenheiten der Landschaft.

\section{b) Der Verlauf der Hagdichtengrenze}

Das Gebiet mit großer Hagdichte beschränkt sich in großen Zügen auf die Gemeinden Menzingen, Neuheim, Hütten und Feusisberg. Die $2000 \mathrm{~m}$ Isolinie der Hagdichte umschließt folgende Zonen: 1. Das Grenzgebiet der Gemeinden Neuheim und Menzingen. Die Grenze verläuft von der Hoflinde (Neuheim) am südlichen Waldrand des Sihltobels entlang bis Unterschwand, von hier über Brandhubel - Zubenweid - Brettingen zur Bachmühle (Menzingen). 2. Den östlichen Teil der Gemeinde Menzingen und den Nordhang der Hohen Rone ohne den Kaltenboden, Kalkofen und Obermoos (Feusisberg). Diese Zone ist im Westen durch die Linie Schurtannen (Menzingen) - Harget - Buchmatt begrenzt. Die übrigen Grenzen bilden die Waldzone der Hohen Rone sowie die südlichen Waldränder des Sihltobels. 3. Die direkt nördlich der Sihl gelegenen Teile der Gemeinden Hütten, Wollerau und Feusisberg. Die Südgrenze dieser Zone bilden die nördlichen Waldränder des Sihltobels mit Ausnahme eines kleinen Stückes bei der Baumannsweid (Feusisberg) und etwas weiter östlich beim Geißboden, wo die Grenze eine kleine Ausbuchtung auf das Südufer der Sihl macht. Die Südgrenze gegen den Hohen Etzel bilden die Waldränder dieses Gebiets, sowie die Alpgrenze, die über die Enzenau verläuft. Die Nordgrenze zieht sich von Haslaub (Schönenberg) über Finsterseehalden (Hütten) - Knäus Hinter Langmoos - Segelweid - Gschwend - Baalet - Ob. Hengerten - Rebgarten - Moos - Blegi - Büelen (Wollerau), umfährt die Neumühle im Norden, erstreckt sich weiter über Weidli (Feusisberg) - Sihlegg - Gibel — Fritsch Oberstoß und den nördlichen Außenrand der Terrasse von Feusisberg. 4. Inseln finden wir bei der Unt. Laubegg (Hütten), südlich des Seeli (Richterswil), westlich der Tanne (Schönenberg), bei Hergisroos und Weingarten (Wollerau) und eine größere in der Umgebung von Schwanden und Feld (Richterswil).

Auffallend in der Gemeinde Menzingen ist die Teilung des Gemeindeareals in zwei Zonen mit größerer Hagdichte. Dazwischen liegt ein Gebiet mit kleinerer Hagdichte. Gründe für die kleinere Hagdichte sind die vielen Sümpfe dieser mittleren Zone und die damit verbundene kleinere Siedlungsdichte. Dieses Sumpfareal eignet sich zudem weniger für Wies- als für Ackerland. Die Siedlung Segel (Hütten) ist vorwiegend von Schwyzerbauern bewohnt. Die Ausbuchtung der Hagdichtengrenze findet zum Teil darin ihre Erklärung.

Im selben Sinne dürften auch die Inseln beim Seeli (Richterswil) und der Unt. Laubegg (Hütten) begründet werden. Mit Sicherheit konnten diese Verhältnisse wegen des Argwohns der betreffenden Leute nicht abgeklärt werden. Eine Erklärung der Existenz der übrigen Inseln kann ich nicht geben.

Im Gebiet des Kalkofens, Kaltenbodens und Obermoos (Feusisberg) sind die Hagdichten sehr klein. Es befindet sich hier kein einziger Bauernhof. Dies kann durch die klimatische (schattig) und pedologische (sumpfig) Ungunst erklärt werden.

\section{c) Die Lebheckengrenze}

Die Hagdichtengrenze wiedergibt vor allem eine feinere Untersuchung in der Nutzungsweise, in diesem Fall der Weidefrequenz und drückt somit gewisse physio- 
logische Beziehungen der Landschaft aus. Diese relative Grenze wirkt aber physiognomisch weniger stark, da der Gradient an einigen Orten nicht sehr groß ist und auch nicht stetig gegen NW abnimmt.

Physiognomisch sehr stark wirksam sind dagegen die Lebhecken. Daher sollen die Gebiete mit Lebhecken noch separat von den andern ausgeschieden und die Strukturgrenze bestimmt werden. Sie kann sehr leicht anhand der Zahlenkarte (Karte 7) gezogen werden. Man umfährt einfach alle Quadrate, die Lebhecken enthalten. Diese Strukturgrenze scheidet somit Zonen ohne Lebhecken klar aus.

Die Lebheckengrenze verläuft von der Hoflinde (Neuheim) über Oberschwelli (Menzingen), wendet gegen Norden, quert die Sihl, umfährt Brunnen (Hirzel) und Aesch (Schönenberg) im Norden, zieht sich dann über Gibel - Säge - Rain Spitzenbühl zur Sihl, dann flußaufwärts bis zur Säge (Hütten) und folgt hier dem Brandbach gegen Süden bis zur Vordern Schönau (Hütten). Die Rodungsinsel des Mistlibühls, Gschwendboden und Schmitten weist als einzige Zone südlich der Sihl keine Lebhecken auf. Die Lebheckengrenze verläuft daher von der Hohen Rone längs des Sagenbaches zur Sihl, flußaufwärts bis zur Kantonsgrenze und dieser entlang bis westlich der Neumühle (Wollerau). Dann zieht sie sich weiter über Samstagern - Zopf (Richterswil) - Vordere Egg - Brüsch - Sennweid (Wädenswil) Frohe Aussicht - Ob. Schwanden - Schwanden - Burghalden - Neugut Reidholz - Schönau - Mühlenen - Steingaß - Grüt - Löchli - Dürsenen Itlimoos (Wollerau) - Schöni - Rohr - Schellhammer zum Sternentobel und dem Mühlebach abwärts zum See.

Sehr auffallend ist die große Ausbuchtung der Grenze nördlich der Neumühle (Wollerau). Sie liegt darin begründet, daß die Bahnlinie Wädenswil - Schindellegi - Einsiedeln beinahe längs der ganzen Strecke von Hecken eingefaßt ist.

In einer zusammenhängenden Insel liegen Spitzen (Hirzel), Mugerrain und Sennhaus (Wädenswil).

\section{Die Obergrenze des Obstbaus}

Bäume spielen im Landschaftsbild eine sehr wichtige Rolle. Am eindrücklichsten tritt das bei raschen Veränderungen, wie z. B. beim Schlagen von Bäumen in Erscheinung. Das Aussehen oder sogar der Charakter einer Straße oder Gegend kann so weitgehend verändert, umgestaltet werden. Eine noch größere Wirkung erzielen Baumgruppen aller Art. Somit ist auch die physiognomische Bedeutung der Obstgärten ins richtige Licht gestellt.

Das ganze linke Zürichseeufer gehört zu den bedeutendsten schweizerischen Obstbaugebieten. Um jede Siedlung reihen sich Obstgärten, die sich zu lichten Wäldern zusammenschließen und in der Regel nur durch Hügelkuppen und Moore unterbrochen sind. Mit der Höhe nimmt die Obstbaumdichte ab, die Bäume schließen sich enger der Siedlung an und wagen sich weniger weit auf die Wiesen hinaus. Schließlich stehen die Weiler und Höfe nackt da, ohne den windbrechenden Schutz der Obstbäume. Je nach den klimatischen und Expositionsverhältnissen wechselt die Höhenlage dieser Obergrenze. Sie könnte auch als Klimagrenze (Isolinie) betrachtet werden. Die Obstbaumgrenze (Strukturgrenze) wurde einfach durch Umfahren der obersten in die Katasterpläne eingezeichneten Obstbäume erhalten (Karte 3).

Sie verläuft von Gschwend (Menzingen) über Vorderblack - Außerblack Dutz - Ober Mühlestock - Ober Sparen - Schönau (Hütten) - Mistlibühl Gschwendboden und erreicht beim Untern Roßberg (Wollerau) mit $960 \mathrm{~m}$ die höchste Höhe. Bei Schindellegi liegt die Grenze bedeutend tiefer auf rund $800 \mathrm{~m}$. Sie zieht sich vom Dorf gegen Osten weiter über Stutz - Schweigwiesweid, umfährt Bleiken und Bühl im Süden, steigt über Loch - Ebnet - Miltenweid hinab zum Rohnen. Hier erreicht sie den tiefsten Punkt bei $750 \mathrm{~m}$, verursacht durch die schlechte Exposition, und steigt dann wieder gegen das Strickli an. 
Dieser Grenzverlauf weist gewisse Parallelen zur Klima- und Vegetationsgrenze auf. Diese Eigenheiten wurden dort kommentiert. Die maximale Höhenschwankung der Obstbaumgrenze beträgt $210 \mathrm{~m}$.

\section{Die Alpweidegrenze}

Die Nutzungsart einer Wiese tut sich deutlich in der Vegetation oder in ihrer Oberflächengestaltung (Kleinrelief) kund. Die Kuhtreien oder der Nesterwuchs einer Mähwiese verraten sofort die Weidenutzung. In Alpweiden, die nur in größern Zeitabständen gemäht werden, stellen sich in der Regel Farnkräuter, Besenheide, Zwergwachholder und Weidehöcker ein, die bei regelmäßiger jährlicher Mahd mit den Gästen niemals im Lebenskampf konkurrieren und sich daher nicht entwickeln könnten.

Am Hohen Etzel und an der Hohen Rone lassen sich diese extensiv genutzten Weideflächen an den Farnkräutern und an den Weidehöckern erkennen. Vor allem die dürren braunen Farnkräuter wirken im Frühjahr schon auf große Entfernung physiognomisch sehr stark.

Diese Alpweiden sind im betrachteten Gebiet durch Lebhecken oder Stangenzäune von den Mähwiesen abgegrenzt. Die Alpweidegrenze ist als scharfe Trennungslinie in der Landschaft vorgezeichnet und kann direkt kartiert werden (Karte 3).

Am Hohen Etzel ist sie oberhalb von Bühl und Loch (Feusisberg) vorhanden und verläuft von der Enzenau südwärts bis zum Sihltobelwald, nordwärts bis ca. $820 \mathrm{~m}$ Höhe hinunter und wendet gegen Osten zum Waldrand.

An der Hohen Rone finden wir sie südlich vom Obern Roßberg, während die Weideflächen in der Gemeinde Menzingen nicht mehr ins untersuchte Gebiet fallen.

\section{Die Grenze nach Fabrikstandorten}

Von großer gestaltender Kraft auf Siedlung und Wirtschaft sind neben Hausindustrien größere mechanische Betriebe aller Art. Die Seitenbäche des Zürichseetales und die Sihl stellen in Bezug auf die Wasserkraft für die Anlage und Verbreitung von Fabriken eine günstige Grundlage dar. Ebenso wichtige Voraussetzungen für solche Gründungen bilden neben der Wasserkraft die Verkehrsgunst und das Vorhandensein von Arbeitskräften. Seit der Elektrifikation sind die beiden zuletzt angeführten Faktoren sogar ausschlaggebend.

Für eine Fabrik, die Massengüter herstellt oder als Rohstoff benötigt, ist die Lage zu einer Bahnstation sehr wichtig. Im untersuchten Gebiet verarbeiten die mechanischen Großbetriebe fast ausschließlich Produkte, die aus dem Ausland herbeigeschafft werden müssen.

Die längsten Anfuhrwege $(1,4 \mathrm{~km})$ von der Bahnstation haben die Teigwarenfabrik in der Mühlenen (Richterswil) und die Tuchfabrik im Reidbach (Wädenswil). Der Betrieb in der Mühlenen ist eine relativ junge Gründung. Es kann daher vorausgesetzt werden, daß diese Zufuhrdistanz wirtschaftlich noch tragbar ist. Wir dürfen sie in unserer Gegend als heutigen praktischen Grenzwert für die Lage einer Fabrik zu einer Bahnstation annehmen. Bei Betrieben, die sehr hochwertige (Uhren) oder sehr leichte Produkte herstellen, kann sich dieser Grenzwert ändern.

Von den Bahnhöfen aus werden nun auf allen Ausfallstraßen 1,4 km abgemessen und als Grenzpunkte miteinander verbunden (Karte 3). Diese Linie nenne ich Fabrikstandort- oder Verkehrsgunstgrenze. Menzingen besitzt eine Bahnstation einer Schmalspurbahn. Diese Zufuhrbedingungen gestalten sich jedoch für einen Großbetrieb ungünstig, da ein Umlad erforderlich ist, die Produkte sich dadurch verteuern und die Absatzmöglichkeiten sich verschlechtern.

Nur Betriebe, die sehr leichte oder hochwertige Fabrikate herstellen, sind von diesem Gesetze etwas unabhängiger. In Menzingen konnte sich daher eine kleine 
Tabakfabrik installieren. Die Möglichkeiten für weitere Industrien sind aber gering. Aus diesen Gründen wurde hier eine Grenzziehung nach Fabrikstandorten unterlassen.

Die Fabrikstandortgrenze hat zum Teil nur theoretischen Wert. Sie tritt heute einzig um die Stationen Wädenswil, Richterswil, Bäch, Wollerau und Schindellegi in Erscheinung, indem um diese Stationen im Abstand von ca. 1,4 km Fabriken bestehen, während sie in kleinern Siedlungen wie Samstagern und Au direkt in der Umgebung des Bahnhofs stehen.

Im Einzugsbereich der Station Burghalden und der zwei Haltestellen von Freienbach befindet sich noch kein Fabrikbetrieb. Sie werden vorläufig von den noch günstiger gelegenen benachbarten Umladeplätzen Richterswil, Samstagern und Pfäffikon konkurrenziert. Die gezogenen Grenzen der Verkehrsgunst haben aber trotzdem ihre Berechtigung, da sie Zonen umschließen, die besondere wirtschaftliche Bedeutung in Bezug auf ihre Lage und quasi größere potentielle Energie besitzen. Innerhalb der Verkehrsgunstgrenze kann die Landschaft durch mechanische Betriebe und ihre Folgeerscheinungen komplexere Struktur annehmen. Latente und akute physiologische Momente treten mit dieser Grenze zutage.

In der Praxis schließt sich diese Isolinie je nach dem Relief und den bestehenden Verkehrswegen der weitern Bahnhofumgebung enger oder weiter um die Bahnstationen.

\section{DIE POLITISCHEN GRENZEN}

Die Lage der Kantonsgrenzen kann man zum überwiegenden Teil als naturgegeben bezeichnen. Die Grenze zwischen den Kantonen Zug und Zürich bilden die in jeder Beziehung trennende Schranke des Sihltobels, das ebenso verkehrsfeindliche Tobel eines linken Zuflusses des Gripbaches, sowie der beidseits steil abfallende Grat der Hohen Rone (Karte 3).

Nicht so eindeutig von der Natur vorgezeichnet ist die Grenze zwischen den Kantonen Schwyz und Zürich. Vom Dreiländerstein (Hohe Rone) zieht sie sich zunächst auf dem Rücken des Roßbergsporns nordwärts. Bei der Kuhnweid verläßt sie diese natürliche Grenze, folgt der Fallinie des Westhangs und gewinnt westlich der Sennrüti einen kleinen Seitenbach der Sihl. Die Kantonsgrenze teilt somit den Hang der Rodungsinsel der Oerischwand (Hütten) und Sennrüti in zwei Hälften, ohne sich an eine naturgegebene Linie zu halten. Erst auf der Terrasse bei der Sennrüti ist ihr Verlauf wiederum vom Relief angedeutet.

Die Kantonsgrenze quert die Sihl bei den Mündung des vorhin erwähnten Baches und folgt einer Hangmulde bis zum Bergli (Hütten), streicht westlich an der Neumühle (Wollerau) vorbei bis zum P. 671. Von hier strebt sie gradlinig auf das Sternentobel östlich der Schanz zu. Dieses Teilstück der Grenze scheint auf den ersten Blick willkürlich zu sein. Es verrät jedoch bei genauerem Studium das gute Empfinden der eidgenössischen Grenzkommission für morphologische Feinheiten des Geländes; die Kantonsgrenze stellt auffallend genau die Trennungslinie zwischen der Rippenlandschaft und dem Moränenplateau dar.

Von der Sternenschanze folgt sie der natürlichen Scheidelinie des Mühlebachgrabens, verläßt das Tobel erst $700 \mathrm{~m}$ oberhalb der Mündung des Baches und umschließt willkürlich das seinerzeit beim Friedensschluß nach dem alten Zürichkrieg hartnäkkig umstrittene Gebiet des Hafens (Richterswil) im Osten.

Die erstmalige Festlegung der heutigen politischen Grenzen zwischen Schwyz und Zürich erfolgte nach dem alten Zürichkrieg an der Tagsatzung von Luzern am 1. Dezember 1440 (36, S. 41-43) und wurde im Kappeler Vertrag vom 8. April 1450 bestätigt. In administrativer Hinsicht weisen somit alle drei Kantonsgebiete eine sehr stetige Entwicklung auf. Umso mehr vermochten sich verwaltungstechnische, politische, konfessionelle und charakterliche Eigenheiten der drei Bevölkerungsteile ins Gesicht der Landschaft einzuprägen. 
Es ist daher zu erwarten, daß die Grenzen der Kulturlandschaft, die weitgehend unter anthropogenem Einfluß stehen, sich mehr oder weniger mit den Kantonsgrenzen decken müssen. Konsultiert man die entsprechenden Karten, so kann man feststellen, daß sich die analytischen Grenzlinien tatsächlich längs den Kantonsgrenzen viel enger zusammenschließen. Der naturgegebene Scheidegürtel des Sihlgrabens zeigt eine ganz besonders ausgeprägte Scharungszone, während bei der offenen Grenze zwischen den Kantonen Schwyz und Zürich die von Menschen beeinflußbaren Grenzen weiter auseinanderrücken und einen breitern Übergangsraum bilden.

\section{Dritter Teil}

\section{DIE SYNTHESE DER LANDSCHAFTEN}

\section{Die Darstellung}

\section{A. DIE SYNTHETISCHE KARTE}

Die synthetische Karte erhält man durch Übertragung aller Grenzlinien auf ein durchsichtiges Papier (Karte 8). Dabei wird jede mit einer eigenen Signatur eingezeichnet. Vorteilhaft verwendet man die gleichen Symbole wie auf den Zahlenkarten. Ihre Stellung soll auch hier die Richtung der $\mathrm{Zu}$ - und Abnahme der Häufigkeit des betreffenden Grenzbildners ausdrücken.

In der folgenden Landschaftsgliederung wird keine Wertung der Grenzen nach ihrer physiognomischen Wirksamkeit vorgenommen, sondern alle als gleichwertig behandelt. Eine Wertung wäre in jedem Fall anfechtbar, denn es treten alle möglichen Übergänge auf, und es hielte schwer, eine eindeutige Trennung in stark und schwach wirkende Grenzen vorzunehmen. Bei relativen Grenzen und Isolinien wäre eine solche Unterscheidung immer fragwürdig, denn sie können an manchen Orten physiognomisch stark, an andern schwach wirken, je nachdem der örtliche Gradient des Grenzbildners größer oder kleiner ist. Zudem gestattet das komplexe Spiel der Wechselbeziehungen keine restlose Abklärung der physiologischen Bedeutung eines Grenzbildners, was schon früher festgestellt wurde.

In der synthetischen Karte kommt es vor, daß sich mehrere analytische Grenzen decken. Dabei ist es graphisch nicht gut möglich, alle Grenzsymbole übereinander zu zeichnen. Im vorliegenden Fall wurde bei Deckung analytischer Grenzen mit der politischen nur diese eingezeichnet und die andern weggelassen. Aus dem Einmündungswinkel der analytischen Grenzen ersieht man, in welcher Richtung sie weiter verlaufen.

\section{Die Landschaftsgliederung}

Die gezogenen Strukturgrenzen, relativen Grenzen und Isolinien stellen drei Grenztypen dar, deren Eigenheiten bereits beschrieben wurden. Für die Landschaftsgliederung stellt sich nun die Frage, ob diese drei Grenztypen überhaupt miteinander vergleichbar sind. Im II. Teil wurde bei der praktischen Grenzziehung bereits darauf hingewiesen, daß zwischen ihnen eine Verwandtschaft besteht und in Spezialfällen eine relative Grenze zugleich auch eine Strukturgrenze oder eine Isolinie sein kann. Eine Strukturgrenze ist immer ein Spezialfall einer Isolinie. Sie verbindet Orte, die die Dichte 0 des betreffenden Landschaftselementes aufweisen; sie besitzt somit den Charakter einer $0 \mathrm{~m}$ oder $0 \mathrm{~m}^{2}$ Isolinie je nach der Dimension des Grenzbildners.

Eine relative Grenze bildet zugleich eine Isolinie, wenn die Intensitätsgrade des betreffenden Grenzbildners längs der relativen Grenze gleich groß sind.

Eine relative Grenze wird zur Strukturgrenze, wenn sie ein Merkmal einseitig absolut begrenzt. Diese Erscheinung tritt abwechselnd meist nur für kürzere Teilstrecken der Grenze auf. 
Die drei Grenztypen sind somit einander sicher wesensverwandt, sodaß Vergleiche unter ihnen gut möglich sind.

In bisherigen Landschaftsgliederungen wurden sie auch schon nebeneinander als gleichwertige Elemente verwendet, jedoch ohne diese Terminologie.

In der synthetischen Karte 8 scharen sich die einzelnen Grenzen mehr oder weniger längs den zu erwartenden Landschaftsgrenzen. Sie bilden Grenzgürtel, welche die Kernlandschaften voneinander trennen. Vereinzelt können Grenzen auch aus solchen Scharungszonen ausbrechen und ein sonst relativ einheitliches Gebiet queren oder Inseln bilden. Das ist meist dann der Fall, wenn der Gradient des betrachteten Grenzbildners sich innerhalb kleiner Gebiete nicht stetig ändert. In extremen Fällen kreuzen sich die einzelnen Grenzen, ohne sich zu scharen. Solche Vorkommnisse erschweren eine Landschaftsgliederung, verunmöglichen sie aber nicht unbedingt. Meistens treten auch dann noch einheitliche Gebiete auf, die allerdings sehr klein und vielleicht nicht gerade Landschaftseinheiten, sondern Teile von Landschaften 2., 3., 4. oder 5. Ordnung darstellen, d. h., daß ein bis vier Landschaftselemente in ihrer Verbreitungsintensität größere Schwankungen aufweisen.

Bei der Gliederung eines Gebiets ist es arbeitstechnisch vorteilhaft, zuerst die sog. Kernlandschaften zu bestimmen. Als solche bezeichne ich ein Gebiet, das von stark in Erscheinung tretenden relativen Grenzen oder von physiognomisch meist stark wirkenden Strukturgrenzen umschlossen wird und einen einheitlichen Kern (einheitlich im Sinne der Homogenität, weniger der Physiologie) besitzt. Sehr ähnlich definiert sie auch O. MAULL (46, S. 157). Eine Kernlandschaft kann jedoch von Isolinien und schwach in Erscheinung tretenden relativen Grenzen durchquert werden. Es ist der Sammelbegriff für Landschaften niedrigster Ordnungen.

Aus dieser Kernlandschaft ist die Landschaft 1. Ordnung oder die Landschaftseinheit auszuwählen. Dies fällt nicht immer leicht, denn die Landschaften niederer Ordnungen sind unter sich sehr ähnlich. Diese Wahl kann je nach dem Bearbeiter ein anderes Resultat zeitigen, bleibt also immer stark subjektiv. Praktisch fällt dies nicht so sehr ins Gewicht, da alle diese verwandten Ganzheiten ein ähnliches Gepräge zeigen und sich daraus nur kleine Abweichungen ergeben, indem benachbarte Ordnungszahlen von Landschaften wechseln können. Es wird sich demnach ein mittlerer Fehler von \pm einer Ordnungszahl einstellen.

Bei der Wahl der Landschaftseinheit ist den Eigenheiten der Region besondere Beachtung zu schenken. Zuerst erwägt man zweckmäßig die allgemeinen Merkmale der Region, um schlußendlich die das Individuum charakterisierenden Erscheinungen herauszuschälen. Dazu sind die erhaltenen Kernzonen der synthetischen Karte auf die regelmäßige Verbreitung und Häufigkeit der Landschaftselemente zu prüfen, denn Grundbedingung für eine Landschaft 1. Ordnung (Landschaftseinheit) muß eine ziemlich weitgehende Einheitlichkeit in ihrem Bau sein. Es wurde dafür auch schon der Begriff Homogenität (44, S. 167, 162) angewandt. Dieser Begriff scheint mir dafür ungeeignet; er fordert zu viel. Bei dieser Voraussetzung gäbe es keine Landschaftseinheiten, denn nicht einmal ein Kristall ist homogen, d. h., besitzt eine absolut regelmäßige innere Struktur.

Bei der Ausscheidung von Landschaften stellt sich auch die Frage der Mindestgröße einer Landschaftseinheit. E. MARkus (44, S. 169) setzt als Kriterium für seine Naturkomplexe deren «Homogenität», also große Gleichartigkeit in der $\mathrm{Zu}$ sammensetzung voraus. Bei seinen Landschaftsgliederungen fand er für seine Kleinstlandschaften praktisch Größen von $100 \mathrm{~m}^{2}-1000 \mathrm{~m}^{2}$, nimmt aber mit Bestimmtheit an, daß es auch große gibt. S. Passarge (50, S. 36) nennt die Individuen kleinster Landschaften landschaftliche Zwergräume, deren Größenordnung sich um $100 \mathrm{~m}^{2}$ bewegt.

Im betrachteten Gebiet sind die Landschaften 1. Ordnung alle bedeutend größer als $1000 \mathrm{~m}^{2}$ und erfüllen somit die obigen Bedingungen. 
Sind nun die Landschaftseinheiten (1. Ordnung) einmal festgelegt, so bestimmt man nach folgendem Vorgehen die Landschaften 2., 3., 4. und 5. Ordnung. Die Landschaft 2. Ordnung erhält man durch Aufhebung derjenigen die Landschaft 1 . Ordnung begrenzenden Isolinie oder schwach in Erscheinung tretenden relativen Grenze. die am meisten Arealzuwachs bringt. Für die Gewinnung der Landschaften 3., 4. und 5. Ordnung werden sinngemäß weitere gleiche Grenztypen eliminiert. Die Landschaft höchster Ordnung ist schließlich mit der Kernlandschaft identisch. Bei diesem Vorgehen verändert sich der Gesamtcharakter der Landschaft höherer Ordnung nur wenig von der Landschaft nächst niederer Ordnung. Die Einheitlichkeit aller dieser Landschaften ist immer noch größer, als sie Kernlandschaften im alten Sinne aufweisen, denn die große Mehrzahl der bis dahin ausgeschiedenen Landschaftseinheiten sind nur von Strukturgrenzen umschlossen. Man kann die Landschaften verschiedener Ordnungen als Unterarten einer Kernlandschaft betrachten, die physiognomisch klarer in Erscheinung tritt.

Struktur- und stark in Erscheinung tretende relative Grenzen dürfen nicht aufgehoben werden, da sich dann meist das Gepräge einer Landschaft ganz ändert. In diesem Sinne wird auch hier zwischen den drei Grenztypen gewertet. Diese Wertung hat aber nicht zur Folge, daß wie in bisherigen Arbeitsweisen der Verlauf einzelner sog. analytischer Grenzen dadurch beeinflußt und korrigiert wird. Sie dient lediglich zur Differenzierung der Landschaft und beruht auf der mathematisch erfaßbaren (Gradient) physiognomischen Wirksamkeit der drei Grenztypen.

O. Maull (46, S. 157) wendet für die Ausscheidung seiner Länder aus den Landschaften ein im Prinzip gleiches Verfahren an.

Somit weisen Landschaften 2. Ordnung ein in der Verbreitungsintensität stärker wechselndes Landschaftselement, 3. Ordnung zwei, 4. Ordnung drei und 5. Ordnung vier solche auf.

Die Ausscheidung der Landschaften höherer Ordnung erfolgt sehr willkürlich. Diese Arbeitsweise kann sich lediglich durch ihre Zweckmäßigkeit und die Güte der so gewonnenen Resultate rechtfertigen.

E. Markus (44, S. 174) schlägt für die Landschaftssystematik ein System vor, das sich in der Einordnung der Landschaften mehr an die Botanik anlehnt. Weitere diesbezügliche Vorschläge von andern Autoren wurden im ersten Teil dieser Arbeit erwähnt.

Es wäre sehr wünschenswert, wenn ein System aufgestellt werden könnte, bei dem die Ordnungszahl noch mehr aussagt, vor allem über ganz bestimmte Merkmale der Landschaft Auskunft gäbe. Davon ist die Geographie noch weit entfernt. Die Schaffung eines solchen praktischen Systems setzt eine systematische Untersuchung größerer Gebiete voraus. Sie übersteigt die Arbeitskraft eines Einzelnen und sollte, wie die Klärung und Vereinheitlichung geographischer Begriffe, durch Arbeitsgemeinschaften oder Kongresse erfolgen.

Man könnte sich dabei fragen, ob nicht die Grenzgürtel als Kernzonen angesprochen werden sollen. Es ließe sich bestimmt auch in dieser Richtung ein System aufbauen, das für eine Kernzone größte Uneinheitlichkeit als Grundlage nähme. Dieses Problem sei hier dahingestellt.

In Bezug auf die Übergangslandschaften existieren schon zahlreiche Begriffe. Zur Hauptsache lassen sie sich aber nur bei der Gliederung von Großräumen anwenden $(45$, S. $601 \mathrm{ff} ; 44$, S. 149).

Die Einteilung der Kerngebiete in Landschaften verschiedener Ordnungen erheischt für die Grenzgürtel logischerweise ein gleichartiges System. Bei straffer Anwendung des bei der Ausscheidung der Kernlandschaften entwickelten Prinzips, müßte die Zone größter Uneinheitlichkeit als Grenzgürtel 1. Ordnung bezeichnet werden. Dieses Vorgehen würde jedoch sehr große Schwierigkeiten verursachen und ließe 
sich in manchen Fällen kaum durchführen, weil die Grenzgürtel meist von vielen, sich oft eng scharenden Grenzen kreuz und quer durchzogen werden.

Einfacher und ebenso zweckmäßig ist die Beurteilung der Grenzgürtel nach ihrer trennenden Wirkung. O. MAUlL (45, S. $601 \mathrm{ff}$.) differenziert nach diesem Gesichtspunkt die Grenzgürtel zwischen Großlandschaften.

Die Klassierung der Grenzgürtel zwischen Kernlandschaften soll nun auf ähnlicher Basis erfolgen. Dazu gilt es vorerst zu erkennen, von welchen Komponenten die Größe der trennenden Wirkung abhängt. Die trennende Wirkung eines Grenzgürtels ist sicher umso größer, je schmäler die Grenzzone und je mehr Struktur- und stark in Erscheinung tretende relative Grenzen, die bei der Ausscheidung der Landschaften verschiedener Ordnungen nicht aufgehoben wurden, diese durchlaufen. Diese Beziehung kann mathematisch durch folgenden Quotienten erfaßt werden:

$$
\text { Wirksamkeit }=\frac{\text { Zahl der Grenzlinien (Struktur- und rel. Grenzen) }}{\text { mittlere Breite der Grenzzone in } \mathrm{km}}
$$

Die mittlere Breite des Grenzgürtels muß folglich zuerst noch bestimmt werden. Sie ergibt sich als Quotient aus der Fläche der Grenzzone und ihrer Länge, wobei die Längenerstreckung innerhalb des Grenzgürtels gemessen werden muß.

Die obige Relation besagt ganz einfach, wieviele Grenzlinien ein Querprofil eines Grenzgürtels pro km aufweist. Der Wirksamkeitsquotient liefert einen Mittelwert, der mit allen Schwächen solcher Mittelzahlen behaftet ist. Mit der Angabe der Extremwerte mildern sich diese Nachteile wesentlich. Der Mittelwert ist jedoch sehr zweckmäßig, denn er gibt eine mathematische Handhabe für die Klassierung der Grenzgürtel.

Man könnte nun als Grenzgürtel 1. Ordnung denjenigen mit dem größten Wirksamkeitsquotienten bezeichnen, als Grenzgürtel 2. Ordnung den mit dem nächst kleinern usw. Nach diesem Verfahren würden nur die Grenzgürtel des untersuchten Gebiets miteinander vergleichbar, wobei die Ordnungszahlen lediglich die Reihenfolge der Quotientengrößen angäben. Es ist deshalb vorteilhafter, man klassiert die Grenzgürtel nach den errechneten Wirksamkeitsquotienten, welche mit andern Arbeiten direkt vergleichbar sind.

Man kann die Quadratmethode sicher auch für die Gliederung eines Großraums in Großlandschaften verwenden. Dazu sind die Kartierungsrichtlinien auf die speziellen Merkmale der Großlandschaft auszurichten. O. MaUlL (47, S. 239) geht bei der Gliederung von Hessen in ähnlicher Weise vor. Sind nun die Kleinlandschaften eịnes Raums bekannt, so kann man eine Großlandschaft auch aus diesen zusammensetzen, ähnlich wie es J. F. Unstead (64) vorschlägt.

Die Arealbestimmung der Landschaften verschiedener Ordnungen, sowie der Grenzgürtel ist einzeln für jede Landschaft vorzunehmen, ohne eine Aufteilung der Grenzgürtel an die benachbarten Landschaften. Eine Flächenmessung mit Hilfe einer abstrahierten Grenzlinie zur Aufteilung des Grenzgürtels (generelle Grenze von W. SchaffNer, 57, S. 50) hat meines Erachtens keine Berechtigung, denn die so bestimmten Areale entsprechen ja nicht den landschaftlichen Gegebenheiten.

Es soll im folgenden kurz auf die praktische Bedeutung von Landschaftsgliederungen eingegangen werden. J. H. Schultze (59, S. 145-160) hat gezeigt, daß es unzweckmäßig ist, wenn eine Landschaft mit einem Verwaltungskreis oder Staat identisch ist. Solche Verwaltungsgebiete sollten besser heterogene wirtschaftliche Struktur besitzen. Eine Zusammensetzung eines Landes aus Landschaften, die sich gegenseitig ergänzen, zeitigt demnach die besten Voraussetzungen für seine wirtschaftliche Blüte. Landschaftsgliederungen bilden für die Neueinteilung von Verwaltungsbezirken aber trotzdem die Grundlage, denn anhand der Untersuchungsergebnisse vermag der Fachmann die geeignetsten Landschaften zu lebensfähigen Verwaltungskreisen zusammenzufügen. 
Auch für die Landesplanung können Landschaftsgliederungen wertvolle Hinweise für eine harmonische Gestaltung liefern.

Die aufgestellte Landschaftssystematik will nur als einfacher Versuch gelten und stellt höchstens eine Diskussionsgrundlage dar. Sie muß sicher auf breiterer Basis ausgebaut werden. Das würde Stoff genug bieten für eine separate Abhandlung.

In den anschließenden Abschnitten folgt nun die praktische Landschaftsgliederung (Karte 9) des untersuchten Gebiets.

In der synthetischen Karte 8 heben sich fünf Kernzonen ab, je zwei im Zürcher und Schwyzer Gebiet und eine im Kanton Zug. Zwischen diesen liegen Grenzgürtel und Übergangsgebiete. Sie werden einzeln auf ihre Zusammensetzung hin untersucht.

Die auf die Ausscheidung der Landschaften und Grenzgürtel folgende Beschreibung erhebt nicht Anspruch auf Vollständigkeit. Es werden nur die wesentlichen Züge skizziert, die für die Grenzziehung ausschlaggebend sind.

\section{B. DIE LANDSCHAFTEN}

\section{Dic Kernlandschaft des südlichen Teils der Vordern Höfe}

\section{Die Landschaft 1. Ordnung}

Zunächst sind die allgemeinen und speziellen Züge der Landschaft herauszuschälen. Nachher folgt, wie im vorhergehenden Abschnitt festgestellt wurde, die Überprüfung der Landschaftselemente auf ihre Einheitlichkeit in den einzelnen $\mathrm{Z}_{\mathrm{o}}$ nen der synthetischen Karte.

Das betrachtete schwyzerische Gebiet gehört nach H. Carol und U. SenN (11, S. 129-134) zum größten Teil dem Mittelland an, nur der südliche, höher gelegene Teil der Gemeinden Feusisberg und Wollerau wird von der Voralpen - Mittellandgrenze durchschnitten. Diese Teile werden bei den Grenzgürteln behandelt.

Hauptmerkmale der mittelländischen Zonen, auch physiognomisch direkt oder indirekt stark in Erscheinung tretend, sind das meist glazial geformte Relief, große jährliche Niederschläge, dadurch bedingt größere Flußdichte, sowie Graswirtschaft mit ausgeprägtem Weidgang und Streusiedlung. Der Höhenlage entsprechend gehören diese Gegenden vegetationskundlich vorwiegend der Bergstufe an.

Spezielle Merkmale des schwyzerischen Gebiets sind die durch die schiefgestellten, harten, z. T. erodierten Gesteinsschichten verursachte Rippung und damit verbundene linienförmige Bewaldung der Landschaft, der sog. Schwyzer Haustyp, die große Hag- und Lebheckendichte, gepaart mit dem wenig entwickelten Ackerbau. Der vorherrschenden Konfession entsprechend ist eine größere Zahl von Kultbauten anzutreffen.

Eine Merkwürdigkeit stellt die relativ günstige Verkehrslage einiger größerer Siedlungen auf den Terrassen dar, vor allem wegen der großen Höhendifferenzen und des Fehlens einer eigentlichen Haupttalung mit Ausnahme des Zürichseetales. Den Grund für die gute Verkehrslage bildet die Pforte von Schindellegi und die geographische Lage der Zone.

Am reinsten und gleichmäßigsten verbreitet treten die speziellen Merkmale (mit Ausnahme der Verkehrslage) auf der 'Terrasse von Feusisberg in Erscheinung. Dieses Gebiet wird von keiner sog. analytischen Grenze durchquert und ist auch topographisch schön als Einheit vorgezeichnet und wahrscheinlich dank seiner natürlichen Abgeschlossenheit weitgehend einheitlich entwickelt.

Ich bestimme diese Terrasse daher als Landschaft 1. Ordnung oder als Landschaftseinheit. Im Norden und Süden bilden die Terrassenränder die natürliche Begrenzung (Karte 9); im Westen ist die Landschaft offener und reicht bis zur Linie Schindellegi - Sihleggrain; im Osten erstreckt sie sich bis zum Rand des betrachteten Gebiets. 
Diese Landschaftseinheit stellt eine nach Westen offene glazial bearbeitete Terrasse mit großer Flußdichte (über $2,66 \mathrm{~km} / \mathrm{km}^{2}$ ) dar. Die zahlreichen Sümpfe sind meist durch die Grundmoränenablagerungen bedingt. Diese Ganzheit ist eine Randlandschaft des schweizerischen Mittellandes und grenzt an die Voralpengrenze (nach H. CARol und U. SenN, 11, 129-134), gehört aber vegetationskundlich in die Bergstufe. Aus der beschriebenen geographischen Lage, verbunden mit der Höhenlage (mittlere Höhe ca. $700 \mathrm{~m}$ ) geht hervor, daß sie wegen den Steigungsregen größere Niederschlagsmengen aufweist. Daraus leitet sich die landwirtschaftliche Nutzung, nämlich Graswirtschaft mit ausgesprochenem Weidgang ab. Das äußert sich im Antlitz der Landschaft in der großen Hagdichte (über $8 \mathrm{~km} / \mathrm{km}^{2}$ ), wovon bis zur Hälfte Lebhecken sind. Im Zusammenhang mit der erwähnten natürlichen Ausstattung steht auch die Streusiedlung, das Wegnetz, sowie mit der Bodenbeschaffenheit der bedeutende Obstbau. Der Ackerbau dagegen rückt ganz in den Hintergrund, denn die Bauern versorgen sich nicht selbst mit Ackerfrüchten.

Die Wirtschaft ist fast ausschließlich auf Viehzucht und Milchverarbeitung abgestimmt. Die prächtige Lage über dem Zürichsee, verbunden mit schönen Ausflugsmöglichkeiten, prädestinieren diese Gegend zur Kurlandschaft. Der selbstbewußte und konservative Zug der Bevölkerung macht sich im Hausbau, dem schönen, meist sehr stilreinen sog. Schwyzerhaus geltend. Die Bevölkerung ist fast zu $100 \%$ katholisch, davon zeugen auch die Kapellen und zahlreichen Wegkreuze.

Als Fremdlingsform ist in dieser Landschaft nach Passarge die 1. Kl. Durchgangsstraße Pfäffikon - Schindellegi anzusehen.

\section{Die Landschaft 2. Ordnung}

Die Landschaft 2. Ordnung erhalten wir durch Aufhebung der Hagdichtengrenze.

Diese vergrößerte Landschaft weist dadurch gegen die Grenze im Norden und Südwesten ein Landschaftselement auf, welches in seiner Verbreitungsintensität größern Schwankungen unterworfen ist. Alle andern Glieder bleiben dieselben wie bei der Landschaftseinheit, woraus die nahe Verwandtschaft klar ersichtlich ist.

Die Landschaft 2. Ordnung wird im Norden begrenzt (Karten 8, 9) durch die Klima- und Vegetationsgrenze sowie durch die Flußdichtengrenze. Im Süden fassen sie die Obstbaum- und die morphometrisch-morphologische Grenze, im Südwesten die Grenze der Verkehrsgunst und im Westen die Flußdichtengrenze ein.

\section{Die Landschaft 3. Ordnung}

Zur Landschaft 3. Ordnung gelangt man durch Eliminierung der Flußdichtengrenze. Das Areal der Landschaft 2. Ordnung erweitert sich dadurch ganz beträchtlich gegen Norden und Westen, und es treten nun viel deutlicher die Sandsteinrippen in Erscheinung. Durch eine solche bedingt ist auch die natürliche, den Verkehr kanalisierende Zufuhrrampe Pfäffikon - Schindellegi. Doch stellen auch in dieser Landschaft die 1. Kl. Straße wie die Bahnlinie immer noch Fremdlingsformen dar, weil sie Glieder der Nachbarlandschaft sind.

Auch dieses größere Gebiet ist noch relativ einheitlich zusammengesetzt. Zudem sind Dichtegrenzen, ohne Messungen anzustellen, im Landschaftsbild nicht immer gut erkennbar. Ihre Sichtbarkeit hängt weitgehend von der Größe des Gradienten oder Gefälles des betreffenden Grenzbildners ab. Der Gradient der Hagdichte ist in diesem Gebiet eher als klein zu bezeichnen, und auch das Gefälle der Flußdichte ist nur nördlich Schindellegi groß.

Die Landschaft 3. Ordnung ist im Norden durch die Klima- und Vegetationsgrenze, die Grenze der Verkehrsgunst, sowie ein kleines Stück durch die morphometrische Grenze von den übrigen Teilen geschieden. Im Westen begrenzt sie zur Hauptsache die Lebheckengrenze, dazu noch die Selbstversorger- und Verkehrsgunst- 
grenze. Im Süden trennt sie die morphometrische, Verkehrsgunst- und Obstbaumgrenze von den übrigen Teilen.

\section{Die Landschaft 4. Ordnung}

Als weitere Isolinie wird die Verkehrsgunstgrenze eliminiert. Somit gelangen die beiden größern Siedlungen Wollerau und Schindellegi mit ihrer Umgebung zur Landschaft 3. Ordnung und geben zusammen die Landschaft 4. Ordnung. Durch diesen Zuwachs wandelt sich die Grundstruktur der Landschaft ziemlich stark, indem Fabriken mit allen ihren Folgeerscheinungen diese Landschaft 4. Ordnung viel komplexer gestalten. Die Bahnlinien und Straßen 1. Kl. bilden nun keine Fremdlingsformen mehr, sondern wichtige integrierende Glieder, nach PASSARGE Heimatfaktoren.

Die Wandlung der Landschaft 4. Ordnung tritt nicht immer sofort jenseits der Grenzen der Verkehrsgunst ein. Diese Isolinie umfährt ja vielmehr Zonen, innerhalb denen diese Umgestaltung sich weiter vertiefen kann, wo für Gründungen von mechanischen Betrieben günstige Vorbedingungen vorhanden sind.

Die Grenzverhältnisse gestalten sich viel einfacher als bei den Landschaften niederer Ordnungen. Im Norden bilden die Klima- und Vegetationsgrenze sowie die morphometrische Grenze die Scheidelinie, im Westen die Grenze der Kultbauten und die Lebheckengrenze und im Süden die morphometrische und Obstbaumgrenze.

\section{Die Landschaft 5. Ordnung}

Die Landschaft 5. Ordnung gewinnt man durch Aufhebung der Klima- und Vegetationsgrenze. Das äußert sich darin, daß wir vom Gebiet des sogenannten Vorlandbuchenwaldes (Fagetum finicola) in dasjenige des aronstabreichen Eichen - Hainbuchenwaldes (Querceto - Carpinetum - aretosum) gelangen. Als weiteres charakteristisches Merkmal stellen sich in unserer Gegend an südexponierten Hängen Rebberge ein, wie an der Rippe von Freienbach und am Eulenbach südlich Wilen.

Die Landschaft weist beim Erlenmoos (Wollerau) eine Insel mit großer Ackerarealdichte auf. Wie schon der Name zeigt, hängt diese Häufung mit ehemaligen Sumpfflächen zusammen. Durch die große Parzellierung haben viele Landwirte Anteil an dem ehemaligen Streueland. Wegen der guten Eignung verlegen sie ihre Akkerflächen für den Anbau von Hackfrüchten meist in dieses meliorierte Land. Das täuscht Selbstversorgerbetriebe vor. Es existieren aber keine. Man kann dieses Gebiet aus diesem Grunde nicht als richtige Selbstversorgerzone betrachten. Es wird darum der Landschaft 5. Ordnung zugerechnet.

Die Landschaft 5. Ordnung weist vier Landschaftselemente auf, die größere Schwankungen in ihrem Auftreten zeigen. Erstens nehmen die Hag- und Flußdichten gegen Norden und Westen ab; weiter greift sie in zwei Vegetationszonen ein, und als letztes zeigt sie große Unterschiede in der Verkehrsgunst. Damit im Zusammenhang stehen die punktförmig auftretenden industriellen Zentren. Alle übrigen in der Landschaft 1. Ordnung beschriebenen Bildner bleiben sich innerhalb kleiner Häufigkeitsschwankungen gleich. Nur das morphologisch auffallendste Formelement, die Rippung mit den charakteristischen Waldstreifen der Nordhänge tritt mit der Vergrößerung der Landschaften immer ausgeprägter in Erscheinung.

Ich bezeichne diese Landschaft 5. Ordnung als schwyzerische Rippenlandschaft, deren Hauptmerkmale aus den beschriebenen Landschaften niederer Ordnungen hervorgehen.

Im Norden scheidet sie die morphometrisch-morphologische Grenze von den Seeuferebenen und der zürcherischen Seehangzone und im Westen die Lebhecken- und Kultbautengrenze vom Moränenplateau. Die letzte Scheidelinie läuft hier gemeinsam mit der morphometrischen und politischen Grenze. Im Süden trennt die morphometrisch-morphologische Grenze die Landschaft vom Sihltobel und dem Hohen Etzel. 


\section{Die Kernlandschaft des Zuger Gebiets}

\section{Die Landschaft 1. Ordnung}

Vom betrachteten zugerischen Gebiet gehört der größere Teil dem Mittelland an. Nur die steileren Nordhänge der Hohen Rone rechnen $\mathrm{H}$. CAROL und U. SENN (11, S. 129-134) zu den Voralpen. Bezeichnend für diesen mittelländischen Teil sind die zahlreichen Moränenhügel und Drumlins und als Folge davon versumpfte Mulden wie Streusiedlung mit dem entsprechenden Wegnetz. Die Gegend liegt ebenfalls im Bereich der voralpinen Steigungsregen, gleichwohl ist die Flußdichte aber unter $2,66 \mathrm{~km} / \mathrm{km}^{2}$.

Vegetationskundlich gehört diese Gegend ganz zur Bergstufe (Vorlandbuchenwald). Boden- und Klimaverhältnisse begünstigen Grasnutzung mit Weidebetrieb und Obstbau. Im Gegensatz zum Schwyzer Gebiet ist aber auch der Ackerbau noch relativ stark entwickelt.

Spezielle Merkmale sind die unterschiedliche, in Wechselbeziehung miteinanderstehende Hag- und Ackerbaudichte, wobei wir Lebhecken aber beinahe im ganzen Gebiet verbreitet finden. Den traditionellen Haustyp stellt das sog. Schwyzerhaus dar; größere Siedlungen zeigen viele neuzeitliche Bautypen. Die überwiegende Mehrheit der Bevölkerung ist katholisch, was in der Landschaft durch Kapellen und zahlreiche Wegkreuze in Erscheinung tritt. Das ganze Gebiet liegt weitab von den Hauptverkehrswegen und bietet darum dank der schönen ruhigen Lage Feriengästen Erholung. Die Haupteinnahmen bringen der Bevölkerung Landwirtschaft und Gastgewerbe.

Für die Wahl als Landschaftseinheit fallen zwei Gebiete in Betracht, das eine mit größerer Heckendichte aber kleinerer Ackerflächenbedeckung, das andere umgekehrt mit kleinerer Hecken- dagegen größerer Ackerdichte. Beide zeichnen sich durch weitgehende Einheitlichkeit in ihrem Bau aus. Das hat seinen Grund in dem kleinen Gradienten für die Selbstversorger- und Hagdichtengrenze in diesem Gebiet. Die geographische und Höhenlage begünstigen die Graswirtschaft. Es ist daher naheliegend und richtiger, den Teil als Landschaft 1. Ordnung zu wählen, der große Hagdichte und kleinere Ackerarealdichte aufweist.

Im Zuger Gebiet erfüllen zwei solche Räume (Karten 8, 9) die aufgestellten Forderungen. Es sind daher zwei Kerne von Landschaftseinheiten vorhanden, der eine bildet die Umgebung von Menzingen und deren benachbarten nordöstlichen Teil, der andere erstreckt sich vom Wilersee gegen Südwesten und umfaßt dazu die Umgebung von Finstersee. Beide Kerne zeigen gleiche Struktur. Ihr Hauptinhalt ist weiter oben beschrieben. Es bleibt nur die Präzisierung anzubringen, daß ihre Hagdichte mehr als $8 \mathrm{~km} / \mathrm{km}^{2}$ und die Ackerarealdichte weniger als $4,8 \mathrm{ha} / \mathrm{km}^{2}$ beträgt.

Der Unterschied zur schwyzerischen Landschaft 1. Ordnung liegt in den morphologischen Formen und den dadurch bedingten Waldarealen. Der Waldanteil ist wie die Flußdichte sehr klein. Diese Elemente verleihen der Landschaft ein ganz anders geartetes Aussehen. Eine weitere, allerdings kleinere Verschiedenheit ersieht man aus der Zahlenkarte der Ackerareale. Der Ackerflächenanteil ist in den zwei Zuger Landschaften 1. Ordnung fast durchwegs größer als auf der Terrasse von Feusisberg.

\section{Die Landschaft 2. Ordnung}

Diese Landschaft erhalten wir durch Ausschaltung der Selbstversorgergrenze. Beide Kerne erhalten einen Gebietszuwachs, und damit ist auch die Variationsbreite der Ackerflächen größer. Die übrigen Landschaftselemente bleiben im wesentlichen dieselben wie in der Landschaft 1. Ordnung. Die Grenze des nördlichen Kerns bilden im Osten die Hagdichten- und morphometrische Grenze, im Norden die Lebheckengrenze und im Westen der Kartenrand. Der südliche Kern wird im Norden 
und Westen begrenzt durch die Hagdichtenisolinie, im Osten und Süden durch die morphometrische und Obstbaumgrenze.

\section{Die Landschaft 3. Ordnung}

$\mathrm{Zu}$ dieser Landschaft gelangen wir durch Eliminierung der Hagdichtenisolinie. Damit schließen sich die beiden Landschaften niederer Ordnungen zusammen. Ihr Gesamtinhalt ist bekannt. Größere Variationsbreiten zeigen die Hag- und Ackerflächendichte. Die übrigen Bauelemente sind sehr einheitlich. Landschaften höherer Ordnungen können hier nicht ausgeschieden werden, denn die Landschaft 3. Ordnung ist allseitig von Strukturgrenzen umschlossen (Karten 8, 9), nämlich im Norden von der Lebhecken-, im Osten von der morphometrischen und im Süden von der Obstbaumgrenze. Würden wir eine dieser Strukturgrenzen fallen lassen, so wäre die Einheitlichkeit weitgehend gestört.

Wir bezeichnen diese Landschaft 3. Ordnung als Zuger Moränenlandschaft. Sie besitzt eine viel einfachere Struktur als die Rippenlandschaft. Das äußert sich in der Ordnungszahl. Die Rippenlandschaft ist eine Landschaft 5. Ordnung, wobei vor allem der guten Verkehrslage eine große Gestaltungskraft zukommt und die Landschaft wesentlich komplexer formt.

Von Grund auf verschieden in den zwei Landschaften sind die morphologischen Formen und damit auch die Waldareale in Form und Größe, sowie die bereits erwähnten, auf der Verkehrslage beruhenden Möglichkeiten für die Gründung mechanischer Betriebe. Es besteht lediglich eine kleine Tabakfabrik in Menzingen (7 Arbeiter).

Weniger große Unterschiede zeigen sich im Klima, Vegetation, Fluß- und Ackerarealdichte. Auch in diesen vier Elementen ist die Zuger Landschaft viel einheitlicher gebaut, vor allem weil sie kleinere Höhendifferenzen aufweist.

Die Zuger Moränenlandschaft ist eine ausgesprochene Kurlandschaft, im Kanton Schwyz trifft das nur für die Landschaft 1. Ordnung zu. In beiden Landschaften gleich sind hingegen: Haustyp, Kultbauten, Konfession und die Streusiedlung mit dem dazu gehörenden Wegnetz. Den landwirtschaftlichen Hauptproduktionszweig bildet hier wie dort die Graswirtschaft verbunden mit Weidenutzung und intensivem Obstbau. Ihre Folgeerscheinungen sind große Hagdichte und Lebhecken.

\section{Die Kernlandschaft des Zürcher Moränenplateaus}

\section{Die Landschaft 1. Ordnung}

Die Landstriche des Kantons Zürich um Hütten, Samstagern, südlich der Sihl und entlang dieses Flusses gehören eindeutig Grenzgürteln an (Karte 8) und werden unter diesem Abschnitt beschrieben.

Die übrigen Teile liegen im Bereich zweier Kernlandschaften, die eine längs des Sees, die andere auf dem Moränenplateau. Beide gehören ganz dem Mittelland an. Die Wesenszüge der Moränenlandschaft sind kurz gefaßt folgende: Moränenhügelzüge und dazwischen eingebettete Sümpfe drücken der unübersichtlichen, aber abwechslungsreichen Landschaft den Stempel auf. Streusiedlung mit einem weitverzweigten Wegnetz stellen Anpassungserscheinungen an die Naturgrundlagen dar. Die Klima- und Vegetationsgrenze, die die Bergstufe (Vorlandbuchenwald) von der Hügelstufe (Aronstabreicher Eichen - Hainbuchenwald) scheidet, quert den nordwestlichen Teil des Gebiets. Die Waldanteile sind sehr klein. Höhenlage und Voralpennähe bedingen große jährliche Regenmengen. Der landwirtschaftliche Hauptproduktionszweig ist Graswirtschaft mit Weidenutzung; Lebhecken und große Hagdichten treten nur in den Grenzgebieten auf.

Die Obstbaumdichte ist groß. Der Ackerbau nimmt mit der Abnahme der Höhe an Bedeutung zu. Seine Dichte liegt im größten Teil der Landschaft über $4,8 \mathrm{ha} / \mathrm{km}^{2}$. 
Traditionelle Haustypen sind das sog. Flarzhaus, Zürcher Dreisäßenhaus und Zürcher Weinbauernhaus. Die Landschaft ist aber mehr von neuzeitlichen Haustypen durchsetzt als die Zuger und Schwyzer Gebiete. Von den traditionellen Haustypen besitzt das sog. Flarzhaus die größte Verbreitung. Es weist aber keinen sehr einheitlichen Baustil auf. Die zwei andern traditionellen Typen treten nur in wenigen Exemplaren auf.

Die Bevölkerung ist mehrheitlich reformiert, aber stark von Katholiken durchsetzt. Die Landschaft ist von den Hauptverkehrslinien abgelegen. Das eingesessene Gewerbe versorgt und bedient hauptsächlich die Landwirtschaft und den Ausflüglerverkehr. Als Fremdlingsform darf die 1. Kl. Straße Wädenswil - Sihlbrugg betrachtet werden.

Als Landschaftseinheiten kommen zwei Zonen in Betracht, die durch die Klimaund Vegetationsgrenze voneinander getrennt sind, wovon die eine der Hügelstufe, die andere der Bergstufe angehört. Die letztere ist von zahlreichen Inseln mit Fremdlingsfaktoren durchsetzt. Ihre Strukturelemente zeigen also größere Variationsbreiten. Diese Zone ist deshalb sicher etwas uneinheitlicher als die andere.

Als Landschaft 1. Ordnung wähle ich das Gebiet vom Wädenswilerberg. Die Landschaft ist relativ einfach begrenzt. Die Nordgrenze (Karten 8, 9) bilden die Selbstversorger- und morphometrische Grenze, im Osten und Süden begrenzt sie die Lebhecken-, sowie die Klima- und Vegetationsgrenze. Von der Schwyzer Landschaft 1. Ordnung hebt sie sich deutlich durch die anders geartete Morphologie, das Klima, die Flußdichte und den Haustyp ab. Sie weist auch keine Lebhecken, keine so große Hagdichte, dafür mehr Ackerland auf.

Die Mehrheit der Bevölkerung ist reformiert; also stehen keine Kapellen und Wegkreuze an den Wegen.

Die wichtigsten gemeinsamen Landschaftsfaktoren sind nur Streusiedlung, Wegnetz, Graswirtschaft und Obstbau.

Beim Vergleich mit der Zuger Landschaft 1. Ordnung kommen zu den vorhin erwähnten gemeinsamen Merkmalen höchstens noch die Morphologie; alle übrigen sind verschieden.

Daraus erhellt sich die Verschiedenheit dieser Landschaft von den zwei andern.

\section{Die Landschaft 2. Ordnung}

Wir erhalten sie durch Aufhebung der Klima- und Vegetationsgrenze. Das Areal erweitert sich dadurch bedeutend gegen Süden und Osten. Ein schmaler Streifen verbindet das Gebiet beim Wolfbühl, Gschwend, südlich von Vorder Schönenberg mit dem übrigen Teil dieser Landschaft. Fünf Inseln (Schlieregg-Spitzen, Neumatt, Kaltenboden, Bubenwies und Neuhausrain) mit Fremdlingsfaktoren (Konfession, große Hagdichte, kleinere Ackerarealdichte) beeinträchtigen die arealmäßige Abrundung dieser Landschaft.

Ganz deutlich kommt damit zum Ausdruck, daß der Gradient der Schwyzer Merkmale (Konfession, Haustyp, große Hagdichte) gegen Westen kleiner ist, als das Gefälle der gleichartigen zürcherischen gegen den Kanton Schwyz. Auch die fast gänzliche Verlegung des Grenzgürtels auf Zürcherboden läßt dies erkennen.

Die Landschaft 2. Ordnung zeigt aber immer noch große Einheitlichkeit im Bau. Als ungleichartige Strukturglieder erweisen sich nur Klima und Vegetation, die in diesem Bereich physiognomisch nur wenig in Erscheinung treten. Der Landschaftsinhalt ist aus dem vorhergehenden Abschnitt bekannt. Diese Landschaft ist im Norden begrenzt durch die morphometrische und Selbstversorgergrenze, im Osten und Süden durch die Lebhecken-, Konfessions-, Hagdichten und Haustypengrenze.

\section{Die Landschaft 3. Ordnung.}

Durch Eliminierung der Selbstversorgergrenze gewinnen wir die Landschaft 3. Ordnung. Das Gebiet südwestlich von Schönenberg, die Umgebung des Hüttnersees 
und andere kleinere, randliche Teile werden so dem Kern angeschlossen. Die Landschaft 3. Ordnung weist sechs Inseln mit Fremdlingsfaktoren auf und enthält als ungleichartige Landschaftselemente die beiden aufgehobenen sog. analytischen Grenzen.

Gegen Hütten zu gestaltet sich der Grenzverlauf noch kompliziert, während die Grenze an andern Orten auf längern Strecken schon Strukturgrenzen folgt.

\section{Die Landschaft 4. Ordnung}

Wir heben die Hagdichtengrenze auf und gewinnen die Landschaft 4. Ordnung. Die arealmäßige Erweiterung ist nicht mehr so bedeutend. Zwei Inseln verschwinden und im übrigen wird das Areal dieser Landschaft noch etwas abgerundet. Sie weist drei Landschaftsbildner auf, die größere Intensitätsschwankungen zeigen, nämlich Hag- und Ackerarealdichten, sowie Klima und Vegetation. Physiognomisch wirkt sich das nicht allzu stark aus, was schon früher festgestellt und diskutiert wurde.

Die Nordgrenze bildet die morphometrische, die Ostgrenze die Lebhecken-, Konfessions- und Kultbautenscheidelinie gemeinsam mit morphometrischer und Haustypengrenze. Im Süden sind die Konfessions-, Haustypen- und Flußdichtengrenze die Trennungslinie und im Südwesten die morphometrische, Lebhecken- und Haustypengrenze.

\section{Die Landschaft 5. Ordnung}

Als letzte lassen wir die hier physiognomisch nur sehr schwach wirksame Konfessionsgrenze fallen. Die Landschaften 4. und 5. Ordnung zeigen somit ein sehr ähnliches Aussehen, da die Konfessionsgrenze mehr latente Gestaltungskräfte in sich birgt. Erst wenn Andersgläubige in einer Gemeinde die Mehrheit erlangen, macht sich eine Konfession physiognomisch stärker geltend. Vorher greifen konfessionelle Minderheiten meist nur durch einen Kirchenbau gestaltend in die Landschaft ein.

Der Gesamtinhalt dieser Landschaft 5. Ordnung ergibt sich aus der Beschreibung der vier Landschaften niederer Ordnung.

Ich bezeichne diese Landschaft 5. Ordnung mit dem bekannten Namén als Zürcher Moränenplateau. Ihre Struktur ist wegen des einfachern Wirtschaftscharakters weniger komplex als die der Rippenlandschaft. Am einfachsten gebaut ist, der niedrigsten Ordnungszahl entsprechend, die Zuger Moränenlandschaft.

Das Zürcher Moränenplateau ist durch folgende Linien umschlossen (Karten 8, 9): Im Norden von der morphometrischen Grenze, im Osten von der Lebheckengrenze, die östlich vom Hüttnersee gemeinsam mit politischer, Haustypen-, morphometrischer und Kultbautengrenze verläuft. Im Süden und Südwesten umfassen die morphometrische, Haustypen-, Lebhecken- und Flußdichtengrenze diese Kernlandschaft.

\section{Die Kernlandschaft des zürcherischen Seeufers}

\section{Die Landschaft 1. Ordnung}

Eine Sonderstellung nimmt der Raum des Seehangs der Gemeinde Wädenswil ein. Das Relief dieser Zone ist gekennzeichnet durch die parallel zum See verlaufenden, übereinander gestaffelten Terrassen und die schmalen Uferebenen. Bäche, die das Moränenplateau und diese Nordhangzonen entwässern, gliedern die Terrassen in einzelne Teilstücke auf.

An der West/Ost-Hauptverkehrslinie unseres Landes, sowie an einer Seitenverbindung des Nord/Süd-Verkehrs gelegen, hat neben Handel und Gewerbe vor allem Textilindustrie unter Ausnützung der Wasserkraft der natürlichen Gefällstufe schon früh Eingang gefunden. Der See trägt zu dieser an sich schon vorzüglichen Verkehrslage weitere positive Momente bei, indem er neben trennenden, ebensoviele verbindende Elemente aufweist. 
Der Textilindustrie folgte als natürliche Ergänzung die Metallindustrie. Zu diesen älteren mechanischen Betrieben gesellten sich neuere, die heute alle in Wädenswil und $\mathrm{Au}$ ansässig sind. Diese wirtschaftliche Entwicklung hinterließ tiefgreifende Änderungen im Siedlungsgefüge der verkehrsgünstigeren Teile der Region.

Streusiedlungen überwiegen in den ländlichen Gebieten und bestimmen auch das dichte Wegnetz. Die traditionellen Haustypen stellen die sog. Flarzhäuser, daneben dominieren aber in den Hauptsiedlungen neuere Haustypen. Die Bevölkerung ist mehrheitlich reformiert, somit beschränken sich die Kultbauten hauptsächlich auf die Kirchen.

Die Urproduktion spielt im Vergleich mit der Industrie in dieser Landschaft nur mehr eine untergeordnete Rolle. Wie in der ganzen Region stellt Graswirtschaft die Grundlage der agrarischen Nutzung dar. Damit ist naturgemäß ziemlich intensive Weidenutzung verknüpft. Die Hagdichte bleibt aber in der ganzen Zone klein. Auch Lebhecken, welche in den vorhin beschriebenen Kernlandschaften häufig Betriebe trennen, sind keine vorhanden. Vegetationskundlich gehört diese Gegend der Hügelstufe an, was sich auch durch das Rebgelände um Wädenswil äußert.

Das hervorstechendste Merkmal der ganzen Seehangzone ist die Häufung von Industrie und Gewerbe in den Hauptsiedlungen am See, bedingt durch die sehr günstige Verkehrslage. Für Wädenswil sind die Vorbedingungen für eine stetige industrielle Entwicklung vorab dank der ausgezeichneten Verkehrslage, der Arbeitskräfte, weniger aber wegen dem Relief sehr gut. Als Landschaftseinheit ergibt sich demnach das von der Fabrikstandortsgrenze eingeschlossene Gebiet von Wädenswil (Karte 9). Es zeichnet sich durch seine komplexe Struktur aus. Diese Zone beherbergt 27 dem Fabrikgesetz unterstehende Betriebe mit rund 1800 Arbeitern. Dazu gesellen sich reges Gewerbe und zentrale Dienste, die einen Einzugsbereich bedienen, der über die Gemeindegrenzen hinausreicht (Spital, Versuchsanstalt für Obst- und Weinbau, Bank usw.). Von ganz untergeordneter Bedeutung ist die Landwirtschaft.

\section{Die Landschaft 2. Ordnung}

Immer noch verkehrsgünstig gelegen ist das Gebiet um die Bahnstation Au. Es siedelten sich daher auch einzelne größere Betriebe an. Gewerbliche Betriebe treten dagegen stark zurück. Die Landwirtschaft spielt in dieser Zone jedoch eine große Rolle. In der Verkehrsgunst zeigt dieser Bereich mit der Landschaft 1. Ordnung die ähnlichsten Züge. Die von der Fabrikstandortsgrenze umschlossene Zone wird als Landschaft 2. Ordnung bezeichnet (Karte 9).

Bei der Ausscheidung dieser Landschaft 2. Ordnung wurde vom üblichen Schema abgewichen, indem zu ihrer Gewinnung keine Grenze aufgehoben wurde. Wir können dieses Gebiet sicher nicht zur Landschaft 1. Ordnung schlagen, denn es weist andern Charakter auf. Aber auch von der restlichen Seehangzone zeichnet es sich durch speziellere Merkmale aus, die hauptsächlich auf der bessern Verkehrslage beruhen. Aus diesen Gründen ist es zweckmäßig, die Umgebung der Station Au als Landschaft 2. Ordnung zu bezeichnen.

\section{Die Landschaft 3. Ordnung}

Durch Aufhebung der Fabrikstandortsgrenze gewinnt man die Landschaft 3. Ordnung. In ihr treten die Terrassen des Seehangs nun stark in Erscheinung. In den höher gelegenen Teilen verringert sich die Verkehrsgunst rasch. Diese Areale bleiben so der Landwirtschaft reserviert, welche die Industrie- und Gewerbezone des Seeufers in vorteilhafter Weise ergänzt. Graswirtschaft mit Obstbau bilden die Haupterwerbsquelle. der Bauern, die ihren Bedarf an Ackerfrüchten zum Teil auf dem Markt decken. Die in den Landschaften 1. und 2. Ordnung erwähnten Elemente treten $z u$ den oben beschriebenen Faktoren. Im Norden ist diese Landschaft durch den See begrenzt, die kompliziert verlaufende Südgrenze bilden die Selbstversorger- und 
morphometrische Grenze, im Osten umfaßt sie die Lebheckengrenze und im Westen der Kartenrand.

\section{Die Landschaft 4. Ordnung}

Zur Landschaft 4. Ordnung gelangt man durch Eliminierung der Selbstversorgergrenze. Das neu dazu kommende Gebiet zeichnet sich durch größere Ackerdichte aus, so daß die Bauern sich selbst mit Ackerfrüchten versorgen können. Breitere Terrassen und bessere Insolation ermöglichen den intensivern Ackerbau. Die übrigen Strukturelemente dieser Landschaft sind aus den Landschaften niederer Ordnungen bekannt. Alle Teile dieser Kernlandschaft stehen noch unter starkem Einfluß ihres innersten Kerns, der Landschaft 1. Ordnung, die zahlreiche physiologische Momente beherrscht.

Die Landschaft 4. Ordnung ist im Norden vom See, im Süden von der morphometrischen Grenze, im Osten von der Lebheckengrenze und im Westen vom Kartenrand begrenzt.

Von besonderer Art ist die Grenze gegen das Moränenplateau, denn es zeichnet sich kein Grenzsaum, sondern eine Linie ab. Das liegt in der großen Ähnlichkeit der randlichen Zonen der beiden benachbarten Landschaften begründet. Es zeigen sich damit aber auch deutlich die Unzulänglichkeiten von Grenzlinien, die immer Übergangsräume ersetzen.

\section{Die Kernlandschaft des schwyzerischen Seeufers}

\section{Die Landschaft 1. Ordnung}

Die Seeuferebenen des Kantons Schwyz sind allgemein breiter als die des Kantons Zürich. Auch die Schwankungen in der Kotenstreuung sind viel kleiner; sie variieren nur zwischen 0 und $10 \mathrm{~m}$. Vegetationskundlich gehört das Gebiet mit Ausnahme sehr schmaler Randstreifen ganz der Hügelstufe an. Es liegt an der wichtigsten West/Ostund an einer bedeutenden Nord/Süd-Verkehrsader der Schweiz. Diese günstige Lage beeinflußt in großem Ausmaß die Wirtschaftsstruktur, indem die Industrie Fuß fassen konnte. Größere Betriebe finden wir in den engsten Zufuhrbereichen der Bahnhöfe. Eine Ausnahme stellen die Haltestellen von Freienbach dar. Die wichtigste Erwerbsquelle neben der Industrie bietet die Landwirtschaft. Ihre Hauptnutzung basiert wiederum auf der Graswirtschaft; eine gute Ergänzung dazu bildet der Obstbau. Lebhecken beleben das Landschaftsbild und hegen einen Teil der Betriebe ein.

Streusiedlungsform herrscht vor; die Siedlungszentren Bäch, Freienbach und Pfäffikon nehmen vom Gebiet jedoch einen namhaften Teil in Anspruch. In ihnen dominieren neuere Bautypen aller Art. Wie im Hofgebiet treffen wir in den Siedlungskernen aber auch sog. Schwyzerhäuser. Die Bevölkerung ist mehrheitlich katholisch, somit weist die Gegend eine größere Kultbautendichte auf.

Als Landschaft 1. Ordnung ergibt sich bei diesem Kerngebiet das Areal innerhalb der Fabrikstandsortsgrenzen. Dazu gehört beinahe die ganze Fläche dieser Zone. Nur südlich von Freienbach liegt eine sog. Selbstversorgerzone innerhalb der Fabrikstandortsgrenze. Der Inhalt der Landschaft ist weiter oben beschrieben.

\section{Die Landschaft 2. Ordnung}

Wir erhalten die Landschaft 2. Ordnung durch Aufhebung der Selbstversorgergrenze. Diese neue Ganzheit ist nur um die relativ kleine Selbstversorgerzone, die südlich von Freienbach liegt, größer als die Landschaftseinheit. Die hinzutretende Fläche besteht zum größten Teil aus melioriertem Sumpfland, wie der Name Langenackerried bezeugt. Der übrige Inhalt der Landschaft 2. Ordnung geht aus der Beschreibung der Landschaftseinheit hervor.

Die kleinen Gebiete, die jetzt noch die Vegetationsgrenze abtrennt, dürfen praktisch vernachlässigt und damit zur Landschaft 2. Ordnung gezählt werden. Sie ist 
somit im Süden von der morphometrisch-morphologischen Grenze, im Norden vom See und im Osten vom Kartenrand begrenzt.

Wie zwischen dem Zürcher Moränenplateau und der Seeuferlandschaft zeichnet sich auch zwischen der Rippen- und der schwyzerischen Seeuferlandschaft kein Grenzgürtel ab. Das beruht wiederum auf der Ähnlichkeit der randlichen benachbarten Zonen der zwei Kernlandschaften, sowie auf den Unzulänglickeiten einer Grenzlinie.

\section{Die Grenzgürtel}

\section{Der westliche Teil des Sihlgrabens}

Dieser Grenzgürtel erstreckt sich längs der Sihl vom westlichen Kartenrand bis zur schwyzerisch-zürcherischen Kantonsgrenze südlich vom Bergli (Hütten). $\mathrm{Er}$ trennt somit das Zürcher Moränenplateau von der Zuger Moränenlandschaft und dem Gebiet der Hohen Rone (Karte 9). Relativ eng scharen sich Struktur- und relative Grenzen längs der Sihl (Karte 8). Als bestimmendes Element für ihren Verlauf tritt eindeutig das Relief auf. Es zeichnet die natürliche Scheidelinie vor, längs der sich Strukturelemente der Landschaft durchdringen, sich ablösen und erlöschen.

Trennende Faktoren zwischen den Kernlandschaften bilden die morphometrischmorphologische, die Lebhecken-, die Haustypen- sowie die Kultbautengrenze. Die letztere ist identisch mit der politischen Grenze. Die Lebhecken treten in der Gemeinde Neuheim (im Westen südlich der Sihl) nicht ganz an das Sihltobel heran. Deshalb verläuft diese Grenze in diesem Abschnitt außerhalb des Sihlgrabens und verbreitert den Grenzgürtel zu seiner größten Breite von $1,5 \mathrm{~km}$. Bei Weißerlen und Bubheini (Schönenberg) erweitert die Lebheckengrenze den Grenzgürtel nochmals, indem sie sich zwischen diesen Siedlungen nördlich der morphometrischen Grenze auf Zürcherboden hinzieht.

Die größte Ausbuchtung bildet nördlich Hütten die Haustypengrenze. In diesem Bereich treffen wir nur wenige ganz stilreine sog. Schwyzerhäuser. Viele zeigen aber die typisch schwyzerischen Merkmale, sodaß sie als solche bezeichnet werden mußten. Der Grenzgürtel ist in diesem Teilstück durch solche Übergangstypen der Häuser charakterisiert. Vielleicht äußert sich in ihnen der schwyzerische Einfluß. Er ist hier über die offene Grenze beim Bergli und der Hüttnerbrücke sicher größer. Ein schönes Beispiel solch wechselseitiger Durchdringung zeigen die Zonen beidseits der Finsterseebrücke. Aus der Zahlenkarte der Haustypen ist ersichtlich, daß hier auf beiden Seiten der Sihl fremde Haustypen zu treffen sind.

Die natürlichen Grundlagen der Kernzone des Grenzgürtels längs der Sihl bieten für die Landwirtschaft nur eine beschränkte Entwicklungsmöglichkeit. Die Hänge des Sihlgrabens sind zum überwiegenden Teil mit Schutzwald bestanden. Westlich vom Haslaub (Schönenberg) nützt ein Elektrizitätswerk die Gefällstufe zwischen dem Tiefenbachweiher und der Sihl aus. Durch einen Stollen werden die Wasser der Sihl von der Säge (Hütten) in dieses Speicherseelein geleitet.

Folgende Zahlen sollen zur weitern Charakterisierung des Grenzgürtels beitragen.

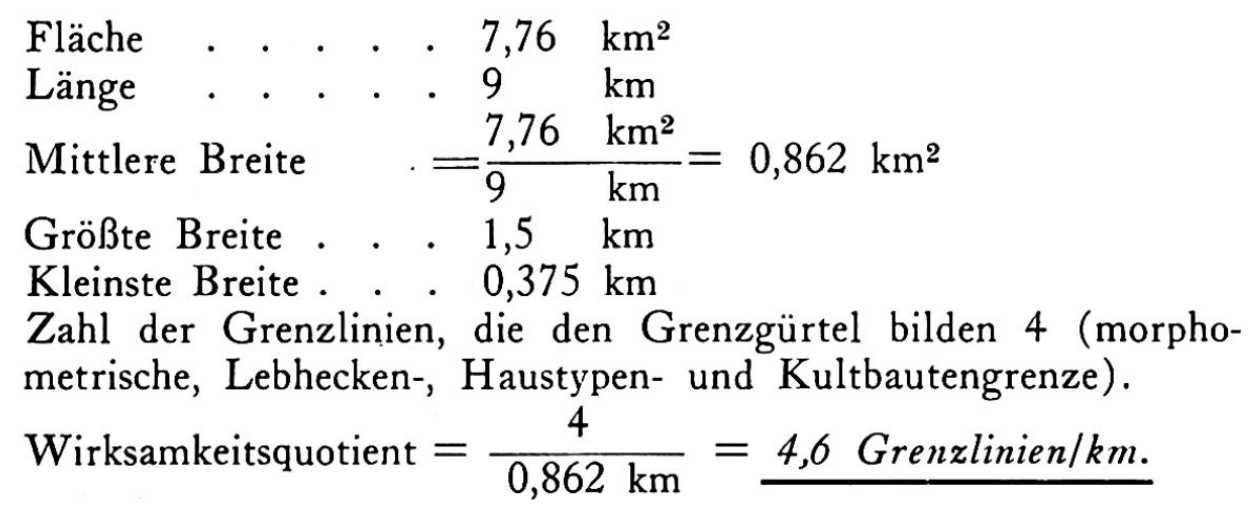


Ein wichtiges Ergebnis liefert der Wirksamkeitsquotient. Er besagt, daß im Mittel 4,6 Grenzlinien pro $\mathrm{km}$ in einem Querprofil des Grenzgürtels auftreten. Dieser Zahlenwert charakterisiert die Wirksamkeit der Übergangszone und dient daher direkt als Klassifizierungszahl.

\section{Der östliche Teil des Sihlgrabens}

Dieser Teil des Sihlgrabens bildet die östliche Fortsetzung des soeben beschriebenen Grenzgürtels. Er erstreckt sich von der Kantonsgrenze südlich vom Bergli (Hütten) bis zur Alpmündung und scheidet die Rippenlandschaft vom Gebiet der Hohen Rone (Karte 9). Er wird nicht mehr von vier Grenzlinien gebildet, sondern nur noch von zwei, nämlich der morphometrisch-morphologischen sowie der Obstbaumgrenze. Diese anders geartete Zusammensetzung forderte eine separate Behandlung.

Die Obstbaumgrenze verläuft beim Stutz (Schindellegi) nördlich des Sihlgrabens und verbreitert damit den Grenzgürtel etwas. Sonst ist seine Breite ausschließlich durch die morphologische Grenze bestimmt. Diese Übergangszone ist demnach wiederum eindeutig durch das Relief vorgezeichnet.

Bei Schindellegi wird die Wasserkraft der Sihl von einer Weberei und einem Sägewerk ausgenutzt. Die Forstwirtschaft hat in diesem Grenzbereich größere Bedeutung als die Landwirtschaft. Ca. $70 \%$ des Gebiets ist mit Schutzwald bestockt.

Über die Größe und Wirksamkeit des Grenzgürtels geben folgende Zahlen Auskunft:

$$
\begin{aligned}
& \text { Fläche . . . . . } 1,95 \mathrm{~km}^{2} \\
& \text { Länge . . . . 4 4,6 } \mathrm{km} \\
& \text { Mittlere Breite }=\frac{1,95 \mathrm{~km}^{2}}{4,6 \mathrm{~km}}=0,424 \mathrm{~km} \\
& \text { Größte Breite . . . } 875 \text { m } \\
& \text { Kleinste Breite . . . } 125 \mathrm{~m} \\
& \text { Zahl der Grenzlinien, die den Grenzgürtel bilden } 2 \\
& \text { (morphologische und Obstbaumgrenze) } \\
& \text { Wirksamkeitsquotient }=\frac{2}{0,424 \mathrm{~km}}=4,9 \text { Grenzlinien } / \mathrm{km}
\end{aligned}
$$

Die Wirksamkeit dieses Grenzgürtels ist größer als diejenige des westlichen Teils des Sihlgrabens, trotzdem ihn nur zwei Strukturgrenzen durchlaufen. Das liegt in der kleinern mittleren Breite begründet. Ein Querprofil weist 4,9 Grenzlinien pro $\mathrm{km}$ auf.

\section{Der Grenzgürtel längs der Kantonsgrenze zwischen Sihl und Zürichsee}

Dieser Übergangsraum trennt die zwei zürcherischen Kernlandschaften von den zwei schwyzerischen (Karte 9). Der Grenzbereich ist vor allem in der Umgebung von Samstagern sehr offen ohne nennenswerte natürliche Schranken. Dementsprechend ist der Grenzgürtel ziemlich breit, nämlich zwischen $200 \mathrm{~m}$ und $3 \mathrm{~km}$. Er wird von folgenden vier Grenzen gebildet: Morphometrische, Lebhecken-, Haustypen- und Kultbautengrenze.

Beim Sternentobel hält sich der Ostrand der Grenzzone an diese natürliche Grenze. Auch der Westrand folgt annähernd der natürlichen Scheidelinie des Reidbachtobels. Drei der erwähnten Grenzen verlaufen fast ausschließlich am Ostrand des Grenzgebiets. Der Westrand wird zum größten Teil durch die Lebheckengrenze gebildet. Auffallenderweise liegt der Grenzgürtel beinahe ganz auf Zürcherboden. Aus diesen Tatsachen läßt sich die Größe der beidseitigen Gradienten klar erkennen. Das Gefälle ist im Grenzgürtel gegen Osten groß, im Westen kleiner.

Diese Übergangszone ist sehr komplex gebaut, denn die Grenzlinien bilden manchmal ein kaum entwirrbares Durcheinander. Der größte Teil des Areals wird landwirtschaftlich genutzt. Im Grenzgürtel liegt der Flecken Richterswil mit industriel- 
len Großbetrieben und einem gut entwickelten Gewerbe. Auch in Samstagern steht in der Nähe des Bahnhofes ein größerer Betrieb nebst der Reparaturwerkstätte der Südostbahn. Diese Elemente, auf der Verkehrsgunst basierend, gestalten die Landschaft noch vielfältiger. Größe und Wirksamkeit des Grenzgürtels sind aus folgenden Zahlen zu ersehen:

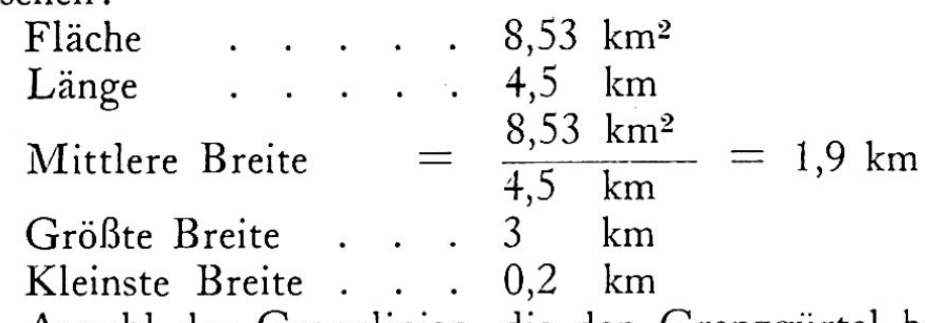

Anzahl der Grenzlinien, die den Grenzgürtel bilden 4 (morphometrische, Lebhecken-, Haustypen- und Kultbautengrenze).

Wirksamkeitsquotient $=\frac{4}{1,9 \mathrm{~km}}=2,1$ Grenzlinien $/ \mathrm{km}$

Die Wirksamkeit dieses Grenzgürtels ist wegen der großen Breite am kleinsten von allen. Er zeigt pro $\mathrm{km}$ im Mittel nur 2,1 Grenzlinien.

\section{Randliche Grenzzonen}

Die drei noch verbleibenden Räume (Karte 9) gehören Landschaften an, die nur zu einem kleinen Teil in das untersuchte Gebiet hineinragen. Sie können daher nicht mit Sicherheit klassiert werden. Sehr wahrscheinlich gehören sie alle Grenzlandschaften an. Die wichtigsten Strukturelemente dieser Grenzgebiete sollen nun kurz beschrieben werden.

\section{a) Die Hohe Rone}

Die große Reliefenergie ist bedingt durch den geologischen Bau und hat zum Teil auch eine größere Flußdichte zur Folge. Durch die größere Höhendifferenz reicht diese Landschaft in Regionen, wo Obstbäume keinen Ertrag mehr abwerfen und zudem kaum mehr richtig gedeihen. Die Obergrenze des Obstbaus verläuft je nach Lokalklima höher oder tiefer den Nordhängen entlang. Auch der Gradient der Akkerarealdichte nimmt rasch ab. Auf dem Roßberg (Wollerau) und bei Unter Gibel (Menzingen) trifft man bereits auf eine Alpmauer, welche die Mähwiesen von den Alpweiden trennt. Siedlungen finden wir auf größern, gut exponierten Terrassen. Ihre Dichte nimmt aber wegen den ungünstigen Reliefverhältnissen stark ab. Den vorherrschenden traditionellen Haustyp stellt das sog. Schwyzerhaus. Im zürcherischen Teil finden wir einige Flarzhäuser. Die politische Grenze bildet zugleich auch die Scheidelinie der Kultbauten. Graswirtschaft mit Weidenutzung stellt die Erwerbsgrundlage der Bevölkerung dar.

Der Wald ist heute das dominierende Element in dieser Landschaft. Noch am Anfang des letzten Jahrhunderts war die Hohe Rone sehr stark entwaldet. Kreuzbrunnen, Brand, Kohlfaß und Kuhn bildeten große Weiden (Zeichnung von David Heß, 1826). Naturkatastrophen erforderten eine dringende Aufforstung.

Das voralpine Randgebiet der Hohen Rone wird im untersuchten Gebiet im Norden von der morphometrischen Grenze gegen das Sihltobel und die Zuger Moränenlandschaft abgegrenzt.

\section{b) Der Hohe Etzel}

Die Westseite des Hohen Etzel steigt im Gegensatz zur Nordflanke relativ sanft an. Beim Ebnet, Loch und Bühl ist der Hang durch eine Terrasse unterbrochen und bietet mit der guten Exposition eine günstige Grundlage für die Besiedlung und Bewirtschaftung. Darum ist der größte Teil der sanft geneigten Westseite gerodet. Höhenlage und Klima begünstigen Graswirtschaft mit Weidenutzung und erlauben 
bis zu den tiefer gelegenen Siedlungen noch Obstbau. Bereits der wenig höher gelegene Hof Stockmattli zeigt schon keine Obstbäume mehr. Günstige Terrainverhältnisse und mooriger Boden bilden gute Voraussetzungen für die ausgedehnten Ackerflächen zwischen der Kastenegg und dem Ebnet, wobei der Gradient aber allseitig rasch abnimmt. Oberhalb von Bühl und Loch trennt die Alpweidegrenze die Mähwiesen von der Bergweide mit Alpställen. Lage und Wirtschaft bedingen als traditionellen Haustyp das sog. Schwyzerhaus. Die Bevölkerung ist mehrheitlich katholisch. Darum gehören Wegkreuze zum Landschaftsbild. Knapp die Hälfte der Landschaft ist mit Wald bedeckt.

Das voralpine Gebiet des Hohen Etzel ist im Norden gegen die Terrasse von Feusisberg wie im Westen und Süden gegen das Sihltobel von der morphometrischmorphologischen Grenze umschlossen.

\section{c) Die Grenzzone nordöstlich von Hirzel}

Diese Zone ist hauptsächlich durch den steilen, schlecht exponierten Nordhang bei Schlieregg bedingt. Daher muß sich die landwirtschaftliche Nutzung ausschließlich auf Graswirtschaft ausrichten. Die von Lebhecken begrenzten Weiden verleihen diesem Landstrich gewisse Ähnlichkeit mit Teilen der Rippenlandschaft. Diese Zone ist von der morphometrischen und der Lebheckengrenze eingèschlossen.

\section{ZUSAMMENFASSUNG UND RESULTATE}

Die vorliegende Abhandlung versucht, die bei geographischen Grenzziehungen verwendeten kartographischen Methoden zu verbessern. Bei Landschaftsgliederungen sollen nicht nur wie bei GRanö die vier « Gesichtserscheinungen » wie Erdrinde, Wasser, Vegetation und der von Mensch und Tier umgeformte Stoff, oder wie ursprünglich bei PAsSARge nur die Elemente der Naturlandschaft Berücksichtigung finden, sondern alle grenzbildend auftretenden Landschaftselemente in die Untersuchung einbezogen und subjektive Momente der Arbeitsweise auf ein Minimum zurückgedämmt werden. Letzteres kann man am besten mit Hilfe von Zahlen erreichen.

Bei der entwickelten Methode, der sogenannten Quadratmethode, werden alle bei den anfänglichen Feldbegehungen als grenzbildend erkannten Landschaftselemente kartiert und zu jedem Element Verbreitungskarten erstellt. Auf diese legt man ein Quadratnetz, dessen Maschenweite sich nach der Erscheinungsart der abzugrenzenden Objekte richten muß. Sie darf nicht zu groß sein, weil sonst die Fehlergrenzen sich vergrößern, aber auch nicht zu klein, ansonst in viele Einheitsflächen keine Untersuchungsobjekte mehr fallen. Am vorteilhaftesten werden daher mittlere Werte benutzt. Dann wird in jeder Einheitsfläche das Auftreten eines grenzbildenden Strukturelementes ausgezählt oder gemessen und durch eine Dichte- oder Häufigkeitszahl ausgedrückt.

Der nächste Arbeitsgang besteht in der Bestimmung des kritischen Grenzwertes oder der Leitzahl für die Ziehung der Isolinien. Eine Isolinie scheidet Zonen verschiedener Dichte oder Intensität eines Landschaftselementes. Es ist nun zu beurteilen, welche Dichtezahl für die Grenzführung am zweckmäßigsten erscheint. Die Größe der Leitzahl kann mit Hilfe von Statistiken, erneuten Feldbegehungen oder aber rein empirisch gefunden werden.

Scheidelinien anderer Art stellen die relativen Grenzen dar. Sie wägen die Dominanz zweier vergleichbarer Merkmale (Konfession, Haustypen, Vegetationszonen) gegeneinander $a b$ und trennen sie.

Die 3. Art von Trennungslinien, die Strukturgrenzen, erhält man durch Umfahrung des Verbreitungsgebietes der betreffenden Grenzbildner. Physiognomisch betrachtet sind die Strukturgrenzen in der Regel am wirksamsten. Ihnen folgen die relativen Grenzen. Im allgemeinen am wenigsten auffallend treten die Isolinien in 
Erscheinung. Die physiognomische Wirksamkeit der Isolinien hängt zudem weitgehend vom Gradient oder Gefälle des betreffenden Grenzbildners ab.

Die Synthese der Landschaften erfolgt wiederum rein kartographisch durch Übereinanderlegen der gewonnenen Grenzen. Dabei ist es arbeitstechnisch vorteilhaft, zuerst die sogenannte Kernlandschaft $\mathrm{zu}$ bestimmen. Als solche bezeichne ich ein Gebiet, das von stark in Erscheinung tretenden relativen oder von physiognomisch meist stark wirkenden Strukturgrenzen umschlossen wird. Eine Kernlandschaft kann jedoch von Isolinien oder von schwach in Erscheinung tretenden relativen Grenzen durchquert werden. Es ist der Sammelbegriff für Landschaften niedrigster Ordnungen. Aus dieser Kernlandschaft ist die Landschaft 1. Ordnung oder Landschaftseinheit auszuwählen. Grundbedingung für diese muß eine ziemlich weitgehende Einheitlichkeit in ihrem Bau sein. Nach ihrer Festlegung erfolgt nach folgendem Vorgehen die Bestimmung der Landschaften 2., 3., 4. und 5. Ordnung.

Die Landschaft 2. Ordnung erhält man durch Aufhebung derjenigen die Landschaft 1. Ordnung begrenzenden Isolinie oder schwach in Erscheinung tretenden relativen Grenze, welche am meisten Arealzuwachs bringt. Für die Gewinnung der Landschaften 3., 4. und 5. Ordnung werden sinngemäß weitere gleiche Grenztypen eliminiert. Die Landschaft höchster Ordnung ist schließlich mit der Kernlandschaft identisch. Die Ordnungiszahl sagt zugleich etwas über die Einheitlichkeit oder den Grad der Komplexheit der Landschaft aus.

Zwischen den Kernzonen liegen die Grenzgürtel. Diese werden nach ihrer trennenden Wirkung klassiert. Diese Wirksamkeit eines Grenzgürtels ergibt sich mathematisch als Quotienten aus der Zahl der Grenzlinien (Struktur- und relativen Grenzen), welche die Grenzzonen durchlaufen und ihrer mittleren Breite. Diese Relation besagt, wieviele Grenzlinien ein Querprofil pro km aufweist. Die angewandte Systematik bei der Ausscheidung der Landschaften ist sehr praktisch und einfach anzuwenden. Sie liefert befriedigende Resultate. Es wäre aber noch von Vorteil, wenn eine bestimmte Reihenfolge für die Aufhebung der einzelnen Isolinien festgelegt werden könnte, sodaß Landschaften mit der gleichen Ordnungszahl ganz bestimmte Strukturelemente enthielten. Eine so weitgehende Systematik kann erst nach gründlicher Kenntnis vieler Kernlandschaften, deren Herleitung durch gleiche oder sehr ähnliche Arbeitsmethoden erfolgte, aufgestellt werden. Im vorliegenden Fall können die Landschaften niederer Ordnungszahl als Unterordnungen der Kernlandschaften aufgefaßt werden.

Die Gewinnung der einzelnen Grenzen aus den Zahlenkarten ist leicht zu bewerkstelligen, sobald die Leitzahlen gefunden sind. Nur die Ziehung der morphometrischen Grenze bereitete Schwierigkeiten. Eine Grenzführung nur nach morphometrischen Gesichtspunkten hätte zum Teil einen unsinnigen Grenzverlauf ergeben. Ich war daher gezwungen, morphologische Daten zu berücksichtigen. Daher muß man diese Grenze eher als morphometrisch-morphologische Grenze bezeichnen. Die Morphometrie bietet für eine Grenzziehung aber eine wertvolle Hilfe.

Die Quadratmethode weist gegenüber bisherigen Arbeitsweisen einige bemerkenswerte Vorzüge auf:

1. Die Grenzführung ergibt sich nach der Festlegung der Leitzahl eindeutig (Ausnahme Morphometrie).

2. Die Leitzahlen bieten gute Vergleichsmöglichkeiten für andere Gebiete.

3. Die Zahlenkarten geben die lokale Verbreitung der betreffenden Grenzbildner, was statistisch ausgewertet werden kann und für spätere Vergleiche eine einzigartige Grundlage darstellt.

4. Die Subjektivität der Grenzführung wird weitgehend zurückgedrängt.

5. Es ist eine Angabe der Fehlergrenzen möglich, im Mittel $\pm 1 / 2$ Quadratseite. In Wirklichkeit sind die Abweichungen kleiner, da man sich bei der Grenzziehung zugleich an die Verbreitungskarte hält. 
6. Strecken- und flächenhaft auftretende Grenzbildner werden sehr gut erfaßt.

7. Die Quadratmethode ermöglicht mit Hilfe der relativen Grenzen und Isolinien feine Nuancierungen bei der Landschaftsgliederung.

8. Wie bei den bisherigen kartographischen Methoden ist ein klarer Arbeitsgang vorgezeichnet.

9. Die Quadratmethode kann beim Einsatz von großen Arbeitsgruppen gut verwendet werden.

10. Bei der angewandten Landschaftssystematik wird mit der Unterteilung der Kernlandschaften in Landschaften verschiedener Ordnungen zugleich auch etwas über die Einheitlichkeit der Landschaften ausgesagt.

Wie alle Methoden besitzt sie auch Nachteile:

1. Es ist bis anhin unmöglich, die gegenseitigen Beziehungen der Landschaftsbildner direkt zu erfassen. Darum tritt die Physiologie der Landschaft etwas in den Hintergrund. Dieser Nachteil wird durch die Tatsache abgeschwächt, daß sich die Physiologie weitgehend in der Physiognomie einer Landschaft äußert.

2. Die zeitraubende Kartierung erschwert die Arbeit. Sie fällt aber auch bei andern Methoden ins Gewicht. Es besteht hier die Möglichkeit, mit der Auswertung von Fliegeraufnahmen den Arbeitsgang zu verkürzen. Jede Kartierung bleibt immer subjektiv. Dieser Einfluß kann durch die Erstellung von Kartierungsrichtlinien etwas abgeschwächt werden.

3. Die Erstellung der Zahlenkarten erfordert viel Zeit.

Die vorliegende Arbeit zeigt, daß sich die Quadratmethode für schweizerische Verhältnisse mit Erfolg anwenden läßt. Auch für die Gliederung anderer Gebiete in Kleinraumeinheiten wird sie sich sicher bewähren. Für die Großraumgliederung müßte ihre Eignung zuerst noch abgeklärt werden. Durch eine geeignete und zweckmäßige Auswahl der Merkmale und entsprechende Kartierungsrichtlinien würden sich sehr wahrscheinlich auch bei solchen Anwendungen annehmbare Resultate ergeben.

\section{LITERATURVER ZEICHNIS}

I Argand, E.: La zone pennique. Geol. Führer der Schweiz, 1934. Fasc. 3. S. 153. 2 BæsChLin, A., Bühler, A. und Gschwend, M.: Wegleitung für die Aufnahmen der bäuerlichen Hausformen und Siedlungen in der Schweiz. Basel 1948. 3 BERnhard, H.: Landwirtschaftlicher Atlas des Kantons Zürich. Zürich 1925. 4 Bertalanffy, L. v.: Theoretische Biologie. Bd. I, S. 97-99, 274/75. Berlin 1932. 5 Boschкoff, L.: Die mittlere Entfernung zwischen den Eisenbahnstationen in einem Lande. Comptes rendus du Congrès international de géographie Amsterdam 1938, Bd. II, $3 \mathrm{~b}, \mathrm{~S}$. 83-89. Leiden 1938. 6 Brockmann-Jerosch, H.: Das Schweizer Bauernhaus. Bern 1933. 7 Bũdel, J.: Die Abgrenzung von Kulturlandschaften auf verschiedenen Wirtschaftsstufen. Festschrift zur Vollendung des sechzigsten Lebensjahres von Norbert Krebs. S. 25-51. Stuttgart 1936. 8 BüHLER, J.: Typen schweizerischer Kulturlandschaft. Zeitschrift für Erdkunde 1939, S. 19-28. Frankfurt am Main 1939. g Bürger, K.: Der Landschaftsbegriff. Ein Beitrag zur geographischen Erdraumauffassung. Dresdener Geograph. Studien, Heft 7, 1935. Dresden 1935. ro CAPr, A.: Die Anwendung von Granö's Methode zur Landschaftsgliederung am Beispiel des Kantons Zürich. Diss. Zürich 1947. ir Carol, H. und Senn, U.: Jura, Mittelland und Alpen, ihr Anteil an Fläche und Bevölkerung der Schweiz. Geographica Helvetica, 1950, S. 129-134. Bern 1950. r 2 Eidgenössische Statistik: Arealstatistik, Betriebszählungen, Obstbaumzählung, Viehzählung, Volkszählungen. I3 ETTER, H.: Über die Waldvegetation am Südostrand des schweizerischen Mittellandes. Mitteilungen der Schweizerischen Anstalt für das forstliche Versuchswesen, Bd. 25, Heft 1, Zürich 1947. I4 FrEY, H.: Die lokalen Winde am Zürichsee. Neujahrsblätter der Naturf. Ges. Zürich 1926. I5 FrEY, H.: Der Frühlingseinzug am Zürichssee. Neujahrsblätter der Naturf. Ges. S. 18. Zürich 1931. I6 FRÜH, J.: Geographie der Schweiz. 3 Bände. St. Gallen 1932. 17 Gassmans, F. und Gutersohn, H.: Kotenstreuung und Relieffaktor. Geographica Helvetica 1947. S. 122-139. Bern 1947. I8 Granö, J. G.: Reine Geographie. Acta Geographica I, Nr. 2, Helsinki 1929. I9 Granö, J. G.: Geographische Ganzheiten. Pet. Mitt. Bd. 81, 1935, S. 295-302. Gotha 1935. 20 GurlitT, D.: Grundbegriffe der Geographie. Universitas S. 431-436. Stuttgart 1948. 2 I Gutersohn, H.: Relief und Flußdichte. Diss. Zürich 1932. 22 Gutersohn, H.: Landschaften der Schweiz. Büchergilde Gutenberg. Zürich 
1950. 23 НАвіснт, K.: Neuere Beobachtungen in der subalpinen Molasse zwischen Zugersee und dem st. gallischen Rheintal. Eclog. geol. Helv., Vol. 38, Nr. 1, 1945. Basel 1945. 24 Hassinger, H.: Über einige Aufgaben geographischer Forschung und Lehre. Kart. und schulgeographische Zeitschrift 8, S. 65-76. Wien 1919. 25 HeTrNeR, A.: Die geographische Einteilung der Erdoberfläche. Hettners Geogr. Zeitschrift 14, S. 1-13, 94-110, 137-150. Leipzig 1908. 26 HeTtNer, A.: Die Geographie, ihre Geschichte, ihr Wesen und ihre Methoden. Breslau 1927. 27 Høzel, E.: Das geographische Individuum bei Karl Ritter und seine Bedeutung für den Begriff des natürlichen Gebietes und der natürlichen Grenzen. Hettners Geogr. Zeitschrift. 1896. Leipzig 1896. 28 НӧHNOchsner, W.: Das Werden unseres Heimatbodens. Die Pflanzen- und Tierwelt unserer Heimat. Die stehenden Gewässer und Moore der Herrschaft Wädenswil. Neujahrsblätter der Lesegesellschaft Wädenswil 1934 (S. 7), 1937, 1939, 1942. 29 HöHN-OCHSNER, W.: Frühjahrsexkursion der Geographisch-Ethnographischen Gesellschaft Zürich durch die Moränenlandschaft zwischen dem Hohen Ron und dem Zürichsee. Mitteil, der Geogr.-Ethnogr. Gẹs. Zürich 1943/44. S. 152-161. Zürich 1944. 3o HunZiker, W.: Der Obstbau in der Nordostschweiz. Diss. Zürich 1936. 3I Huttenlocher, F.: Versuche kulturlandschaftlicher Gliederung am Beispiel von Württemberg. Forschungen zur Deutschen Landeskunde. Bd. 47, 1949. Stuttgart 1949. 32 IмноF, E.: Das Siedlungsbild in der Karte. Mitt. d. Geogr.-Ethnogr. Ges. Zürich 1936/37, S. 17-86. Zürich 1937. 33 JÆGER, F.: Neuer Versuch einer anthropogeographischen Gliederung der Erdoberfäche. Pet. Mitt. 1943, S. 313-323. Gotha 1943. 34 JÆGER, F.: Eine kulturlandschaftliche Gliederung der Schweiz. Schweizer Geograph, 1944, S. 8-10. Bern 1944. 35 Jessen, O.: Feldeinfriedungen im Bild der Kulturlandschaft. Hettners Geogr. Zeitschrift 1937, S. 136-143. Leipzip 1937. 36 Keller, A.: Aus der Geschichte der Herrschaft Wädenswil. Neujahrsblätter der Lesegesellschaft Wädenswil 1930, 1931 (S. 41-43), 1932, 1933, 1936. 37 KIRCHEN, E.: Die Einheitsflächenmethode, eine Anwendung der „Unit-Area-Method“ zur Kartierung von Agrarlandschaften im Gebiet Domleschg, Heinzenberg, Bezirk Imboden, Kanton Graubünden. Diss. Zürich 1949. 38 LAUTENSACH, H.: Wesen und Methoden der geographischen Wissenschaft. Handbuch der Geogr. Wissenschaft, hg. von F. Klute: Allgemeine Geographie I, S. 26, Potsdam 1933. 39 LaUtensach, H.: Über die Erfassung und Abgrenzung von Landschaftsräumen. Comptes rendus du Congrès international de géographie Amsterdam 1938, Bd. II, sec. 5, S. 12-25. Leiden 1938. 40 LaUteNsaCH, H.: Der geographische Formenwandel. Studien zur Landschaftssystematik. Colloquium Geographicum, Bd.3, Bonn 1952. ${ }_{4} I$ LeEmand, W.: Landeskunde der Schweiz. Zürich-Erlenbach 1939. 42 LehmanN, O.: Die Stellung der Geographie in der Wissenschaft. Vierteljahresschrift d. Naturf. Ges. Zürich 81, 1936. S. 234/35. Zürich 1936. +3 Markus, E.: Chorogenese und Grenzverschiebung. Tartu 1934. 44 MArkus, E.: Geographische Kausalität. Acta et Commentationes Universitas Tartuensis. Tartu 1936. 45 Maull, O.: Politische Geographie. Berlin 1925. 46 MaUll, O.: Die Einheit der Landschaft und länderkundliche Einheiten. Comptes rendus du Congrès international de géographie Amsterdam 1938, Bd. II, sec. 5, S. 150-157. Leiden 1938. 47 Maull, O.: Die Bedeutung der Grenzgürtelmethode für die Raumforschung. Zeitschrift f. Raumforschung, S. 236-241. Bonn 1950. 48 Maurer, J., Billwiller, R. und Hess, C.: Das Klima der Schweiz. Frauenfeld 1909. 49 Paravicini, E.: Die Bodennutzungssysteme der Schweiz in ihrer Verbreitung und Bedingtheit. Pet. Mitt. 1928. S. 392-404, 451-466. Gotha 1928. 50 Passarge, S.: Wesen, Aufgaben und Grenzen der Landschaftskunde. Pet. Mitt. Ergh. Nr. 209, 1930, S. 35/36. Gotha 1930. 5 I Passarge, S.: Die Bedeutung der beschreibenden Landschaftskunde für die Geographie und deren Nachbarwissenschaften. Geogr. Anzeiger 32, 1931, S. 321-327. Gotha 1931. 52 Passarge, S.: Einführung in die Landschaftskunde. Berlin/Leipzig 1933. 53 PAvoNı, N.: Die rückläufigen Terrassen am Zürichsee und ihre Beziehungen zur Geologie der Molasse. Geographica Helvetica 1953, S. 217-225. Bern 1953. 54 RATZEL, F.: Politische Geographie. S. 448. München und Leipzig 1897. 55 Regel, C. v. und WinkLER, E.: Zur Landschafts-Diskussion in der Sowjetgeographie. Geographica Helvetica 1953, S. 234-248. Bern 1953. 56 ReNz, H. H.: Die subalpine Molasse zwischen Aare und Rhein. Eclog. geol. Helv., Vol. 30, Nr. 1, 1937. Basel 1937. 57 Schaffner, W.: Die geographische Grenze zwischen Jura und Mittelland. Diss. Zürich 1946. $58 \mathrm{Schосн,} \mathrm{A.:} \mathrm{Beiträge} \mathrm{zur} \mathrm{Siedlungs-} \mathrm{und} \mathrm{Wirtschaftsgeographie} \mathrm{des} \mathrm{Zürichseegebietes.} \mathrm{Diss.}$ Zürich 1917. 59 Schultze, J. H.: Der ideale Landkreis und seine Grenzen. Pet. Mitt. 1949, S. 145 -160. Gotha 1949. 6o SidLER, W.: Das ehemalige Gebiet des Stiftes Einsiedeln als Einleitung zur Geschichte von Einsiedeln. Einsiedeln 1902. 6I SIEGER, R.: Zur politisch-geographischen Terminologie. Zeitsch. Ges. Erdkunde, Berlin, ohne Bandangabe, S. 506. Berlin 1917/18. 6z SöLch, J.: Die Auffassung der "natürlichen Grenzen" in der geographischen Wissenschaft. Innsbruck 1924. $\sigma_{3}$ Stauber, E.: Die zürcherischen Schanzen an der schwyzerischen Grenze. Wädenswil 1905. 6f UnSTEAD, J. F.: A synthetic method of determing geographical regions. Geogr. Journal 1916, S. 230-249. London 1916. ${ }_{5}$ VOLKaRT, A.: Dreifelder- und Egartenwirtschaft in der Schweiz. Festschrift zur Feier des 70. Geburtstages von Prof. A. Kræmer. Frauenfeld 1902. 66 Windler, H. und WiNkLeR, E.: Zur quantitativen Bestimmung von Siedlungseinheiten. Plan, Schweiz. Zeitschr. für Landes-, Regional- und Ortsplanung Nr. 6, 1950. Solothurn 1950. 67 WINkLER, E.: Das System der Geographie und die Dezimalklassifikation. Geographica Helvetica 1946, S. 337-349. Bern 1946. 68 WINKLER, E.: Kulturlandschaft an schweizerischen Sprachgrenzen. Eidgenössische Technische Hochschule, Kultur- und staatswissenschaftliche Schriften, Nr. 53. Zürich 1946. 


\section{KARTEN UND PLÄNE}

1 Topographischer Atlas der Sch.weiz, 1:25 000, Blatt 177, 191, 228, 242, 243. Eidgenössische Landestopographie Bern. 2 Katasterpläne 1:5000 der Gemeinden Wädenswil, Richterswil, Schönenberg, Hütten. Kantonales Vermessungsamt Zürich. 3 Katasterpläne 1:5000 der Gemeinden Wollerau und Freienbach. Kantonales Vermessungsamt Schwyz. 4 Vergrößcrungen der Meßtischblätter des Top. Atlas für die Gemeinden Feusisberg, Menzingen, Neuheim. Eidgenössische Landestopographie Bern. 5 Geotechnische Karte der Sch-weiz. Blatt II. Geotechnische Kommission der Schweiz. Natf. Ges. Bern.

\section{METHODS OF GEOGRAPHICAL DELIMITATION}

The present study attempts to improve the cartographic methods used in geographical delimitation by examining the frontier area between the Swiss Cantons of Schwyz, Zug and Zurich. When we analyse a certain region it is not enough to take into consideration, as Grasö does, the four optical features such as the crust of earth, water, vegetation and matter transformed by man and animal, nor may we confine ourselves to the elements of virgin country as PASSARGE originally suggested. Rather, we must include in our examination all the border-forming features of landscape and reduce to a minimum the subjective elements of our method. This can be done best by means of figures. With the developed method, the so-called grid method all the regional elements which on initial inspection of the region have been found to be border-forming are mapped out and maps of distribution are drawn for each element. These are covered with a grid the mesh-width of which must depend on the appearance of the objects to be delimitated. It must not be too wide as that might increase our margin of error, neither should it be so narrow as to exclude certain objects from the units of the grid. It is, therefore, best to use average values. Then the appearance of border-forming elements in each unit is numbered or measured and represented by density or frequency numbers. The next process consists in determining the decisive limits or guide numbers for the drawing of the isolines. An isoline separates zones of various density or intensity of a regional element. We have now got to decide which density figure is best adapted to the delimitation. The size of the guide number may be calculated by means of statistics, by repeated field inspections or by purely empirical methods. Relative borders are represented by boundaries of a different type. They compare the predominance of two characteristics such as religious denomination, housetypes, vegetation zones, with each other and separate them. These boundaries, too, are drawn by means of number maps. A third type of boundary, the structure borders, are obtained by inspecting the area of distribution of border-forming elements. Physiognomically considered, the structure borders are most effective as a rule. Then the relative borders follow. Generally speaking it is the isolines which appear least striking to the eye, moreover, the physiognomical effectiveness of isolines largely depends on the gradient of the border-forming element in question. Synthesis of landscapes is achieved in a purely cartographical way by superimposition of the borders. Here it is methodically advantageous first to determine the so-called core area by which is meant a region which is surrounded by physiognomical structure borders. Such a core area may, however, be plotted by isolines or faintly perceptible relative borders. It is the collective term for landscapes of the lowest order. From this core area the first order landscape or unit area has to be selected. Basic condition for such a unit area must be its convincing structural unity. Once the unit area is determined the landscapes of second, third, fourth and fifth order have to be worked out as follows: A landscape of the second order is obtained by removing the isolines limiting the first order landscape or the faintly showing relative border, which brings about the largest increase of area. In order to obtain landscapes of the third, fourth or fifth order, further similar boundary types have to be eliminated correspondingly. The landscape of the highest order will be found, in the end, to be identical with the core area. The ordinary number, at the same time, indicates the degree of complexity of a landscape. Between the core areas are the border zones. They are classified according to their separation effects. Mathematically this effectiveness appears as the quotient of the frequency of border lines running through the border zones and their average width. This relation indicates how many border lines per $\mathrm{km}$ there are in the cross profile of a border belt. This systematic process of separating various landscapes' is very practical and easy to apply and produces satisfactory results. The present study shows that the grid method can be successfully applied to Swiss conditions. It will certainly prove useful for the analysis of small area units in other regions, too. It remains to be seen whether it is equally applicable to large area analysis, but a careful and appropriate selection of the characteristics as well as corresponding cartographic lines are likely to produce satisfactory results even in such large area cases. 